\title{
An Untargeted Approach for Revealing Electrophilic Metabolites
}

Yan Yu, Henry H. Le, Brian J. Curtis, Chester J. J. Wrobel, Bingsen Zhang, Danielle N. Maxwell, Judy Y. Pan, and Frank C. Schroeder*

Table of Contents

1. Experimental 2

2. Supporting figures 14

3. Supporting tables 32

4. Supporting references 35

5. NMR spectra 36 


\section{Experimental}

\section{General information}

Chemicals were purchased from Sigma-Aldrich or Fisher Scientific. The following abbreviations are used: dichloromethane (DCM), N,N-dimethylformamide (DMF), dimethyl sulfoxide (DMSO), methanol $(\mathrm{MeOH})$, hexane, ethyl acetate, hydroxylamine hydrochloride $\left(\mathrm{NH}_{2} \mathrm{OH} \cdot \mathrm{HCl}\right)$, 4dimethylaminopyridine (DMAP), $N$-(3-dimethylaminopropyl)- $N$ '-ethylcarbodiimide hydrochloride $(\mathrm{EDC} \cdot \mathrm{HCl}), \quad \mathrm{N}$-acetylcysteamine (NAC), Lennox Broth (LB), Terrific Broth (TB), nematode growth medium (NGM), and glucose minimal medium (GMM), Phosphate buffered saline (PBS) was prepared as a $10 \mathrm{X}$ stock solution and stored at room temperature.

Nuclear Magnetic Resonance (NMR) spectra were recorded on Varian INOVA 600 (600 MHz) and Bruker Avance 500 (500 MHz) at Cornell University's NMR facility. ${ }^{1} \mathrm{H}$ NMR chemical shifts are reported in ppm $(\delta)$ relative to residual solvent peaks (7.26 ppm for chloroform- $d, 3.31 \mathrm{ppm}$ for methanol- $d_{4}$ and 2.50 ppm for DMSO- $d_{6}$ ). NMR-spectroscopic data are reported as follows: chemical shift, multiplicity $(\mathrm{s}=$ singlet, $\mathrm{d}=$ doublet, $\mathrm{t}=$ triplet, $\mathrm{q}=$ quartet, $\mathrm{m}=$ multiplet, $\mathrm{br}=$ broad), coupling constants $(\mathrm{Hz})$, and integration and often tabulated including $2 \mathrm{D}$ NMR data. ${ }^{13} \mathrm{C}$ NMR chemical shifts are reported in ppm $(\delta)$ relative to residual solvent peaks $(77.16 \mathrm{ppm}$ for chloroform- $d, 49.00$ ppm for methanol- $\mathrm{d}_{4}$ and $39.52 \mathrm{ppm}$ for DMSO- $d_{6}$ ).

C. elegans metabolites are referred to by their SMID identifiers, e.g., "icas\#3" or "ascr\#10". The SMID database (www.smid-db.org) is an electronic resource maintained in collaboration with WormBase (www.wormbase.org). A complete list of SMIDs can be found at www.smid$\mathrm{db}$. org/browse. Portions of figures were created using Biorender.com.

\section{C. elegans strains}

C. elegans strains were maintained under standard growth conditions ${ }^{1}$. Bristol N2 (wild type), VC1785 acox-1.1(ok2257), RB859 daf-22(ok693), and JJ1271 glo-1(zu391) strains were obtained from the Caenorhabditis Genetics Center (CGC), which is funded by NIH Office of Research Infrastructure Programs (P40 OD010440). The strain PHX1951 acot-1(syb1951) (K05B2.4(syb1951)) was generated by SunyBiotech (Fujian, China). The allele syb1951 represents a $1156 \mathrm{bp}$ deletion, flanked by ataatgtacccacctgtcttgatatcactgttttagcatagtcATGTCTTAGGAAGgtgcattttagaaaaatgtcattttcattaaatgtttataa. This removes 830 base pairs from the $N$ terminal coding sequence and introduces an early stop codon. 


\section{FCS43 (acot-1(syb1951); acox-1.1(ok2257)) cross}

L4 acox-1.1(ok2257) worms were heat-shocked for $6 \mathrm{~h}$ at $30{ }^{\circ} \mathrm{C}$ and moved to room temperature overnight. After three days, 10-12 male acox-1.1 adults were picked and cultured with one L4 acot-1(syb1951) hermaphrodite on a $6 \mathrm{~cm}$ nematode growth medium (NGM) agar plate with $10 \mu \mathrm{L}$ concentrated OP50 (see below) overnight. Then, the acot-1 hermaphrodite was isolated onto a new $6 \mathrm{~cm}$ plate. F1 hermaphrodite progenies were isolated on to new plates, and after three days, 32 F2 hermaphrodite progenies were isolated onto $326 \mathrm{~cm}$ plates. Genotypes were confirmed by PCR and sequencing.

\section{E. coli OP50 suspension for nematode cultures}

E. coli OP50 was maintained by streaked on Lennox Broth (LB) agar plates containing no antibiotics and grown at $37{ }^{\circ} \mathrm{C}$ for $24 \mathrm{~h}$. Plates were then sealed and stored at $4{ }^{\circ} \mathrm{C}$ for up to 4 weeks. Liquid cultures were initiated by inoculating a single OP50 colony into $15 \mathrm{~mL}$ culture tubes containing $5 \mathrm{~mL}$ LB. Cultures were shaken at $250 \mathrm{RPM}$ at $37^{\circ} \mathrm{C}$ for $24 \mathrm{~h}$, and then diluted into Terrific Broth (TB) at $10 \mathrm{~mL}$ LB per $1 \mathrm{~L}$ TB. $1 \mathrm{~L}$ TB cultures were grown to stationary phase by shaking at $220 \mathrm{RPM}$ at $37^{\circ} \mathrm{C}$ for $24 \mathrm{~h}$ in $4 \mathrm{~L}$ Erlenmeyer flasks. OP50 was harvested by centrifugation at $5,250 \mathrm{G} 20 \mathrm{~min} 4{ }^{\circ} \mathrm{C}$, and the spent media was carefully decanted. The OP50 bacterial pellet was resuspended at $1 \mathrm{~g}$ wet mass per $1 \mathrm{~mL} \mathrm{M9}$ buffer and stored at $4{ }^{\circ} \mathrm{C}$.

\section{Nematode cultures}

Cultures were started by picking 20 C. elegans hermaphrodites onto $10 \mathrm{~cm}$ NGM agar plates (each seeded with $750 \mu \mathrm{L}$ of concentrated E. coli OP50 (see above)) and incubated at $22{ }^{\circ} \mathrm{C}$. After $96 \mathrm{~h}$, each plate was washed with $25 \mathrm{~mL}$ of S-complete medium into a $125 \mathrm{~mL}$ Erlenmeyer flask, $1 \mathrm{~mL}$ of concentrated E. coli OP50 was added (see above), and cultures were shaken at $220 \mathrm{RPM} 22^{\circ} \mathrm{C}$. After $72 \mathrm{~h}$, cultures were centrifuged at $1000 \mathrm{G}$ for $1 \mathrm{~min}$. After discarding the supernatant, worm pellets were washed with $30 \mathrm{~mL}$ of $\mathrm{ddH}_{2} \mathrm{O}$ and centrifuged at 1,000 $\mathrm{G}$ for 1

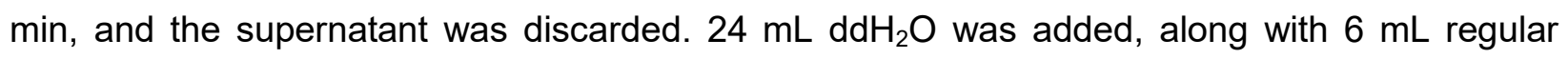
bleach (Clorox, Oakland, California) and $900 \mu \mathrm{L} 10 \mathrm{M} \mathrm{NaOH}$, and the mixture was shaken for $2.5 \mathrm{~min}$ to prepare eggs. Eggs were centrifuged at $1,000 \mathrm{G}$, the supernatant was removed. Eggs were then washed with $30 \mathrm{~mL}$ M9 buffer twice, and suspended in a final volume of $5 \mathrm{~mL}$ M9 buffer in a $50 \mathrm{~mL}$ centrifuge tube. Eggs were placed on a rocker and allowed to hatch for 24 $\mathrm{h}$ at $22^{\circ} \mathrm{C}$. L1 larvae were counted and seeded at $\sim 30,000 \mathrm{~L} 1 \mathrm{~s}$ per $25 \mathrm{~mL}$ S-complete culture, and $1 \mathrm{~mL}$ of $E$. coli OP50 was added per $25 \mathrm{~mL}$ culture. Cultures were maintained in Erlenmeyer flasks roughly 5 times the culture volume, e.g. $200 \mathrm{~mL}$ cultures were seeded with $\sim 250,000$ L1s with $8 \mathrm{~mL}$ concentrated OP50 in $1 \mathrm{~L}$ Erlenmeyer flasks. Cultures were incubated 
at 220 RPM $22{ }^{\circ} \mathrm{C}$ for $72 \mathrm{~h}$. One $10 \mathrm{~cm}$ plate generally yielded 65,000 L1s, and thus e.g. 200 $\mathrm{mL}$ cultures would be started with four $10 \mathrm{~cm}$ plates.

\section{${ }^{14} \mathrm{NH}_{2} \mathrm{OH}-,{ }^{15} \mathrm{NH}_{2} \mathrm{OH}-$ labeling and extraction of $\mathrm{C}$. elegans}

C. elegans cultures were harvested by centrifugation using $50 \mathrm{~mL}$ centrifuge tubes at 1,000 $\mathrm{G}$ at room temperature for $10 \mathrm{~min}$, and the supernatant was removed. Each tube of worm pellets was washed with $40 \mathrm{~mL}$ of $0.1 \mathrm{X}$ PBS, and centrifugation was repeated. After discarding the supernatant, the worms from several tubes were combined and gently brought to homogeneous suspension and distributed equally into three $15 \mathrm{~mL}$ centrifuge tubes, for control, ${ }^{14} \mathrm{NH}_{2} \mathrm{OH}$, and ${ }^{15} \mathrm{NH}_{2} \mathrm{OH}$ treatment. To the control tube, $10 \mathrm{~mL}$ of $0.1 \mathrm{X}$ PBS was added, to the second tube, 10 $\mathrm{mL}$ of $100 \mathrm{mM}{ }^{14} \mathrm{NH}_{2} \mathrm{OH} \cdot \mathrm{HCl}$ in $0.1 X$ PBS $(\mathrm{pH}=7)$ was added and to the third tube, $10 \mathrm{~mL}$ of $100 \mathrm{mM}{ }^{15} \mathrm{NH}_{2} \mathrm{OH} \cdot \mathrm{HCl}$ in $0.1 \mathrm{X}$ PBS $(\mathrm{pH}=7$ ) was added. Tubes were immediately (within 5 seconds) sonicated following addition, with a microtip probe sonicator (Qsonica Ultrasonic Processor, Model Q700) for $5 \mathrm{~min}$, power of 5, 30\% duty cycle, with the sample on an ice bath. Following sonication, each sample was frozen over liquid nitrogen and lyophilized to dryness. Samples were then extracted with $15 \mathrm{~mL} \mathrm{MeOH}$ for $24 \mathrm{~h}$. The extracts were clarified via centrifugation at $5,250 \mathrm{G}$ for $10 \mathrm{~min}$ at room temperature. The extracts were dried with a SpeedVac Vacuum Concentrator (ThermoFisher Scientific) and resuspended in $700 \mu \mathrm{L} \mathrm{MeOH}$. Samples were centrifuged at $10,000 \mathrm{G}$ and $4{ }^{\circ} \mathrm{C}$ to remove particulates and analyzed by HPLCHRMS.

\section{Niacin feeding experiment}

Approximately $70,000 \mathrm{~L} 1 \mathrm{~s}$ were seeded in $25 \mathrm{~mL}$ cultures of S-complete with $1 \mathrm{~mL}$ of OP50 and incubated at $220 \mathrm{RPM} 22{ }^{\circ} \mathrm{C}$ in $125 \mathrm{~mL}$ Erlenmeyer flasks. A concentrated solution of niacin was prepared in $\mathrm{ddH}_{2} \mathrm{O}$, sterilized through a $0.2 \mu \mathrm{m}$ cellulose acetate membrane filter, and added to each experimental culture to a final concentration of $250 \mu \mathrm{M}$. Control cultures received the equivalent volume of $\mathrm{ddH}_{2} \mathrm{O}$ only. After $96 \mathrm{~h}$, worms were centrifuged at 1,000 $\mathrm{G}$ for $5 \mathrm{~min}$, and the spent medium was separated from the worm body pellet. Separated medium and worm pellets were flash frozen over liquid nitrogen until further processing. Frozen samples were lyophilized to dryness. Lyophilized media were extracted with $30 \mathrm{~mL} \mathrm{MeOH}$ on an orbital shaker set to $200 \mathrm{RPM}$ for $24 \mathrm{~h}$ at $20{ }^{\circ} \mathrm{C}$. Extractions were centrifuged at $5,000 \mathrm{G}$ for $10 \mathrm{~min}$ at $4{ }^{\circ} \mathrm{C}$, and clarified extraction solvent was transferred to clean glass vials and dried on a SpeedVac (ThermoFisher Scientific) vacuum concentrator. The dried samples were resuspended in $700 \mu \mathrm{L}$ of $\mathrm{MeOH}$, transferred to $1.7 \mathrm{~mL}$ centrifuge tubes and centrifuged at $20,000 \mathrm{G}$ for $20 \mathrm{~min}$ at $4{ }^{\circ} \mathrm{C}$. 
Clarified concentrated extracts were transferred to HPLC vials and stored at $-20{ }^{\circ} \mathrm{C}$ until HPLCHRMS analysis.

\section{FreeStyle 293-F cell culture}

Cultures were started by inoculating freshly thawed FreeStyle 293-F Cells (Gibco by Life Technologies) in $25 \mathrm{~mL}$ of FreeStyle 293 Expression Medium (Gibco by Life Technologies) prewarmed to $37{ }^{\circ} \mathrm{C}$ in a $250 \mathrm{~mL}$ sterile polycarbonate Erlenmeyer culture flask. After $48-72 \mathrm{~h}$ of incubation in a $37{ }^{\circ} \mathrm{C}$ incubator with humidified atmosphere of $8 \% \mathrm{CO}_{2}$ on an orbital shaker rotating at 135 RPM, cells were split in to nine $250 \mathrm{~mL}$ culture flasks containing $80 \mathrm{~mL}$ of FreeStyle 293 expression medium pre-warmed to $37^{\circ} \mathrm{C}$ at a concentration of $0.3 \times 10^{6} \mathrm{cells} / \mathrm{mL}$. After 72-96 h of incubation, cells were harvested.

\section{${ }^{14} \mathrm{NH}_{2} \mathrm{OH}-,{ }^{15} \mathrm{NH}_{2} \mathrm{OH}-$ labeling and extraction of FreeStyle 293-F Cell}

$720 \mathrm{~mL}$ FreeStyle 293-F cell cultures were harvested by centrifugation in sixteen $50 \mathrm{~mL}$ centrifuge tubes at $1,000 \mathrm{G}$ at room temperature for $10 \mathrm{~min}$, and the supernatant was removed. Each tube of cell pellets was washed with $40 \mathrm{~mL}$ of $1 \mathrm{X}$ PBS and then spun again. After discarding the supernatant, the cells were combined and gently brought to homogeneous suspension and then distributed equally into three $15 \mathrm{~mL}$ centrifuge tubes. To the control tube, $10 \mathrm{~mL}$ of $1 \mathrm{X}$ PBS was added and immediately sonicated with a microtip probe sonicator for 5 min, power of $5,30 \%$ duty cycle, with the sample on an ice bath. To the second tube, $10 \mathrm{~mL}$ of $100 \mathrm{mM}{ }^{14} \mathrm{NH}_{2} \mathrm{OH} \cdot \mathrm{HCl}$ in $1 \mathrm{X}$ PBS $(\mathrm{pH}=7)$ was added, followed by immediate sonication. To the third tube, $10 \mathrm{~mL}$ of $100 \mathrm{mM}{ }^{15} \mathrm{NH}_{2} \mathrm{OH} \cdot \mathrm{HCl}$ in $1 \mathrm{X}$ PBS $(\mathrm{pH}=7)$ was added, followed by immediate sonication. Following sonication, each sample was frozen using liquid nitrogen and lyophilized to dryness. Samples were extracted with $15 \mathrm{~mL} \mathrm{MeOH}$ for $24 \mathrm{~h}$. The extracts were clarified via centrifugation at $5250 \mathrm{G}$ for $10 \mathrm{~min}$ at room temperature and dried with a SpeedVac Vacuum Concentrator. The dried extracts were then resuspended in $700 \mu \mathrm{L} \mathrm{MeOH}$, centrifuged at $10,000 \mathrm{G} 4^{\circ} \mathrm{C}$ to remove particulates, and analyzed by HPLC-HRMS.

\section{Aspergillus fumigatus glucose minimal medium (GMM) agar plates}

Aspergillus fumigatus plates were prepared as in Baccile et al., 2016 ${ }^{2}$. Briefly, 20X sodium nitrate salt mixture was made by mixing $120 \mathrm{~g}$ sodium nitrate $\left(\mathrm{NaNO}_{3}\right), 10.4 \mathrm{~g}$ potassium chloride $(\mathrm{KCl}), 10.4 \mathrm{~g}$ magnesium sulfate $\left(\mathrm{MgSO}_{4} \cdot 7 \mathrm{H}_{2} \mathrm{O}\right)$ and $30.4 \mathrm{~g}$ potassium phosphate monobasic $\left(\mathrm{KH}_{2} \mathrm{PO}_{4}\right)$ in $1 \mathrm{~L} \mathrm{H}_{2} \mathrm{O}$. This solution was autoclaved and stored at room temperature. Aspergillus agar medium was prepared by mixing $50 \mathrm{~mL} 20 \mathrm{X}$ sodium nitrate salt mixture, $1 \mathrm{~mL}$ of trace elements (TAP) and $15 \mathrm{~g}$ of generic agar to a final volume of $975 \mathrm{~mL}, \mathrm{pH}=6.5$. The 
medium was autoclaved and added to $25 \mathrm{~mL}$ of autoclaved $10 \mathrm{~g} / 25 \mathrm{~mL}$ dextrose solution in $\mathrm{H}_{2} \mathrm{O}$ using a $0.22 \mu \mathrm{m}$ syringe filter. Then, $20 \mathrm{~mL}$ medium was aliquoted into a petri dish, cooled to room temperature, and stored at $4{ }^{\circ} \mathrm{C}$.

\section{Aspergillus fumigatus cultures}

Aspergillus fumigatus cultures were prepared as in Baccile et al., 2016 ${ }^{2}$. Briefly, cultures were started by placing $10,000 \mathrm{~A}$. fumigatus spores on GMM agar plates and incubated at $37{ }^{\circ} \mathrm{C}$ for 120 h. Plates were washed with $5 \mathrm{~mL}$ of $0.1 \%$ Tween-20 in $\mathrm{dd}_{2} \mathrm{O}$, and the spore-containing wash solution was stored at $4{ }^{\circ} \mathrm{C}$. Then, to three Erlenmeyer flasks each containing $25 \mathrm{~mL}$ of $A$. fumigatus growth media, spore-containing $0.1 \%$ Tween-20 solution was added to a final concentration of $0.1 \times 10^{6}$ cells $/ \mathrm{mL}$. After incubation at $220 \mathrm{RPM} 37^{\circ} \mathrm{C}$ for $96 \mathrm{~h}$, A. fumigatus were harvested.

\section{${ }^{14} \mathrm{NH}_{2} \mathrm{OH}-,{ }^{15} \mathrm{NH}_{2} \mathrm{OH}-$ labeling and extraction of Aspergillus fumigatus}

$75 \mathrm{~mL}$ A. fumigatus cultures were harvested by centrifugation in two $50 \mathrm{~mL}$ centrifuge tubes at $1,000 \mathrm{G}$ at room temperature for $10 \mathrm{~min}$, and the supernatant was removed. The pellets were washed with $40 \mathrm{~mL}$ of $0.1 \mathrm{X}$ PBS and then spun again. After discarding the supernatant, the pellets were combined, gently brought to homogeneous suspension, and then distributed equally into three $15 \mathrm{~mL}$ centrifuge tubes. To the control tube, $10 \mathrm{~mL}$ of $0.1 \mathrm{X}$ PBS was added, and the tube was immediately sonicated with a microtip probe sonicator for 5 min, power of 5 , $30 \%$ duty cycle, with the sample on an ice bath. To the second tube, $10 \mathrm{~mL}$ of $100 \mathrm{mM}$

${ }^{14} \mathrm{NH}_{2} \mathrm{OH} \cdot \mathrm{HCl}$ in $0.1 \mathrm{X}$ PBS $(\mathrm{pH}=7$ ) was added, followed by immediate sonication. To the third tube, $10 \mathrm{~mL}$ of $100 \mathrm{mM}{ }^{15} \mathrm{NH}_{2} \mathrm{OH} \cdot \mathrm{HCl}$ in $0.1 \mathrm{XBS}(\mathrm{pH}=7)$ was added followed by immediate sonication. Following sonication, each sample was frozen over liquid nitrogen and then lyophilized. The samples were extracted with $15 \mathrm{~mL} \mathrm{MeOH}$ for $24 \mathrm{~h}$, and the extracts were clarified via centrifugation at 5,250 G for $10 \mathrm{~min}$ at room temperature. The extracts were dried with a SpeedVac Vacuum Concentrator and then resuspended in $700 \mu \mathrm{L} \mathrm{MeOH}$. Finally, samples were then centrifuged at $10,000 \mathrm{G}$ and $4^{\circ} \mathrm{C}$ for $30 \mathrm{~min}$ to remove particulates and analyzed by HPLC-HRMS.

\section{Mass spectrometric analysis}

High resolution LC-MS analysis was performed on a ThermoFisher Scientific Vanquish Horizon UHPLC System coupled with a Thermo $Q$ Exactive HF hybrid quadrupole-orbitrap highresolution mass spectrometer equipped with a HESI ion source. Metabolites were separated using a water-acetonitrile gradient on an Agilent Zorbax Eclipse XDB-C18 column (150 mm $\times$ 
$2.1 \mathrm{~mm}$, particle size $1.8 \mu \mathrm{m}$ ) maintained at $40{ }^{\circ} \mathrm{C}$. Solvent A: $0.1 \%$ formic acid in water; Solvent B: $0.1 \%$ formic acid in acetonitrile. A/B gradient started at $1 \% \mathrm{~B}$ for $5 \mathrm{~min}$ after injection and increased linearly to $100 \% \mathrm{~B}$ at $20 \mathrm{~min}$, using a flow rate $0.5 \mathrm{~mL} / \mathrm{min}$. Mass spectrometer parameters: spray voltage $3.0 \mathrm{kV}$, capillary temperature $380{ }^{\circ} \mathrm{C}$, probe heater temperature $300{ }^{\circ} \mathrm{C}$; sheath, auxiliary, and spare gas 60, 20, and 2, respectively; S-lens RF level 50, resolution 240,000 at $\mathrm{m} / \mathrm{z} 200$, AGC target $3 \times 10^{6}$. The instrument was calibrated with positive and negative ion calibration solutions (ThermoFisher). Each sample was analyzed in positive and negative modes using an $\mathrm{m} / \mathrm{z}$ range 70 to 1000 . Tandem mass spectrometry parameters: Resolution 45,000, AGC target $5 \times 10^{4}$, Maximum IT $80 \mathrm{~ms}$, loop count 5, TopN 5, isolation window $1.0 \mathrm{~m} / \mathrm{z}$, stepped NCE 25 to 50 , minimum AGC target $8 \times 10^{3}$, intensity threshold $1 \times 10^{5}$, no apex trigger, no charge exclusion, no peptide match, exclude isotopes on, dynamic exclusion $2.0 \mathrm{~s}$, if idle, do not pick others.

\section{Comparative analysis to identify labeled compounds}

The HPLC-HRMS RAW files for control treatment ("PBS"), ${ }^{14} \mathrm{NH}_{2} \mathrm{OH}$ ("N14") and ${ }^{15} \mathrm{NH}_{2} \mathrm{OH}$ ("N15") were converted to mzXML file using MSConvertGUI, with output format mzXML. Binary encoding precision 32-bit, peakPicking vendor msLevel $=1$. The $\mathrm{mzXML}$ files were uploaded to METABOseek.com, version 0.9.2. $\mathrm{XCMS}^{3}$ analysis was performed with automatic postprocessing of MS data and FastPeakShape analysis. Within METABOseek (www.metaboseek.com), the file peak_grouped.csv from the XCMS analysis and the mzXML files were uploaded onto Data Explorer, using N14 MS data as the group of interest, N15 and PBS file as control groups, and FastPeakShapes was included as a column. The following filters were used: retention time from 200 seconds to 1,200 seconds, FastPeakShapes, a peak quality parameter, from 0.95 to the max value, N14_minlnt from 50,000 to the maximum value, and N14_minFoldOverControl from 5 to the maximum value, whereby the latter two filters eliminated small peaks below the selected intensity threshold. After differential features were detected in this manner, $\mathrm{NH}_{2} \mathrm{OH}$ labeled features were confirmed by identifying the presence of a peak exhibiting a mass shift of exactly 0.99703 at corresponding retention times in the N15 files.

\section{MS $^{2}$ molecular networking}

$M^{2}$ spectra were converted to mzXML file using MSConvertGUI. Then mzXML files were uploaded to gnps.ucsd.edu for networking. Networking parameters: PAIRS MIN COSINE 0.5, ANALOG SEARCH 0, tolerance.PM tolerance 2.0, tolerance.lon tolerance 0.5, MIN MATCHED PEAKS 4, TOPK 10, CLUSTER MIN SIZE 2, MAXIMUM COMPONENT SIZE 100, MIN PEAK INT 0.0, FILTER STDDEV PEAK INT 0.0, RUN MSCLUSTER on, FILTER PRECURSOR 
WINDOW 1, FILTER LIBRARY 1, WINDOW FILTER 1, SCORE THRESHOLD 0.5, MIN MATCHED PEAK SEARCH 4. MAX SHIFT MASS 100. After networking was complete, the file was processed with Cytoscape software.

\section{Synthesis of fatty acyl hydroxamide standards}

A $5 \mathrm{~mL}$ solution of a mixture of fatty acids $\left(\mathrm{C}_{13}-\mathrm{C}_{16}, 5 \mathrm{mg}\right.$ each, $0.085 \mathrm{mmol}$ in total $)$ in $\mathrm{DCM}$ was added 4-dimethylaminopyridine (DMAP, $186 \mathrm{mg}, 1.52 \mathrm{mmol}$ ), followed by $\mathrm{N}$-(3dimethylaminopropyl)- $N$ '-ethylcarbodiimide hydrochloride (EDC $\cdot \mathrm{HCl}, 145 \mathrm{mg}, 0.76 \mathrm{mmol}$ ). The solution was stirred at room temperature for $15 \mathrm{~min}$ and was then treated with hydroxylamine hydrochloride $\left(\mathrm{NH}_{2} \mathrm{OH} \cdot \mathrm{HCl}, 49 \mathrm{mg}, 0.71 \mathrm{mmol}\right)$. The solution was stirred overnight, dried in vacuo, and distributed between $10 \mathrm{~mL}$ of brine containing $0.1 \mathrm{M} \mathrm{HCl}$ and $10 \mathrm{~mL}$ of DCM. The DCM layer was dried in vacuo to the appearance of white crystals (15 mg, 70\% yield).

\section{Quantitative RNA analysis of C. elegans thioesterases}

N2 and acox-1.1 mutant L1 larvae were prepared (see above) and seeded at a concentration of 28,000 larvae in $10 \mathrm{~mL}$ S-complete media using $125 \mathrm{~mL}$ Erlenmeyer flasks. $1 \mathrm{~mL}$ of OP50 solution (see above) was added to each flask, and worms were cultured for three days as above. Worms were transferred to $15 \mathrm{~mL}$ centrifuge tubes and harvested by centrifugation at 1,000 $\mathrm{G}$ and $22{ }^{\circ} \mathrm{C}$ for $5 \mathrm{~min}$. The supernatants were discarded, and the worm pellets were washed with $5 \mathrm{~mL}$ of M9 buffer three times. Worms were resuspended in $500 \mu \mathrm{L}$ of M9, then transferred into $1.5 \mathrm{~mL}$ tubes, spun again at $500 \mathrm{G}$ and $22^{\circ} \mathrm{C}$ for $1 \mathrm{~min}$, and the supernatant was removed. 600 $\mu \mathrm{L}$ of TRIzol Reagent (Invitrogen) was added. Five rapid freeze-thaw cycles were carried out using liquid nitrogen and a $37^{\circ} \mathrm{C}$ water bath, with vortexing before each freeze cycle. Finally, $120 \mu \mathrm{L}$ of chloroform was added, and the tubes were inverted several times before leaving the sample to rest at room temperature for $3 \mathrm{~min}$. The samples were then spun at 12,000 $\mathrm{G}$ and $4{ }^{\circ} \mathrm{C}$ for $10 \mathrm{~min}$, and $330 \mu \mathrm{L}$ of the RNA containing layer was carefully pipetted away and then further purified with the RNA Clean and Concentrator 5 (Zymo Research) per manufacturer's protocol. $9 \mu \mathrm{g}$ total RNA was moved for use with the SuperScript III Reverse Transcriptase Kit (Invitrogen) for conversion to cDNA per manufacture's protocol. Real time quantitative PCR was performed with Power SYBR Green Master Mix (Life Technologies) per manufacture's protocol on a Light Cycler 480 (Roche). All samples were analyzed in duplicate. Gene expression was normalized to actin. RT-qPCR data was quantified using the Roche LightCycler 480 Software, version 1.5, utilizing the Abs Quant/2nd Derivative Max feature, and values were averaged and analyzed in Microsoft Excel. 


\section{$\mathrm{H}_{2} \mathrm{OH}$ labeling of activated 2E-decenoic acid}

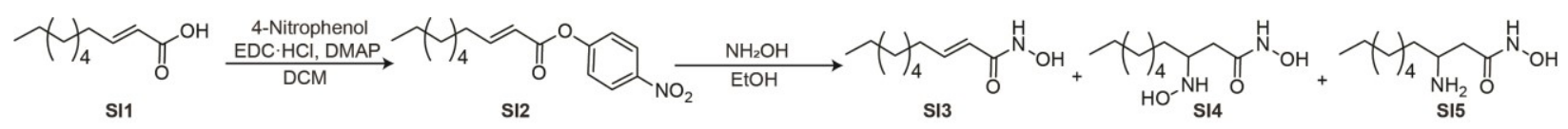

A $1 \mathrm{~mL}$ solution containing $2 E$-decenoic acid (SI1, $5 \mathrm{mg}, 30 \mu \mathrm{mol}$ ) in DCM was added to a mixture of $\mathrm{EDC} \cdot \mathrm{HCl}(7 \mathrm{mg}, 37 \mu \mathrm{mol})$ and 4-nitrophenol ( $5 \mathrm{mg}, 36 \mu \mathrm{mol})$, followed by immediate addition of DMAP $(5 \mathrm{mg}, 40 \mu \mathrm{mol})$. The solution was stirred at room temperature overnight, dried in vacuo, and 2E-decenoic acid nitrophenol ester (SI2, $6 \mathrm{mg}, 68.7 \%$ yield) was isolated via flash column chromatography on silica using a gradient of $0-100 \%$ hexane in ethyl acetate.

SI2, ${ }^{1} \mathrm{H}$ NMR (500 MHz, chloroform-d): $\delta(p p m) 8.29$ (d, J = 9.2 Hz, 2H), 7.33 (d, J = 9.2 Hz, 2H), 7.26 (dt, $J=15.6,7.0 \mathrm{~Hz}, 1 \mathrm{H}), 6.04$ (dt, $J=15.6,1.5 \mathrm{~Hz}, 1 \mathrm{H}), 2.33$ (dq, $J=7.2,1.5 \mathrm{~Hz}, 2 \mathrm{H}$ ), 1.54 (quintet, $J=7.1 \mathrm{~Hz}, 2 \mathrm{H}), 1.40-1.25(\mathrm{~m}, 8 \mathrm{H}), 0.91(\mathrm{t}, J=7.0 \mathrm{~Hz}, 3 \mathrm{H})$.

SI2, ${ }^{13} \mathrm{C}$ NMR (125 MHz, chloroform-d): $\delta$ (ppm) 164.1, 155.8, 153.9, 145.3, 125.3, 122.6, $119.8,32.7,31.9,29.3,29.2,28.0,22.8,14.2$.

$\mathrm{NH}_{2} \mathrm{OH} \cdot \mathrm{HCl}(10 \mathrm{mg}, 144 \mu \mathrm{mol})$ in $1 \mathrm{~mL}$ of water $(\mathrm{pH}=7)$ was stirred with $6 \mathrm{mg}$ of SI2 in $5 \mathrm{~mL}$ $\mathrm{EtOH}$ at room temperature overnight. The solution was dried in vacuo and extracted with $3 \mathrm{~mL}$ of DCM and $3 \mathrm{~mL}$ of water. The DCM layer was analyzed by HPLC-HRMS, and SI3 was detected as the major product, with bis-adduct SI4 as a minor product and trace amounts of the reduced bis-adduct SI5. SI3 was isolated via flash column chromatography on silica using a gradient of $0-100 \% \mathrm{MeOH}$ in DCM. See Figure S1 for MS ion chromatograms of SI3, SI4, and SI5.

SI3, HRMS (ESI) $m / z:[M+H]^{+}$calculated for $\mathrm{C}_{10} \mathrm{H}_{20} \mathrm{NO}_{2}$ 186.14940; found 186.14827.

SI4, HRMS (ESI) $m / z$ : $[\mathrm{M}+\mathrm{H}]^{+}$calculated for $\mathrm{C}_{10} \mathrm{H}_{23} \mathrm{~N}_{2} \mathrm{O}_{3}$ 219.17032; found 219.16974.

SI5, HRMS (ESI) $m / z$ : [M + H] $]^{+}$calculated for $\mathrm{C}_{10} \mathrm{H}_{23} \mathrm{~N}_{2} \mathrm{O}_{2}$ 203.17540; found 203.17496.

SI3, ${ }^{1} \mathrm{H}$ NMR (500 MHz, DMSO-d $\left.d_{6}\right): \delta(p p m) 10.50$ (s, 1H), 8.83 (s, 1H), 6.61 (dt, $J=15.5,6.9$ $\mathrm{Hz}, 1 \mathrm{H}$ ), $5.72(\mathrm{~d}, J=15.5 \mathrm{~Hz}, 1 \mathrm{H}$ ), 2.11 (q, $J=7.0 \mathrm{~Hz}, 2 \mathrm{H}$ ), 1.38 (quintet, $J=7.0 \mathrm{~Hz}, 2 \mathrm{H}$ ), 1.32$1.18(\mathrm{~m}, 8 \mathrm{H}), 0.86(\mathrm{t}, J=6.8 \mathrm{~Hz}, 3 \mathrm{H})$.

SI3, ${ }^{13}$ C NMR (125 MHz, DMSO-d (1) $\delta$ (ppm) 162.7, 142.2, 121.7, 31.2, 30.7, 28.5, 28.4, 27.8, 22.1, 14.0 . 
Synthesis of $\quad 8 R$-(3'R-hydroxy-5'R-O-(nicotinoyl)-6' S-methyl-(2H)-tetrahydropyran-2'yloxy)-2E-nonenoic acid (ncas\#3, 18)

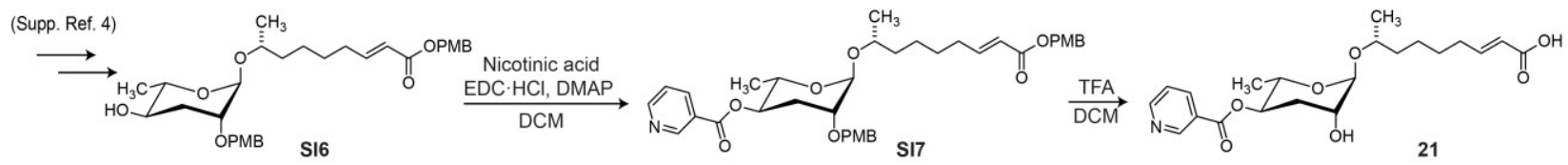

Precursor SI6 was synthesized as described by Zhang et. al ${ }^{4}$. Nicotinic acid $(14.7 \mathrm{mg}, 0.120$ $\mathrm{mmol})$ and $\mathrm{EDC} \cdot \mathrm{HCl}(23 \mathrm{mg}, 0.120 \mathrm{mmol})$ were added to $1.3 \mathrm{~mL}$ of DCM. The suspension was rapidly stirred until a homogeneous solution formed, and then SI6 (12 $\mathrm{mg}, 0.022 \mathrm{mmol})$ and DMAP (14.6 mg, $0.120 \mathrm{mmol}$ ) in $1.3 \mathrm{~mL}$ of DCM were added. After stirring for $12 \mathrm{~h}$ at room temperature, the solution was concentrated in vacuo, and the product was isolated utilizing flash column chromatography on silica using a gradient of $0-50 \%$ ethyl acetate in hexanes, affording SI7 (13.7 mg, $96 \%$ ) as a colorless oil.

${ }^{1} \mathrm{H}$ NMR (600 MHz, chloroform-d): $\delta(\mathrm{ppm}) 9.22(\mathrm{~d}, J=2.2 \mathrm{~Hz}, 1 \mathrm{H}), 8.78(\mathrm{dd}, J=5.0,1.7 \mathrm{~Hz}$, $1 \mathrm{H}), 8.28$ (dt, $J=7.9,1.7 \mathrm{~Hz}, 1 \mathrm{H}), 7.40(\mathrm{dd}, J=7.9,5.0 \mathrm{~Hz}, 1 \mathrm{H}), 7.34-7.28(\mathrm{~m}, 4 \mathrm{H}), 7.00$ (dt, 15.6, 7.0 Hz, 1H), 6.91-6.86 (m, 4H), $5.86(\mathrm{dt}, J=15.6,1.5 \mathrm{~Hz}, 1 \mathrm{H}), 5.12(\mathrm{dt}, J=10.3,4.5 \mathrm{~Hz}$, 1H), 4.80 (br. s, 1H), 4.64 (d, J = 11.7 Hz, 1H), 4.52 (d, J = 11.7 Hz, 1H), 3.97 (dq, J = 9.6, 6.3 $\mathrm{Hz}, 1 \mathrm{H}), 3.81(\mathrm{~s}, 6 \mathrm{H}), 3.82-3.78(\mathrm{~m}, 1 \mathrm{H}), 3.58-3.55(\mathrm{~m}, 1 \mathrm{H}) 2.38(\mathrm{dt}, J=13.1,4.0 \mathrm{~Hz}, 1 \mathrm{H}), 2.22$ (dq, $J=7.1,1.4 \mathrm{~Hz}, 2 \mathrm{H}), 1.89$ (ddd, $J=13.6,11.1,2.9 \mathrm{~Hz}, 1 \mathrm{H}), 1.63-1.34(\mathrm{~m}, 6 \mathrm{H}), 1.23(\mathrm{~d}, J=$ $6.3 \mathrm{~Hz}, 3 \mathrm{H}), 1.10(\mathrm{~d}, J=6.1 \mathrm{~Hz}, 3 \mathrm{H})$.

To a stirring solution of SI7 $(13.7 \mathrm{mg}, 0.021 \mathrm{mmol})$ in $1.9 \mathrm{~mL}$ DCM, trifluoroacetic acid (TFA) $(168 \mu \mathrm{L}, 2.20 \mathrm{mmol})$ was added. The solution was stirred for $20 \mathrm{~min}$ at room temp. and concentrated in vacuo. Flash column chromatography on silica using a gradient of $0-50 \% \mathrm{MeOH}$ in DCM was performed, affording ncas\#3 (21) (5.9 mg, $65 \%$ ) as a colorless oil. HRMS (ESI) m/z: [M - H] calculated for $\mathrm{C}_{21} \mathrm{H}_{28} \mathrm{NO}_{6}$ 406.18713; found 406.18677 For spectroscopic data, see Figure S9 (MS2) and Table S3 $\left({ }^{1} \mathrm{H}\right.$ and ${ }^{13} \mathrm{C}$ NMR).

\section{$10 R-\left(3^{\prime} R, 5^{\prime} R\right.$-dihydroxy-6'S-methyl-(2H)-tetrahydropyran-2'-yloxy)-undecanoyl}

\section{hydroxamate (ascr\#18-HA, 8)}

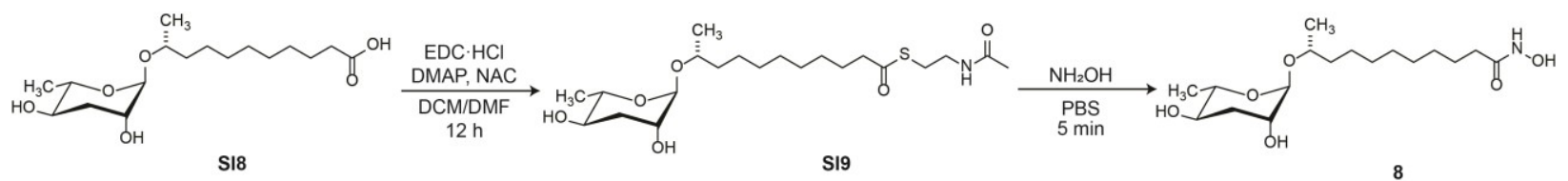

$200 \mu \mathrm{L}$ of a solution containing ascr\#18 (SI8, $1 \mathrm{mg}, 3 \mu \mathrm{mol})$ in 3:1 DCM:DMF was added to a mixture of EDC $\cdot \mathrm{HCl}(1 \mathrm{mg}, 5 \mu \mathrm{mol})$ and $N$-acetylcysteamine (NAC, $0.6 \mathrm{mg}, 5 \mu \mathrm{mol})$ in $200 \mu \mathrm{L}$ of 3:1 DCM:DMF, followed by immediate addition of DMAP $(0.6 \mathrm{mg}, 5 \mu \mathrm{mol})$. The solution was stirred at room temperature overnight, dried in vacuo, and ascr\#18 $\mathrm{N}$-acetylcysteamine thioester 
(SI9, $0.8 \mathrm{mg}, 61 \%$ yield) was isolated via flash column chromatography on silica using a gradient of $0-50 \% \mathrm{MeOH}$ in DCM.

SI9, HRMS (ESI) m/z: [M + Na] $]^{+}$calculated for $\mathrm{C}_{21} \mathrm{H}_{39} \mathrm{NO}_{6} \mathrm{SNa}$ 456.23903; found 456.23798.

SI9, ${ }^{1} \mathrm{H}$ NMR (500 MHz, chloroform-d): $\delta$ (ppm) $4.70(\mathrm{~s}, 1 \mathrm{H}), 3.60-3.85(\mathrm{~m}, 4 \mathrm{H}), 3.43$ (q, $\mathrm{J}=$ $6.3 \mathrm{~Hz}, 2 \mathrm{H}) 3.02$ (t, $J=6.5 \mathrm{~Hz}, 2 \mathrm{H}), 2.57(\mathrm{t}, J=7.4 \mathrm{~Hz}, 2 \mathrm{H}), 2.07(\mathrm{~m}, 1 \mathrm{H}), 1.97(\mathrm{~s}, 3 \mathrm{H}), 1.60-$ $1.92(\mathrm{~m}, 15 \mathrm{H}), 1.28(\mathrm{~d}, J=6.2 \mathrm{~Hz}, 3 \mathrm{H}), 1.12(\mathrm{~d}, J=6.0 \mathrm{~Hz}, 3 \mathrm{H})$.

SI9, ${ }^{13} \mathrm{C}$ NMR (125 MHz, chloroform-d): $\delta$ (ppm) 200.6, 170.5, 96.2, 71.7, 70.0, 69.5, 68.3, $44.2,40.0,37.3,35.4,29.5,29.4,29.2,29.0,28.6,25.8,23.4,19.1,17.8$.

To $200 \mu \mathrm{L}$ of a solution containing SI9 $(0.8 \mathrm{mg}, 1.84 \mu \mathrm{mol})$ in $\mathrm{MeOH}$ was added $1 \mathrm{~mL}$ of $0.1 \mathrm{M}$ $\mathrm{NH}_{2} \mathrm{OH} \cdot \mathrm{HCl}$ in $0.1 X$ PBS $(\mathrm{pH}=7)$. The solution was stirred at room temperature for 5 min, frozen over liquid nitrogen, lyophilized, and then extracted with $1 \mathrm{~mL} \mathrm{MeOH}$. From the extract, ascr\#18-HA (8) was isolated via flash column chromatograph on silica using a gradient of 0-100\% $\mathrm{MeOH}$ in DCM and analyzed by HPLC-HRMS. The retention time of synthetic ascr\#18-HA (8) matched that of the corresponding peak in the $\mathrm{NH}_{2} \mathrm{OH} \cdot \mathrm{HCl}$-treated natural samples.

HRMS (ESI) m/z: [M - H] calculated for $\mathrm{C}_{17} \mathrm{H}_{32} \mathrm{NO}_{6}$ 346.22351; found 346.22379.

${ }^{1} \mathrm{H}$ NMR (500 MHz, methanol-d $\left.)_{4}\right): \delta(p p m) 4.66(\mathrm{~s}, 1 \mathrm{H}), 3.79(\mathrm{~m}, 1 \mathrm{H}), 3.73(\mathrm{~m}, 1 \mathrm{H}), 3.65(\mathrm{dq}, J$ $=9.5,6.2 \mathrm{~Hz}, 1 \mathrm{H}), 3.53(\mathrm{ddd}, J=11.2,9.5,4.6 \mathrm{~Hz} 1 \mathrm{H}), 2.33(\mathrm{t}, J=7.5 \mathrm{~Hz}, 2 \mathrm{H}), 1.96(\mathrm{dt}, J=$ 13.3, 3.8 Hz, 1H), 1.78 (ddd, $J=13.3,11.6,3.0 \mathrm{~Hz}, 1 \mathrm{H}), 1.62-1.3(\mathrm{~m}, 12 \mathrm{H}), 1.23(\mathrm{~d}, J=6.3 \mathrm{~Hz}$, $3 \mathrm{H}), 1.13(\mathrm{~d}, J=6.1 \mathrm{~Hz}, 3 \mathrm{H})$.

${ }^{13} \mathrm{C}$ NMR (125 MHz, methanol-d 4 ): $\delta$ (ppm) 163.4, 97.6, 72.5, 71.2, 70.0, 68.3, 38.4, 36.0, 34.8, $30.8,30.6,30.5,30.4,30.2,26.9,26.0,19.4,18.0$.

3-Hydroxyamino-8R-(3'R,5'R-dihydroxy-6' S-methyl-(2H)-tetrahydropyran-2'-yloxy)nonanoic acid (ascr\#3-HAM, 15)

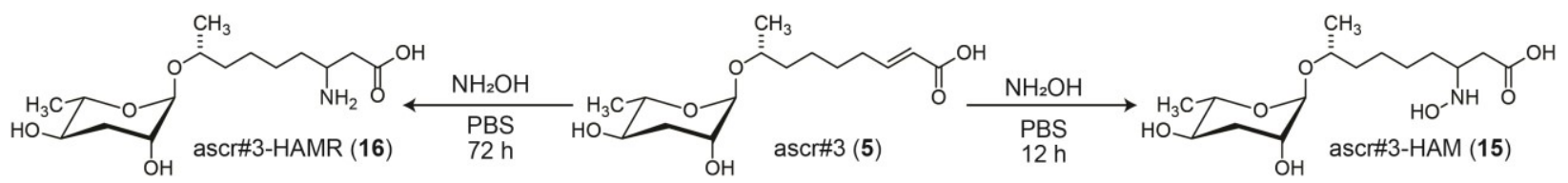

A $10 \mu \mathrm{L}$ solution containing ascr\#3 (5) $(0.5 \mathrm{mg}, 1.7 \mu \mathrm{mol})$ in $\mathrm{MeOH}$ was added to $1 \mathrm{~mL}$ of $0.1 \mathrm{M}$ $\mathrm{NH}_{2} \mathrm{OH} \cdot \mathrm{HCl}$ in $0.1 X$ PBS $(\mathrm{pH}=7$ ). The solution was stirred at room temperature overnight, frozen over liquid nitrogen, lyophilized, and then extracted with $1 \mathrm{~mL} \mathrm{MeOH}$. From the extract, ascr\#3-HAM (15) was isolated via flash column chromatograph on silica using a gradient of 0$100 \% \mathrm{MeOH}$ in DCM and analyzed by HPLC-HRMS. The retention time of synthetic ascr\#3HAM (15) matched that of the corresponding peak in the $\mathrm{NH}_{2} \mathrm{OH} \cdot \mathrm{HCl}$-treated natural samples. 
HRMS (ESI) $\mathrm{m} / \mathrm{z}$ : $[\mathrm{M}+\mathrm{H}]^{+}$calculated for $\mathrm{C}_{15} \mathrm{H}_{30} \mathrm{NO}_{7}$ 336.20168; found 336.19998.

${ }^{1} \mathrm{H}$ NMR (500 MHz, methanol- $\left.d_{4}\right): \delta$ (ppm) 4.66 (br. s, 1H), $3.80(\mathrm{~m}, 1 \mathrm{H}), 3.73(\mathrm{~m}, 1 \mathrm{H}), 3.65(\mathrm{~m}$, $1 \mathrm{H}), 3.53(\mathrm{~m}, 1 \mathrm{H}), 2.19(\mathrm{~m}, 2 \mathrm{H}), 1.97(\mathrm{dt}, J=13.1,3.8 \mathrm{~Hz}, 1 \mathrm{H}), 1.87-1.75(\mathrm{~m}, 2 \mathrm{H}), 1.65-1.3(\mathrm{~m}$, $8 \mathrm{H}), 1.23(\mathrm{~d}, J=6.2 \mathrm{~Hz}, 3 \mathrm{H}), 1.13(\mathrm{~d}, J=6.1 \mathrm{~Hz}, 3 \mathrm{H})$.

${ }^{13} \mathrm{C}$ NMR (125 MHz, methanol- $\left.d_{4}\right): \delta(p p m)$ 97.5, 72.4, 71.2, 70.0, 68.4, 53.4, 38.1, 36.0, 32.9, 29.7, 27.6, 26.4, 19.3, 18.1, carbonyl not detected.

MS reference sample of 3-amino-8R-(3'R,5'R-dihydroxy-6'S-methyl-(2H)-tetrahydropyran2'-yloxy)-nonanoic acid (ascr\#3-HAMR, 16)

A $10 \mu \mathrm{L}$ solution containing ascr\#3 (5) $(10 \mu \mathrm{g}, 33 \mathrm{nmol})$ in $\mathrm{MeOH}$ was added to $1 \mathrm{~mL}$ of $0.1 \mathrm{M}$ $\mathrm{NH}_{2} \mathrm{OH} \cdot \mathrm{HCl}$ in $0.1 \times \mathrm{PBS}(\mathrm{pH}=7)$. The solution was stirred at room temperature for $72 \mathrm{~h}$, frozen over liquid nitrogen, lyophilized, and then extracted with $1 \mathrm{~mL} \mathrm{MeOH}$. The extract was clarified via centrifugation and analyzed by HPLC-HRMS. The retention time of synthetic ascr\#3-HAMR (16) matched that of the corresponding peak in the $\mathrm{NH}_{2} \mathrm{OH} \cdot \mathrm{HCl}$-treated natural samples. HRMS (ESI) $m / z:[M+H]^{+}$calculated for $\mathrm{C}_{15} \mathrm{H}_{30} \mathrm{NO}_{6} 320.20676$; found 320.20547.

MS reference sample of $8 R$-(3' $R, 5^{\prime} R$-dihydroxy-6' $S$-methyl-(2H)-tetrahydropyran-2'-yloxy)nonanoyl hydroxamate (ascr\#10-HA, 7)

A $50 \mu \mathrm{L}$ solution containing ascr\#10 (4) $(10 \mu \mathrm{g}, 33 \mathrm{nmol})$ in 3:1 DCM:DMF was added to a mixture of $\mathrm{EDC} \cdot \mathrm{HCl}(10 \mu \mathrm{g}, 50 \mathrm{nmol})$ and $\mathrm{NH}_{2} \mathrm{OH} \cdot \mathrm{HCl}(10 \mu \mathrm{g}, 140 \mathrm{nmol})$ in $50 \mu \mathrm{L}$ DMF, followed by immediate addition of DMAP $(25 \mu \mathrm{g}, 21 \mathrm{nmol})$. The solution was stirred at room temperature overnight, dried in vacuo, and resuspended in $100 \mu \mathrm{L} \mathrm{MeOH}$. The extract was clarified via centrifugation and analyzed by HPLC-HRMS. The retention time of synthetic ascr\#10-HA (7) matched that of the corresponding peak in the $\mathrm{NH}_{2} \mathrm{OH} \cdot \mathrm{HCl}$-treated natural samples.

HRMS (ESI) m/z: [M - H] calculated for $\mathrm{C}_{15} \mathrm{H}_{28} \mathrm{NO}_{6} 318.19221$; found 318.19272.

MS reference sample of $8 R$-(3' $R, 5^{\prime} R$-dihydroxy-6'S-methyl-(2H)-tetrahydropyran-2'-yloxy)heptenoyl hydroxamate (ascr\#7-HA, 9)

A $50 \mu \mathrm{L}$ solution containing ascr\#10 (7) $(10 \mu \mathrm{g}, 36 \mathrm{nmol})$ in 3:1 DCM:DMF was added to a mixture of EDC $\cdot \mathrm{HCl}(10 \mu \mathrm{g}, 50 \mathrm{nmol})$ and $\mathrm{NH}_{2} \mathrm{OH} \cdot \mathrm{HCl}(10 \mu \mathrm{g}, 140 \mathrm{nmol})$ in $50 \mu \mathrm{L} \mathrm{DMF}$, followed by immediate addition of DMAP $(25 \mu \mathrm{g}, 21 \mathrm{nmol})$. The solution was stirred at room temperature overnight, dried in vacuo, and resuspended in $100 \mu \mathrm{L} \mathrm{MeOH}$. The extract was clarified via centrifugation and analyzed by HPLC-HRMS. The retention time of synthetic ascr\#7-HA (9) matched that of the corresponding peak in the $\mathrm{NH}_{2} \mathrm{OH} \cdot \mathrm{HCl}$-treated natural samples. HRMS (ESI) m/z: [M - H] calculated for $\mathrm{C}_{13} \mathrm{H}_{22} \mathrm{NO}_{6}$ 288.14526; found 288.14532. 
MS reference sample of 9-(3'R,5'R-dihydroxy-6'S-methyl-(2H)-tetrahydropyran-2'-yloxy)nonanoyl hydroxamate (oscr\#10-HA, 17)

A $50 \mu \mathrm{L}$ solution containing oscr\#10 (10 $\mu \mathrm{g}, 33 \mathrm{nmol})$ in 3:1 DCM:DMF was added to a mixture of $\mathrm{EDC} \cdot \mathrm{HCl}(10 \mu \mathrm{g}, 50 \mathrm{nmol})$ and $\mathrm{NH}_{2} \mathrm{OH} \cdot \mathrm{HCl}(10 \mu \mathrm{g}, 140 \mathrm{nmol})$ in $50 \mu \mathrm{L} \mathrm{DMF}$, followed by immediate addition of DMAP $(25 \mu \mathrm{g}, 205 \mathrm{nmol})$. The solution was stirred at room temperature overnight, dried in vacuo and resuspended in $100 \mu \mathrm{L} \mathrm{MeOH}$. The extract was clarified via centrifugation and analyzed by HPLC-HRMS.

HRMS (ESI) m/z: [M - H] calculated for $\mathrm{C}_{15} \mathrm{H}_{28} \mathrm{NO}_{6}$ 318.19221; found 318.19257.

\section{MS reference sample for mass spectrometry of butan-2-one oxime (butanone-OX)}

$1 \mathrm{~mL}$ of $0.1 \mathrm{M} \mathrm{NH}_{2} \mathrm{OH} \cdot \mathrm{HCl}$ in $0.1 \mathrm{X}$ PBS $(\mathrm{pH}=7)$ was stirred with $10 \mu \mathrm{L}$ of butanone at room temperature overnight and then analyzed by HPLC-HRMS. Butanone-OX was detected as the major product.

HRMS (ESI) $m / z$ : $[\mathrm{M}+\mathrm{H}]^{+}$calculated for $\mathrm{C}_{4} \mathrm{H}_{10} \mathrm{NO}$ 88.07569; found 88.07555. 


\section{Supporting figures}

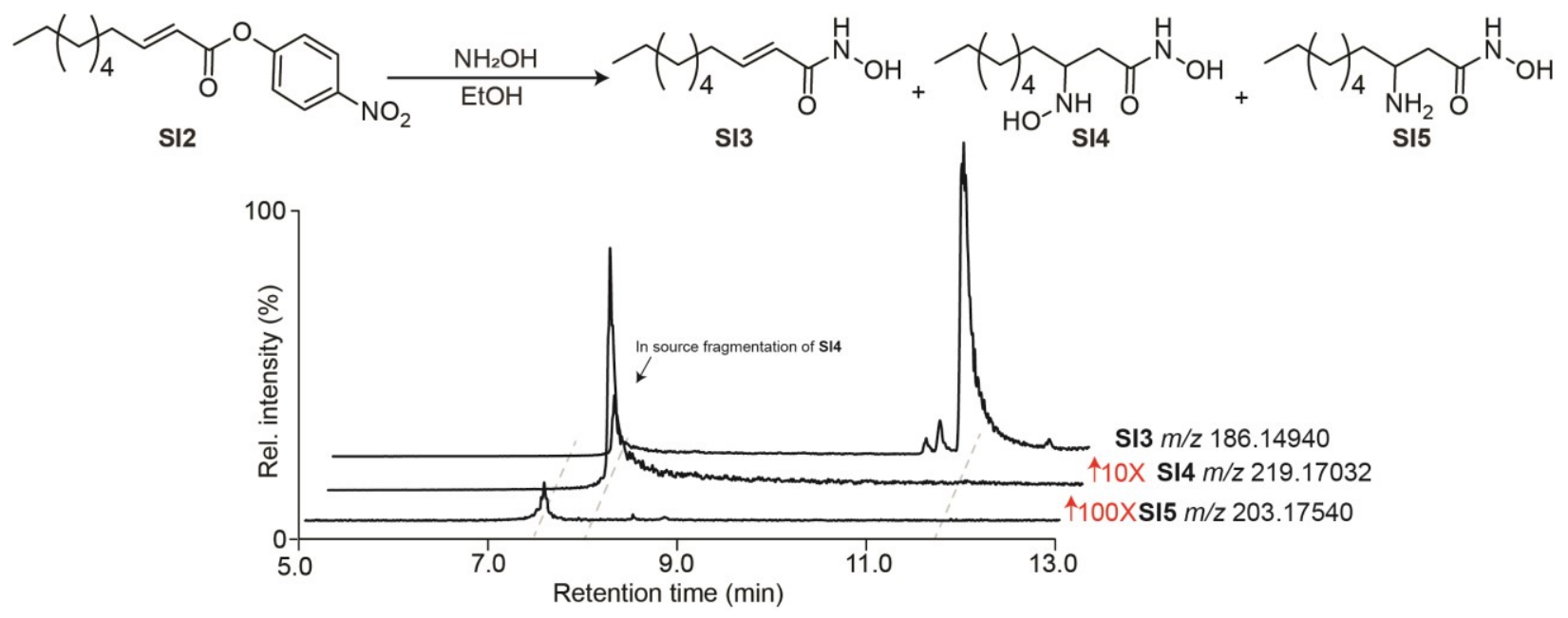

Figure S1. Ion chromatograms (positive ionization mode) of SI3, SI4, and SI5 from $\mathrm{NH}_{2} \mathrm{OH}$ labeling of activated $2 E$-decenoic acid. 


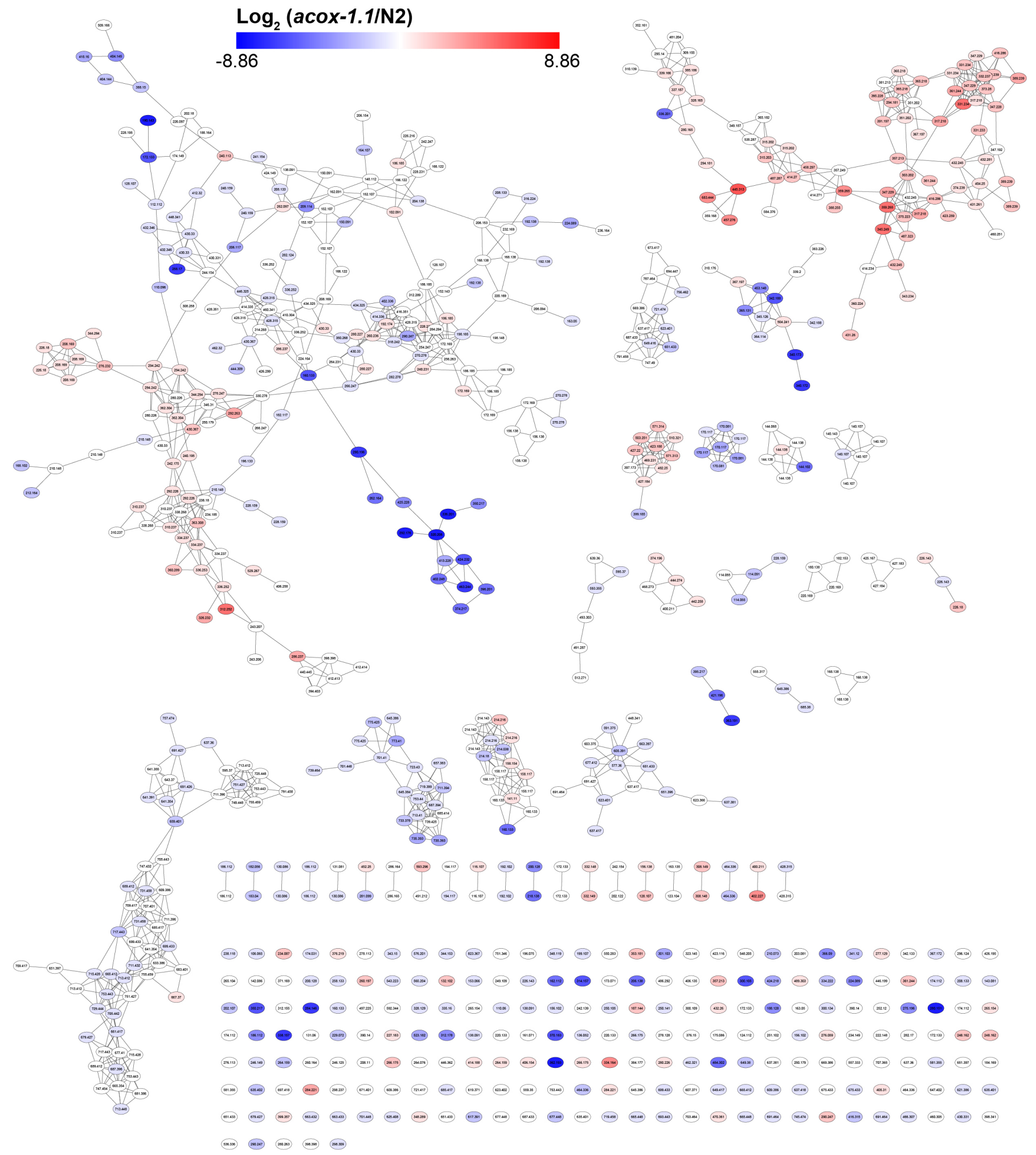

Figure S2. Positive ion $\mathrm{MS}^{2}$ network of $\mathrm{NH}_{2} \mathrm{OH}$-labeled features from $\mathrm{C}$. elegans endometabolome confirmed via ${ }^{15} \mathrm{NH}_{2} \mathrm{OH}$-labeling. Color represents the $\log _{2}$ ratio of peak areas in the acox-1.1 and wildtype HRMS data, where blue represents down-regulated features and red represents up-regulated features in the acox-1.1 null mutant. 


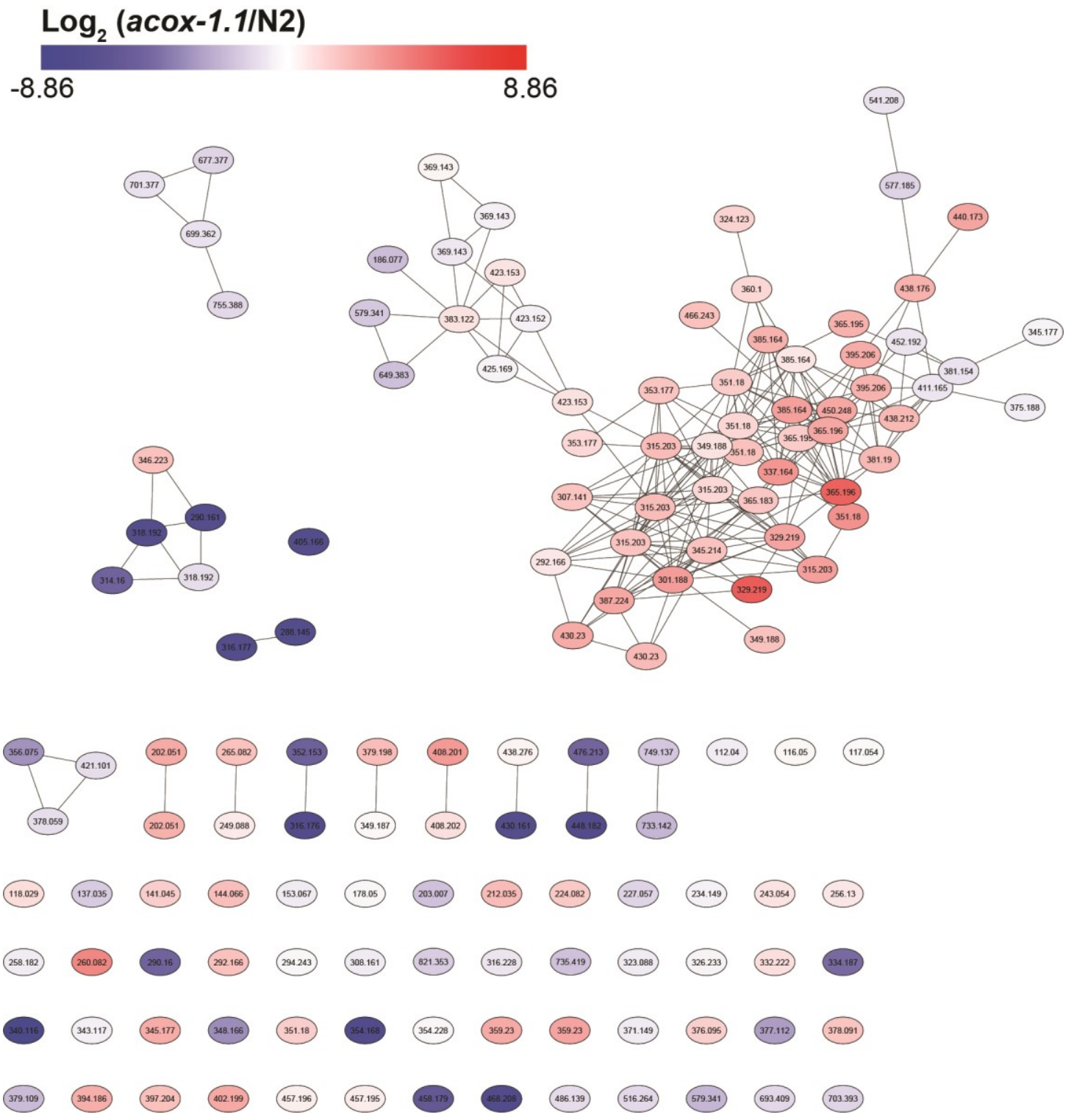

Figure S3. Negative ion $\mathrm{MS}^{2}$ network of $\mathrm{NH}_{2} \mathrm{OH}$-labeled features from $\mathrm{C}$. elegans endometabolome confirmed via ${ }^{15} \mathrm{NH}_{2} \mathrm{OH}$-labeling. Color represents the $\log _{2}$ ratio of peak areas in the acox-1.1 and wildtype HRMS data, where blue represents down-regulated features and red represents up-regulated features in the acox-1.1 null mutant. 
$\mathrm{NH}_{2} \mathrm{OH}$-labeled ascaroside

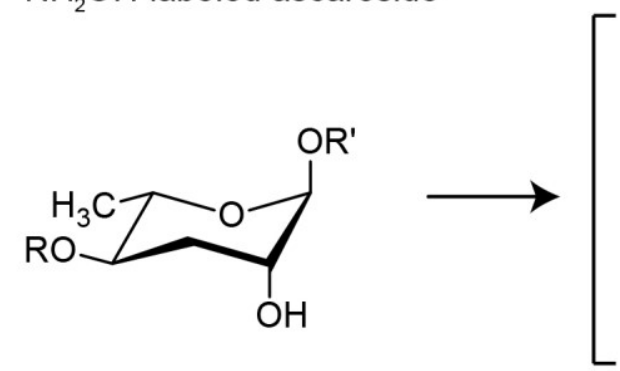

R: H, or 4'-head group

R': Fatty acid tail $\left(\mathrm{NH}_{2} \mathrm{OH}\right.$-labeled)

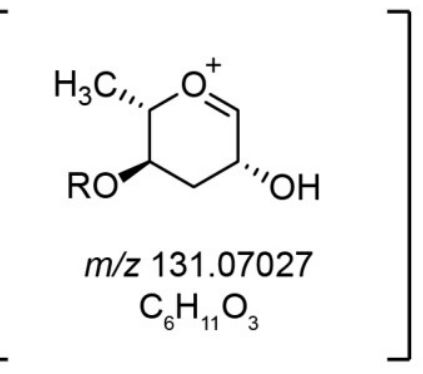

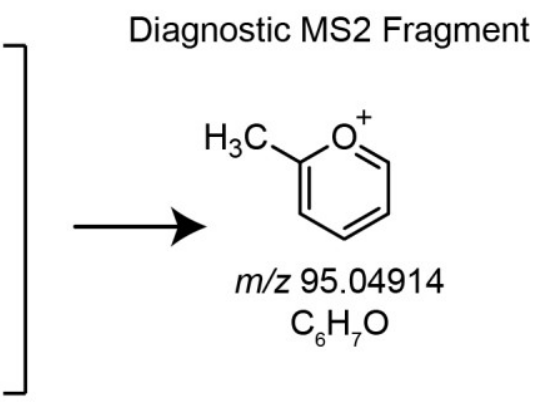

Figure S4. $\mathrm{NH}_{2} \mathrm{OH}$-labeled ascarosides produce a diagnostic positive $\mathrm{MS}^{2}$ fragment ion likely associated with the ascarylose core giving rise to a methylpyrylium ion. 

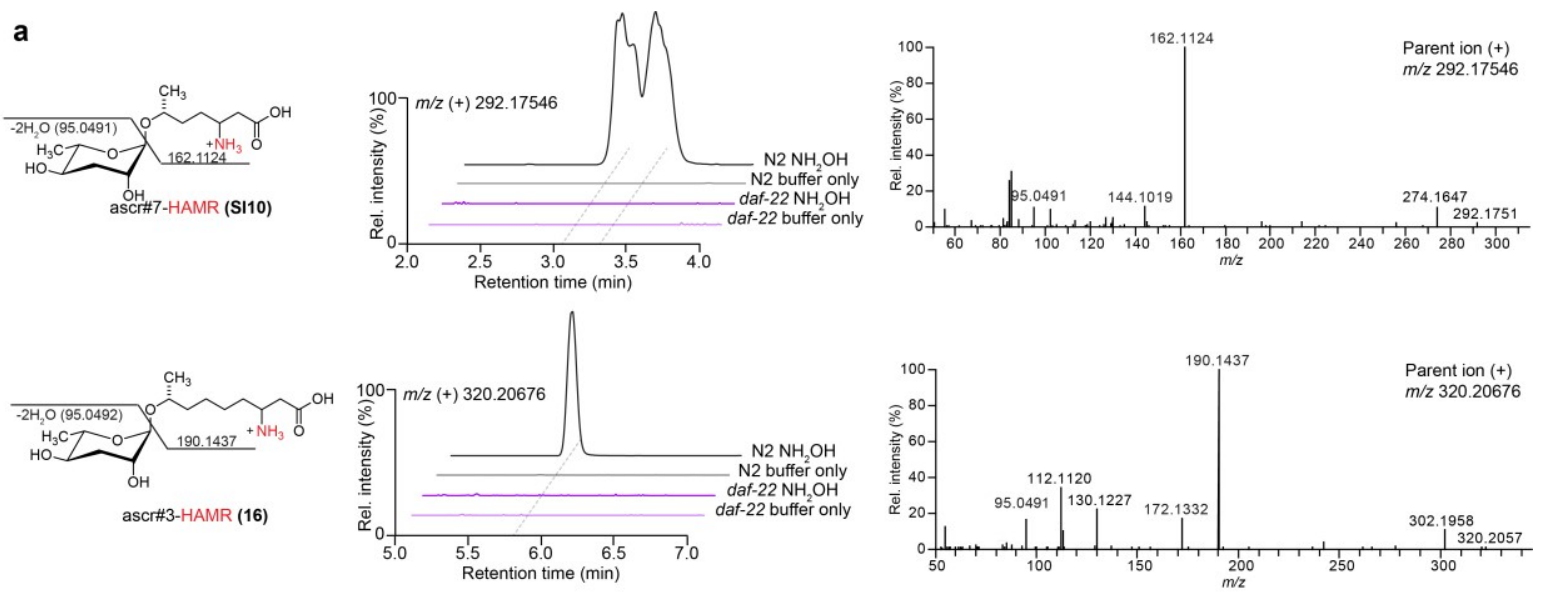

b
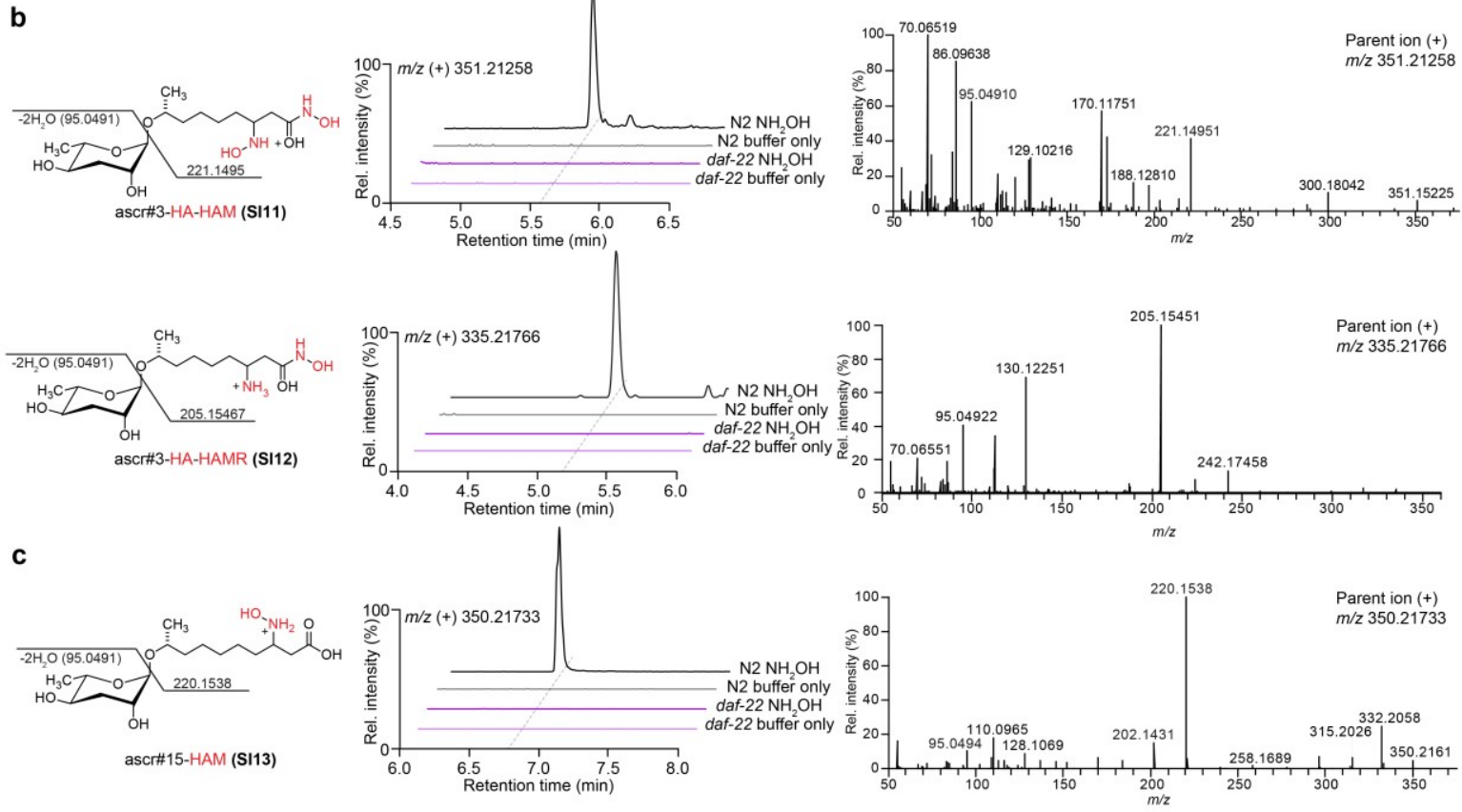

d

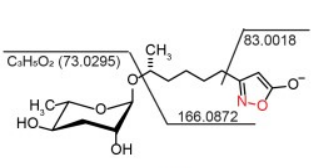

bkas\#10-HA (13)

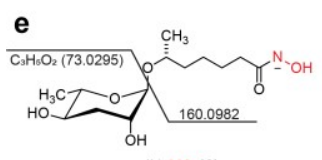

ascr\#1-HA (6)
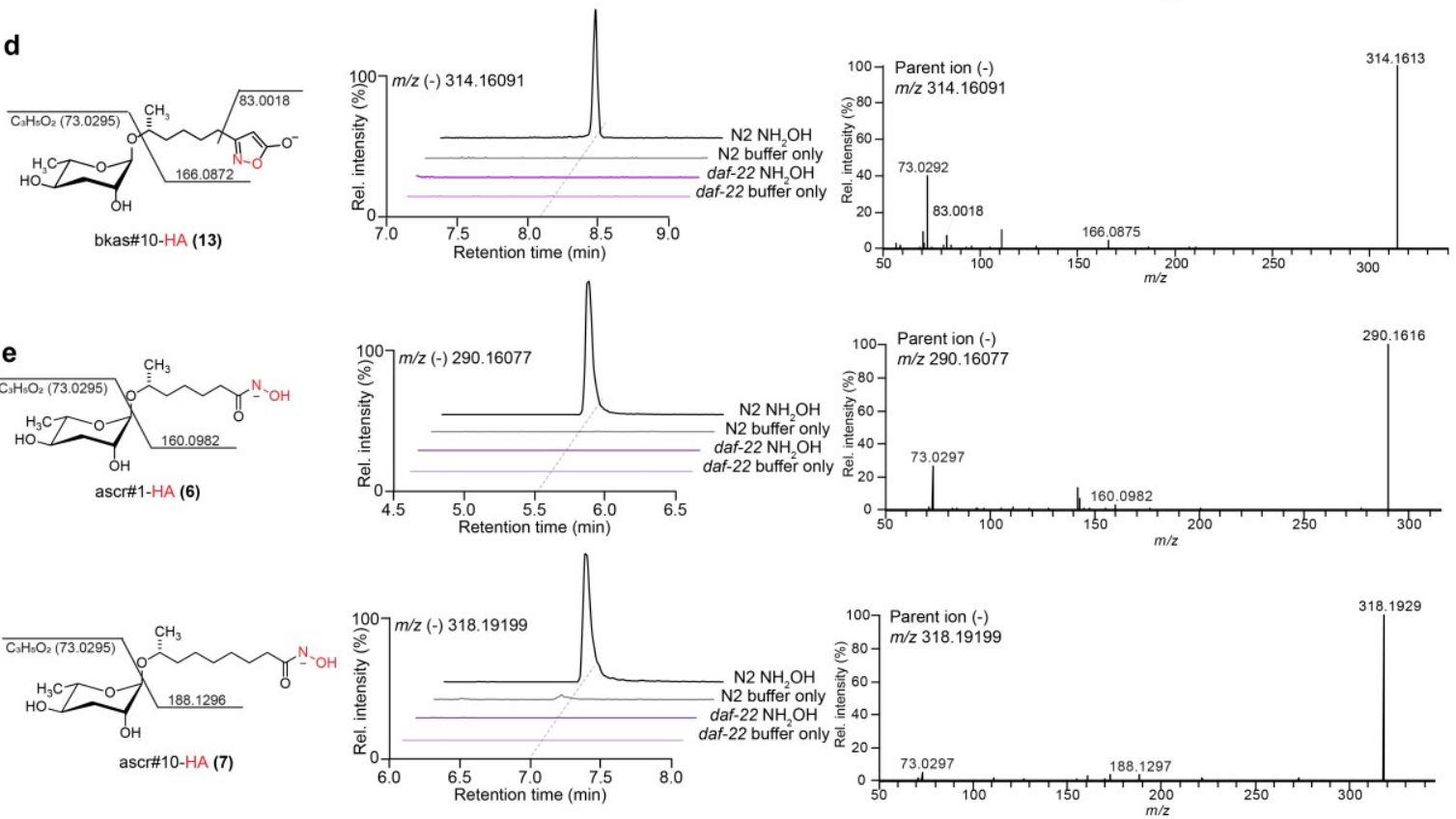

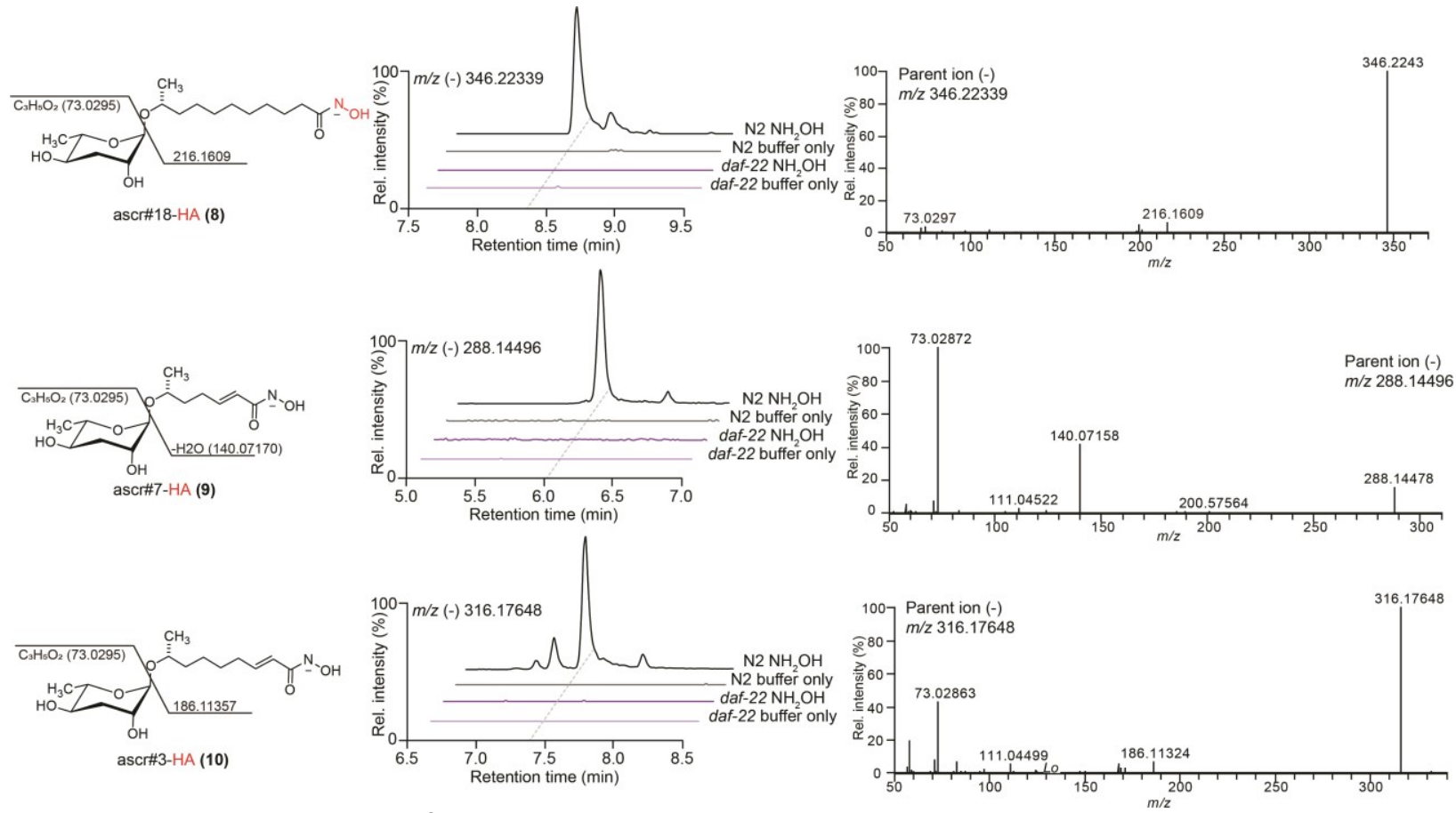

Figure S5. Diagnostic $\mathrm{MS}^{2}$ fragments and ion chromatograms of wildtype (N2) and daf-22 mutant cultures, and $\mathrm{MS}^{2}$ spectra of representative HA-labeled ascarosides. (a) HA-derivatives of the ascr\#7 (ascr\#7-HAMR, two partially separated diastereomers, SI10), and ascr\#3 (ascr\#3HAMR, 16), (b) HA bis-adducts of the a, $\beta$-unsaturated ascr\#3-CoA (ascr\#3-HA-HAM, SI11 and ascr\#3-HA-HAMR, SI12), (c) HA-derivative of ascr\#15 (ascr\#15-HAM, SI13), (d) HA-derivative of the $\beta$-keto acyl bkas\#10-CoA (bkas\#10, 13), and (e) HA-derivative of the ascr\#1, 10, 18, 7, 3 -CoA (ascr\#1-HA, 6, ascr\#10-HA, 7, ascr\#18-HA, 8, ascr\#1-HA, 9 and ascr\#10-HA, 10), 
a

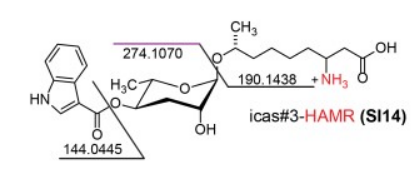

b
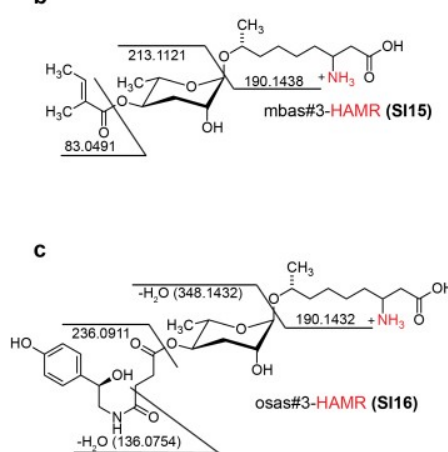

d
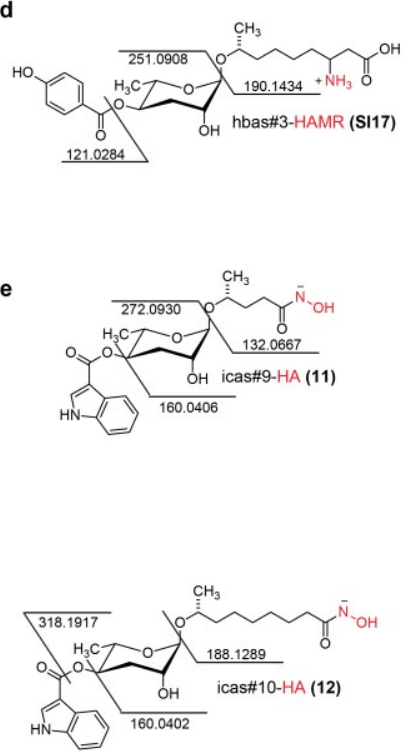
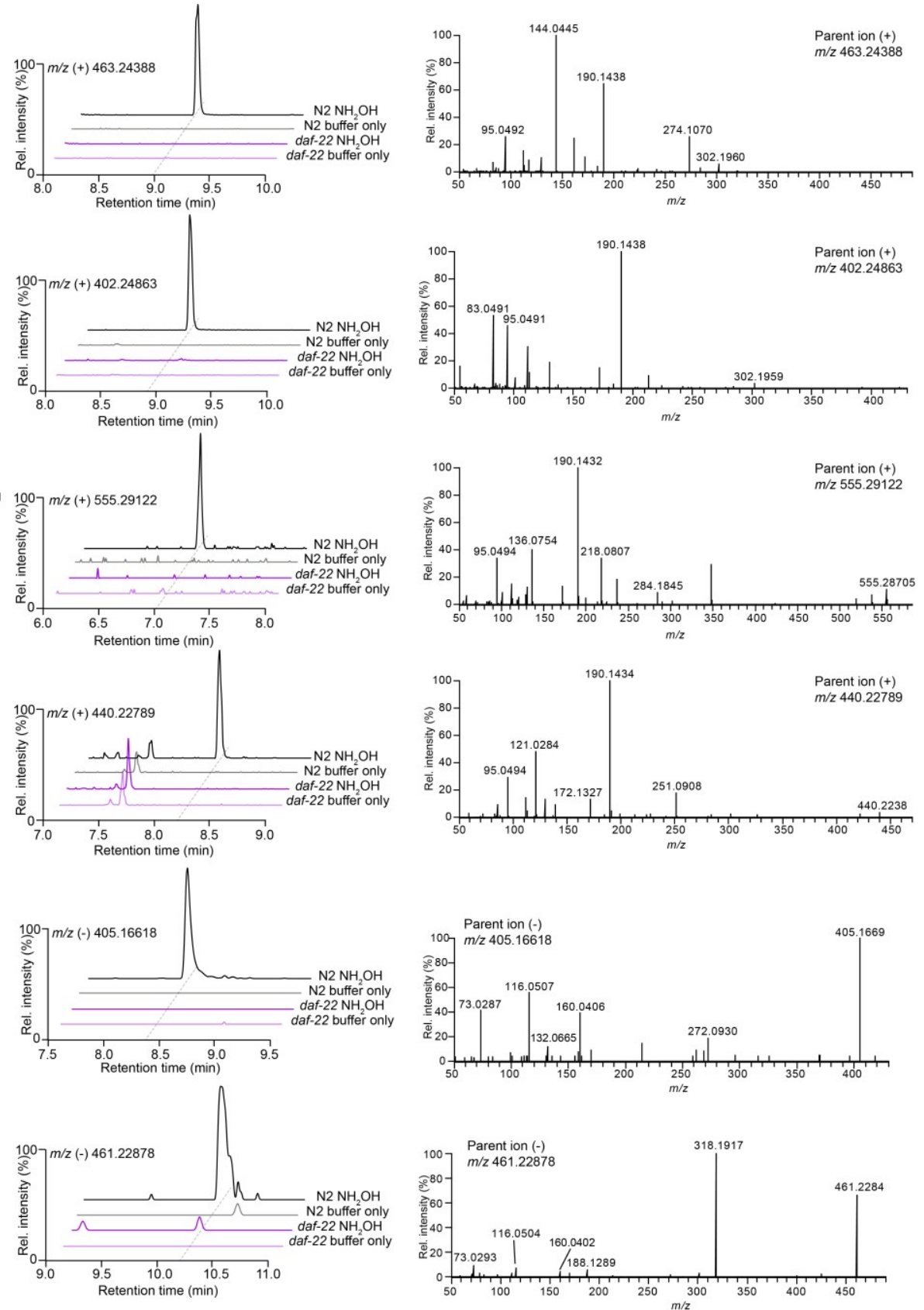

Figure S6. Diagnostic $\mathrm{MS}^{2}$ fragments and of ion chromatograms from C. elegans wildtype (N2) and daf-22 mutant cultures, and $\mathrm{MS}^{2}$ spectra of representative $\mathrm{NH}_{2} \mathrm{OH}$-labeled 4'-modified ascarosides with: (a) indole-3-carbonyl, icas\#3-HAMR (SI14), (b) 2-methylbut-2E-enoyl, mbas\#3-HAMR (SI15), (c) octopamine succinyl, osas\#3-HAMR (SI16), (d) p-hydroxybenzoyl, hbas\#3-HAMR (SI17) bearing side chains, and (e) icas\#9-HA (11) and icas\#10-HA (12) 
a

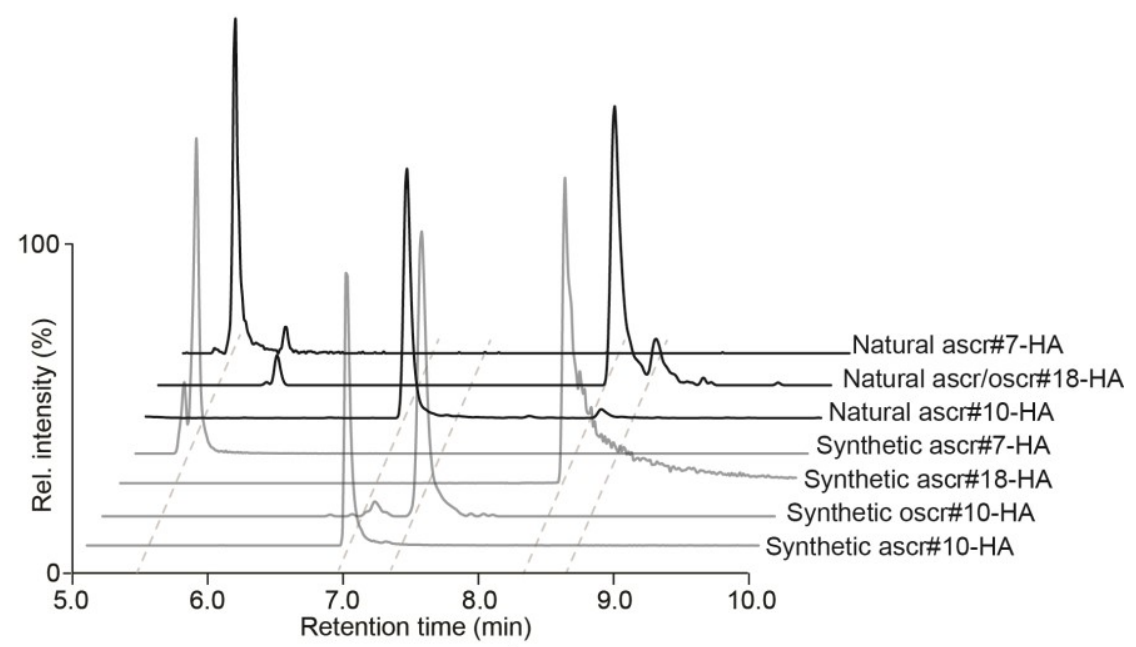

b

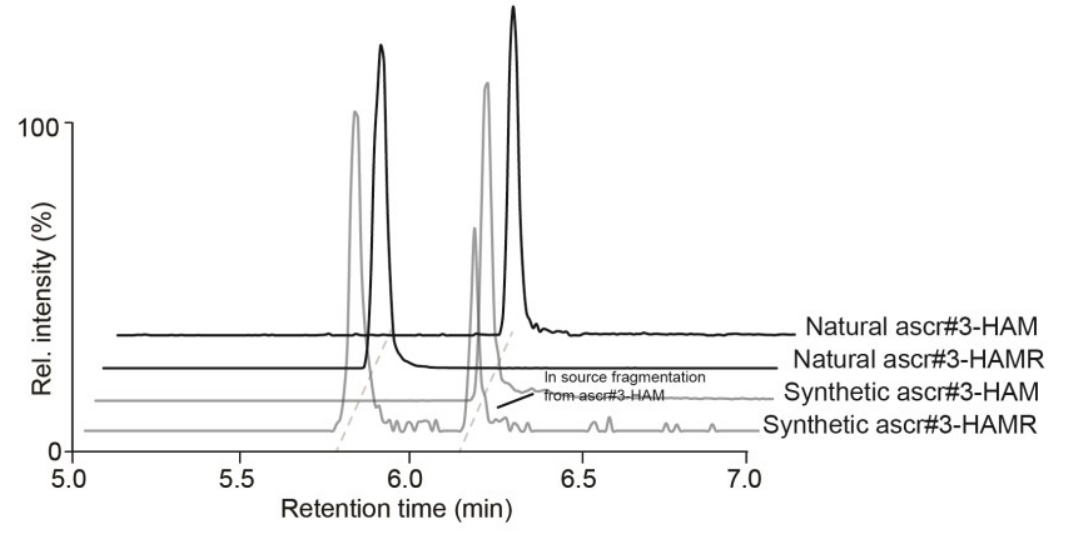

\section{C}

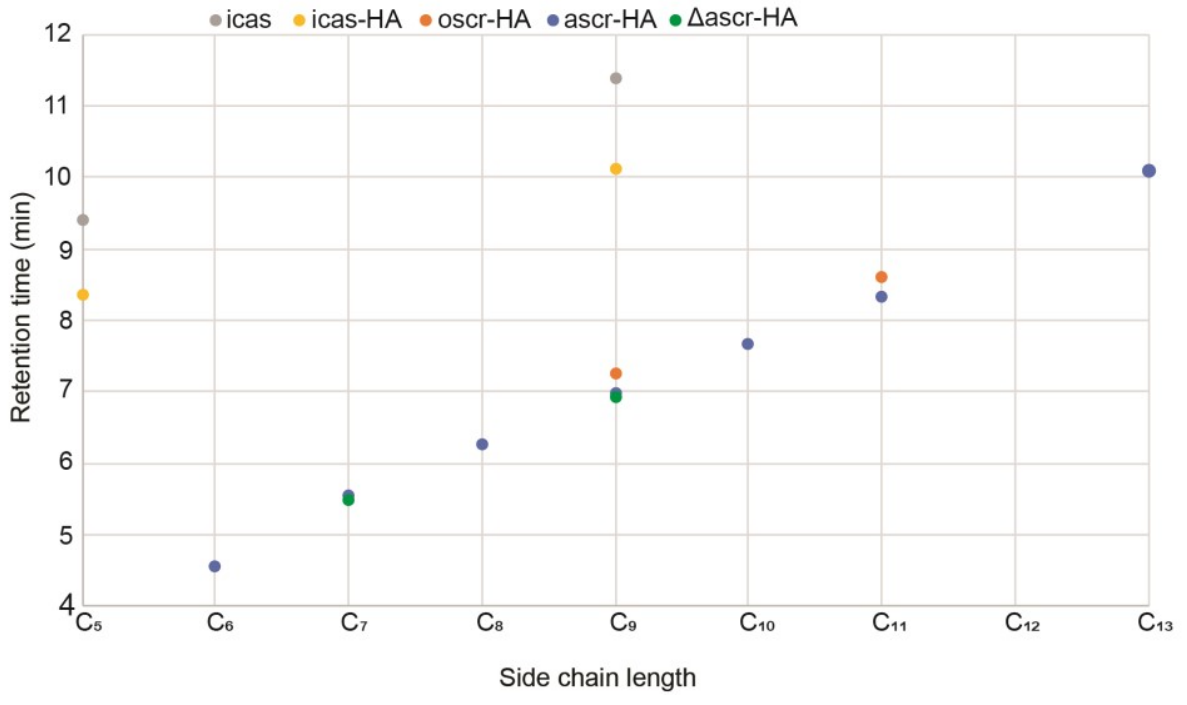

Figure S7. Ion chromatograms of (a) ascr\#7-HA (9), ascr\#18-HA (8), oscr\#18-HA (SI18), ascr\#10-HA (7), and oscr\#10-HA (17), detected in negative ionization mode and (b) ascr\#3HAM (15) and ascr\#3-HAMR (16), detected in positive ionization mode, from $\mathrm{NH}_{2} \mathrm{OH}$ treated wildtype endo-metabolomes (black) and synthetic reactions (grey). (c) HPLC elution profiles of ascr-HA, oscr-HA, icas-HA and icas ascarosides. 

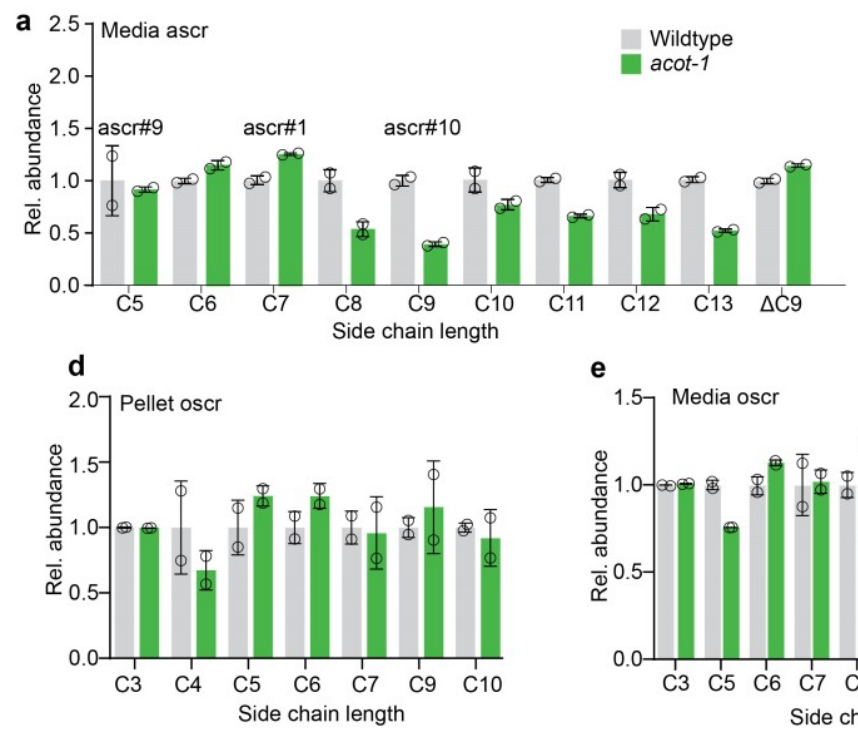

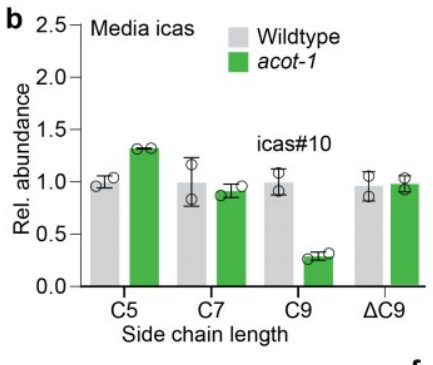

e 1.5 Media osc

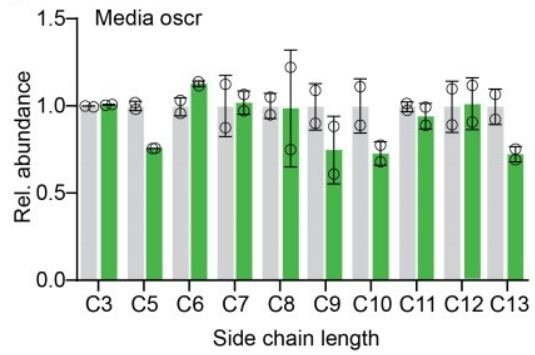

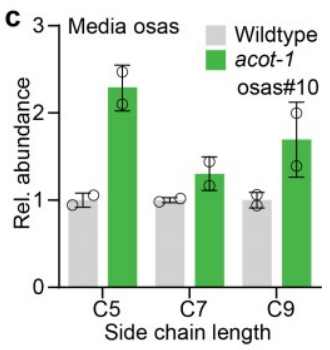

$\mathbf{f}$

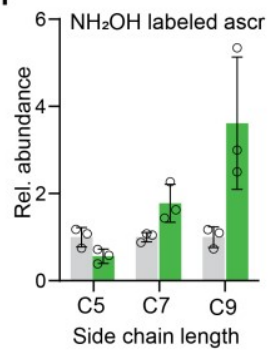

Figure S8. Relative abundances of (a) simple ( $\omega-1)$-ascarosides, (b) 4'-indole-3-carbonyl, and (c) 4'-octopamine succinyl ascarosides from exo-metabolomes, as well as simple $(\omega)$ ascarosides from (d) endo-metabolomes and (e) exo-metabolomes. (f) $\mathrm{NH}_{2} \mathrm{OH}$ labeled $(\omega-1)$ ascarosides of wildtype (N2, grey) and acot-1 null mutant worms (green). 


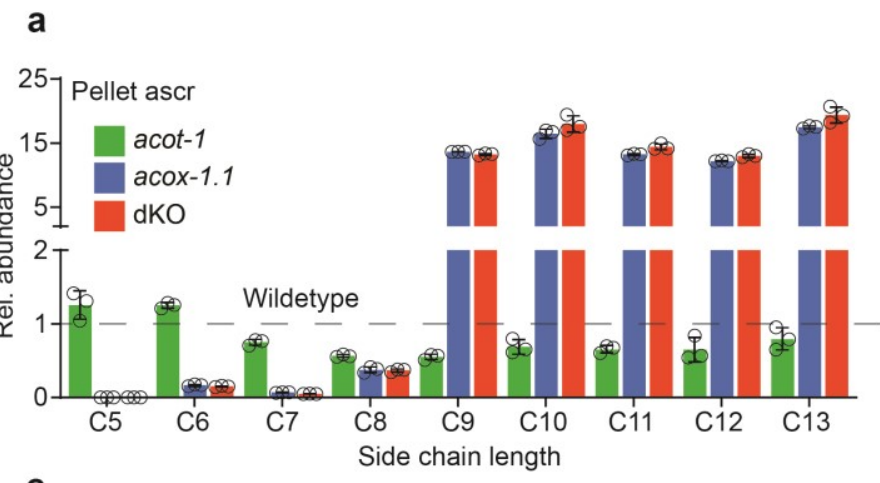

b

C
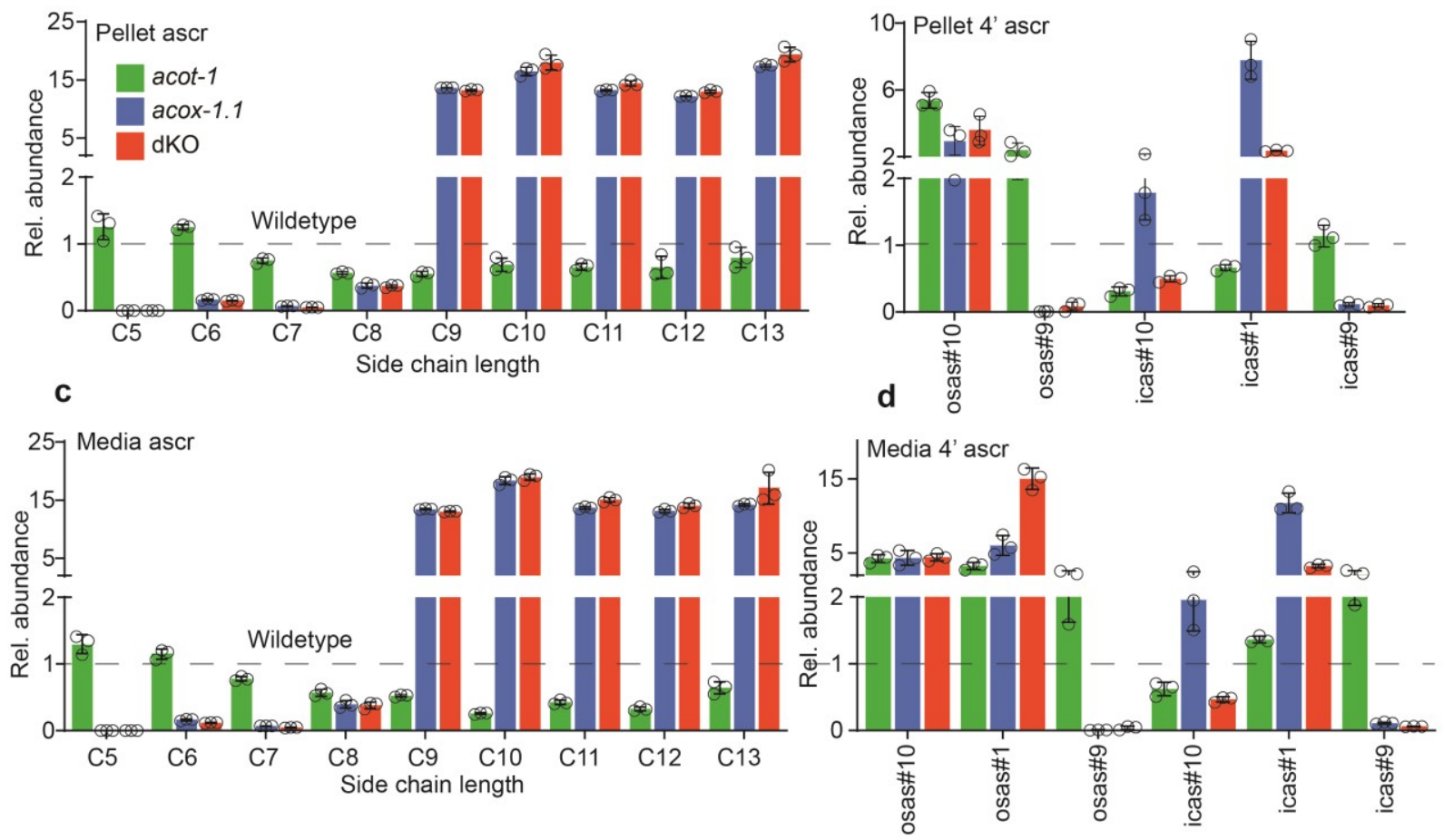

Figure S9. Relative abundances of (a) simple ( $\omega-1)$-ascarosides, and (b) 4'-modified ascarosides from endo-metabolomes, and (c) simple ( $\omega-1)$-ascarosides, and (d) 4'-modified ascaroside from exo-metabolomes of acot-1 null mutant worms (green), acox-1.1 null mutant worms (blue) and acot-1;acox-1.1 double mutant worms (dKO, red) relative to wildtype (N2) worms. 

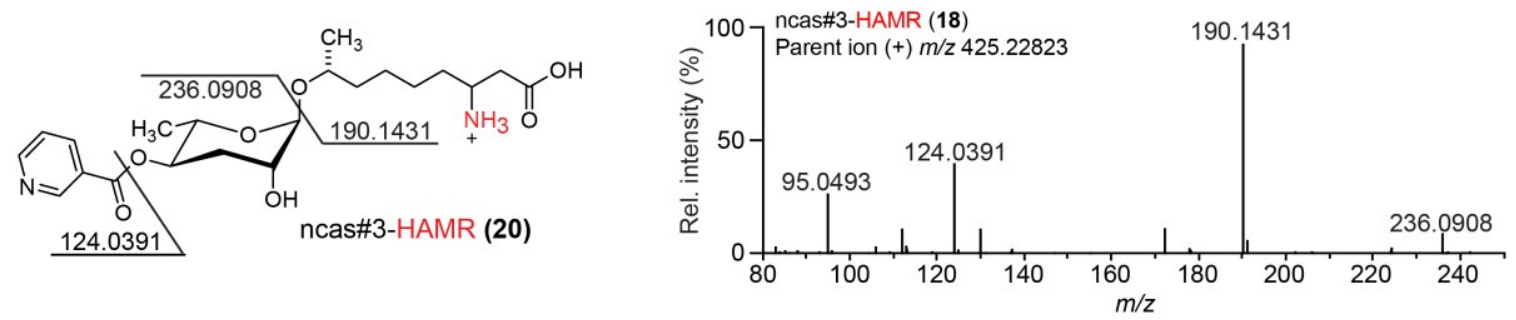

b
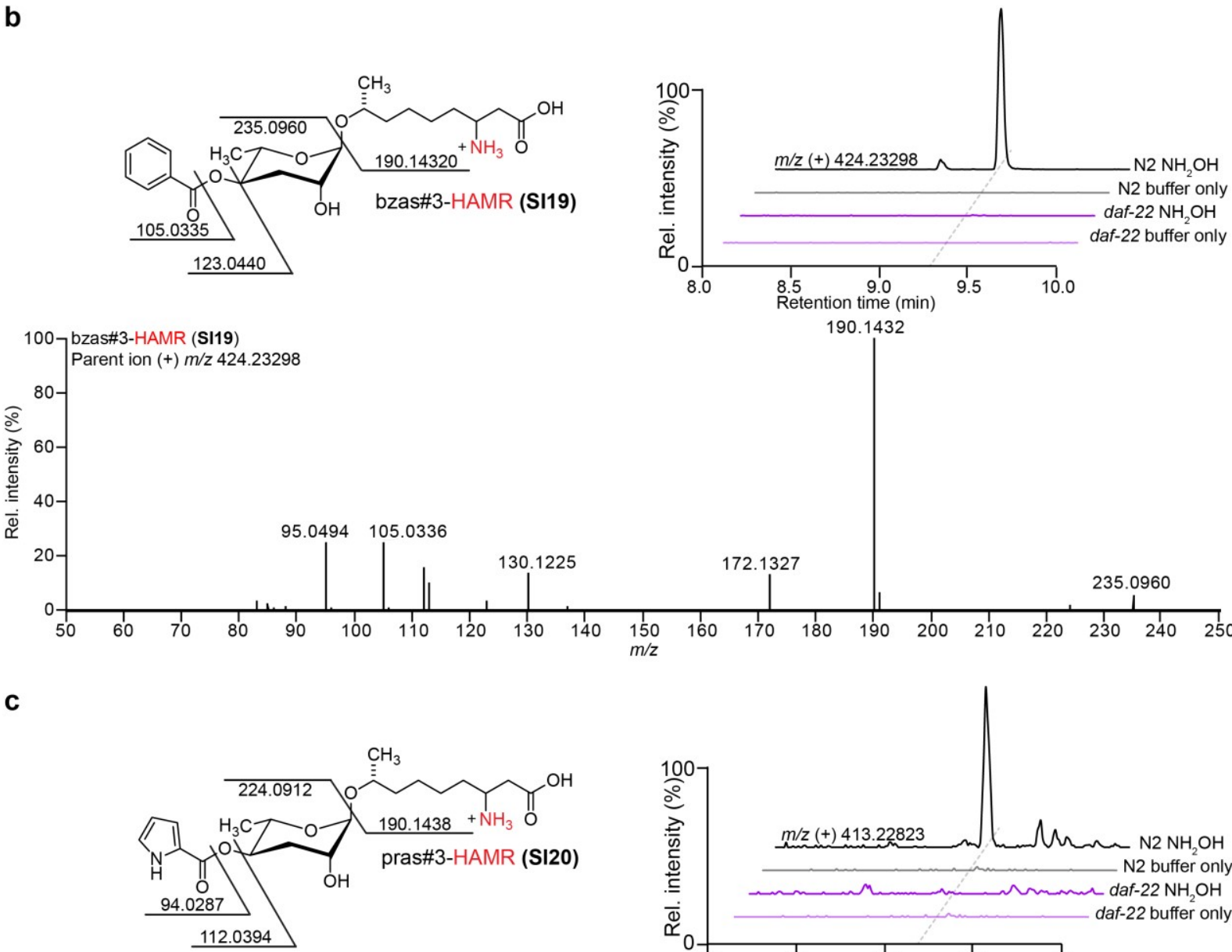

190.1432

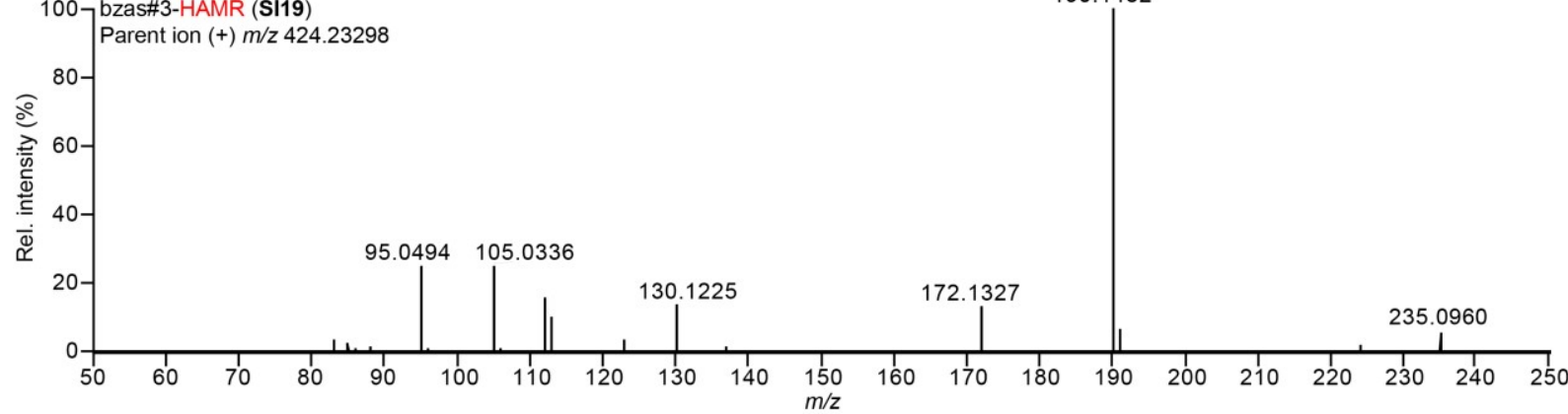

${ }^{100} 7$ pras\#3-HAMR (SI20)

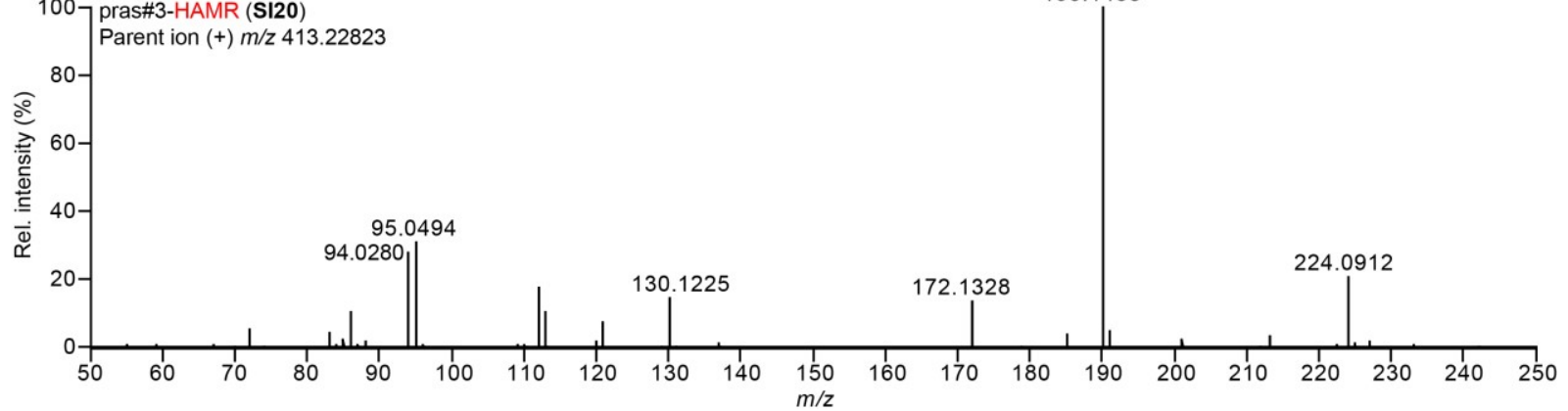

Figure S10. (a) $\mathrm{MS}^{2}$ spectrum of ncas\#3-HAMR (20). Diagnostic $\mathrm{MS}^{2}$ fragments, comparison of ion chromatograms from C. elegans. wildtype (N2) and daf-22 mutant cultures, and $\mathrm{MS}^{2}$ spectra of $\mathrm{NH}_{2} \mathrm{OH}$-labeled ascarosides, (b) bzas\#3-HAMR (SI19) and (c) pras\#3-HAMR (SI20). 

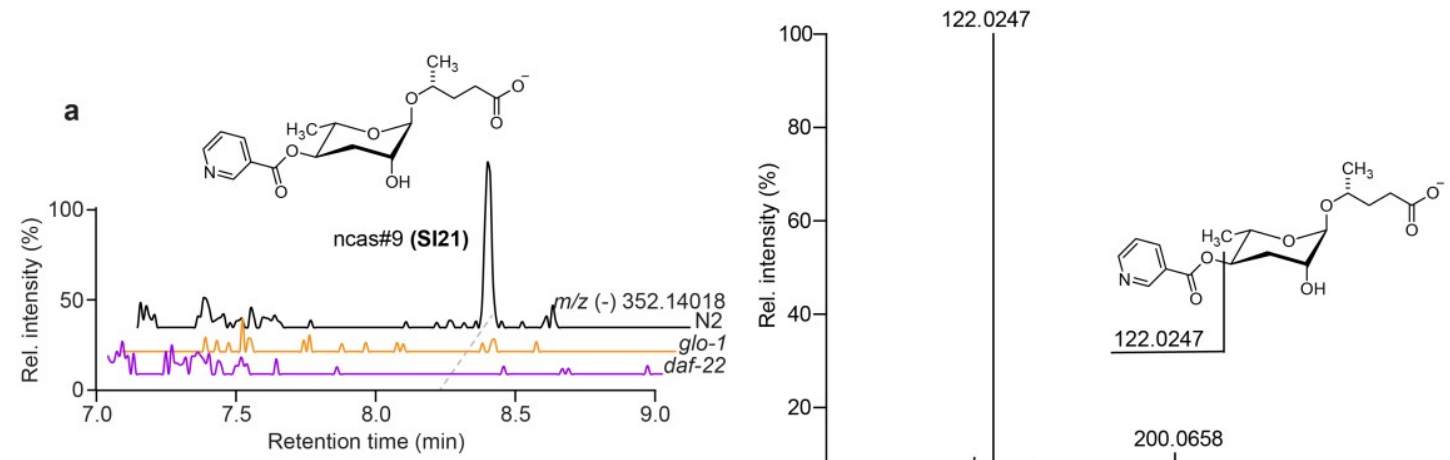

Parent ion (-)

$\mathrm{m} / \mathrm{z} 352.14018$

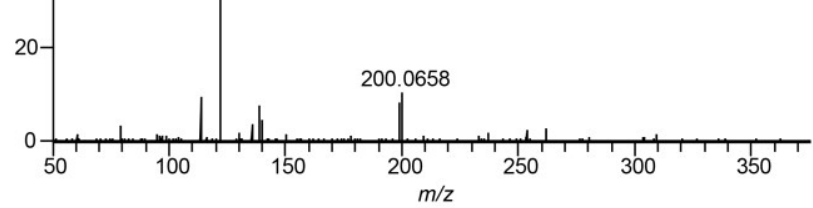

b
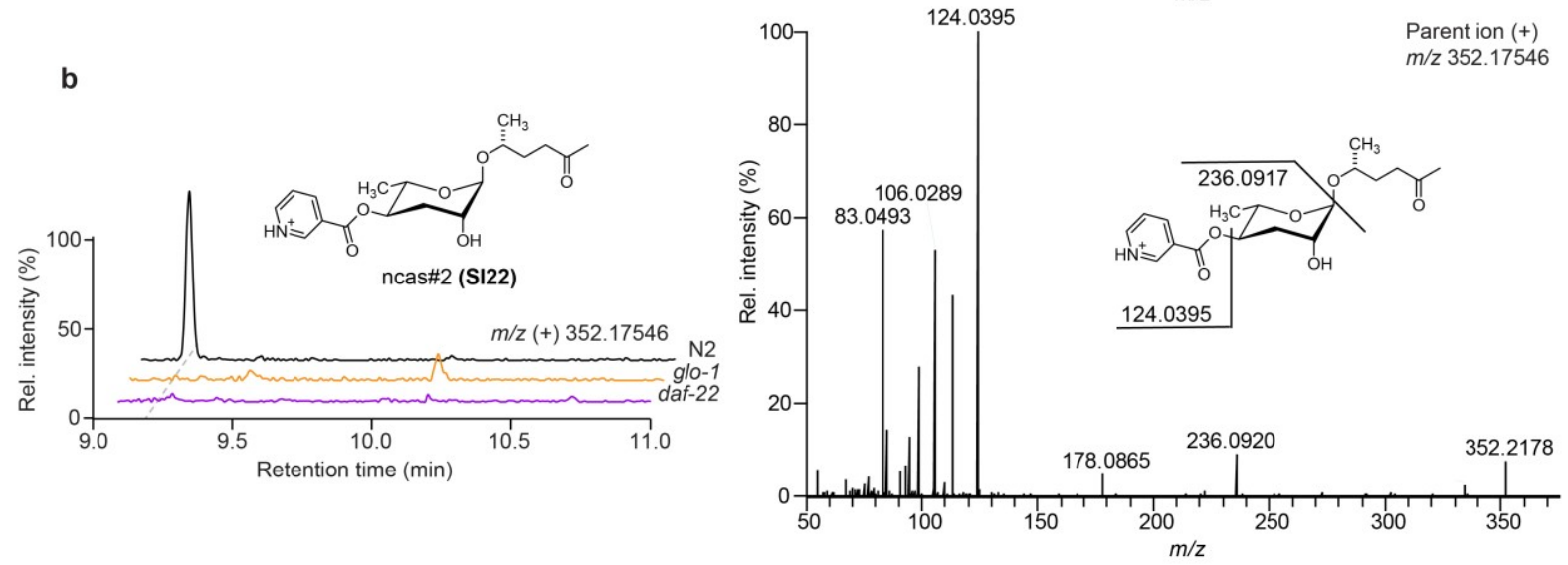

C
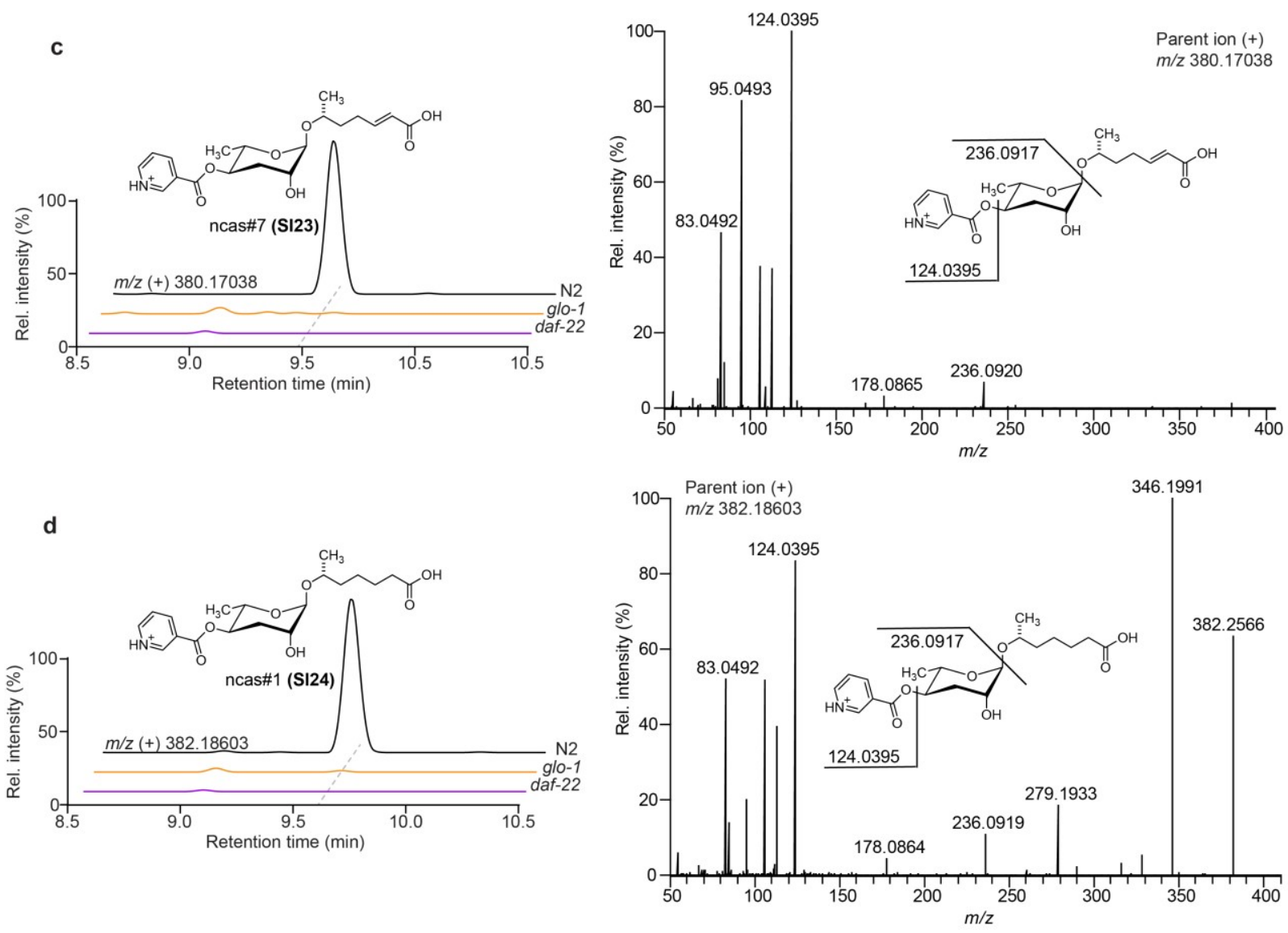

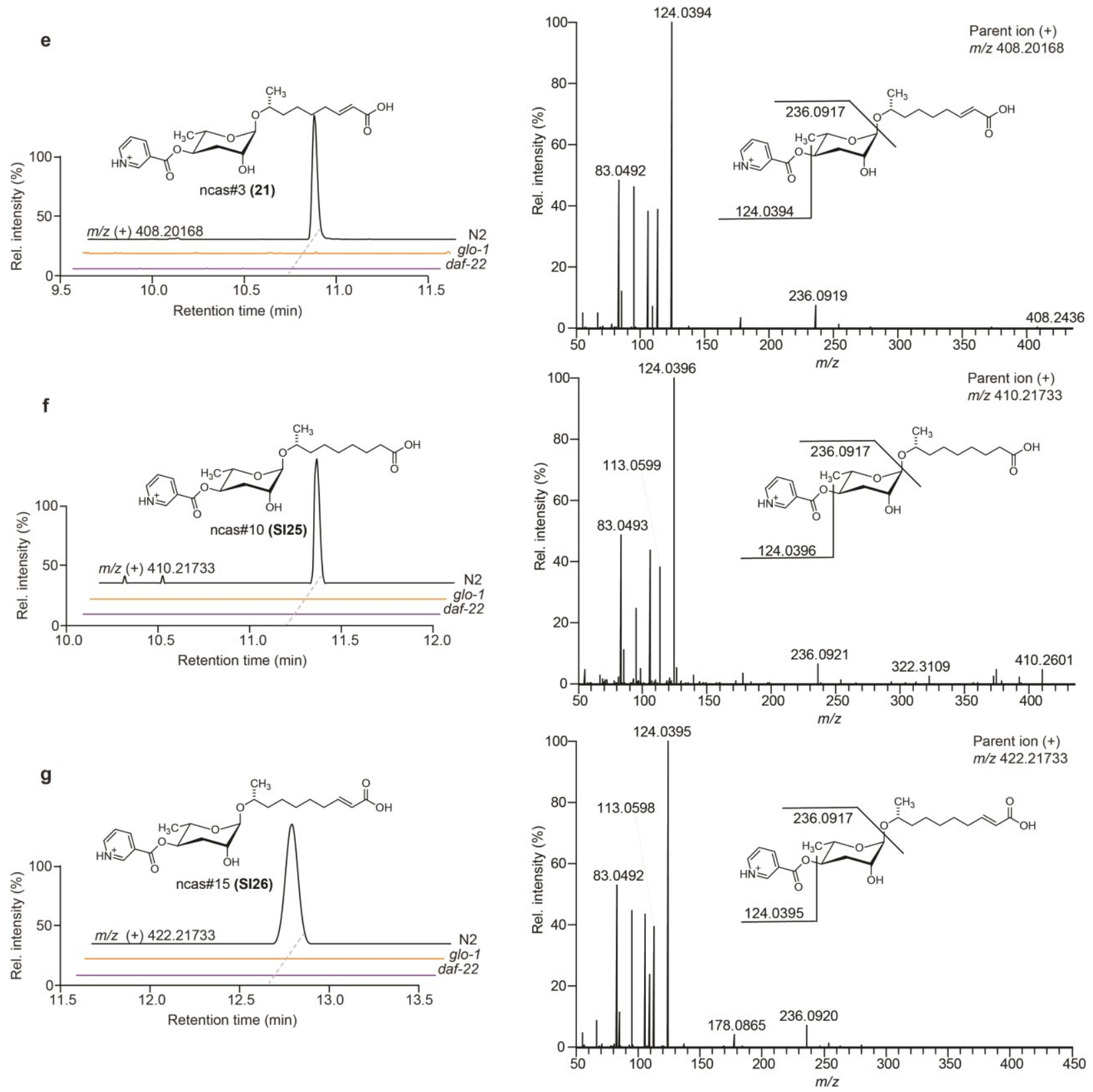

Figure S11. Ion chromatograms from cultures of $C$. elegans wildtype (N2), daf-22 mutants, and glo-1 mutants, as well as $\mathrm{MS}^{2}$ spectra of niacin-bearing ascarosides (a) ncas\#9 (SI21), (b) ncas\#2 (SI22), (c) ncas\#7 (SI23), (d) ncas\#1 (SI24), (e) ncas\#3 (21), (f) ncas\#10 (SI25), and (g) ncas\#15 (SI26). 

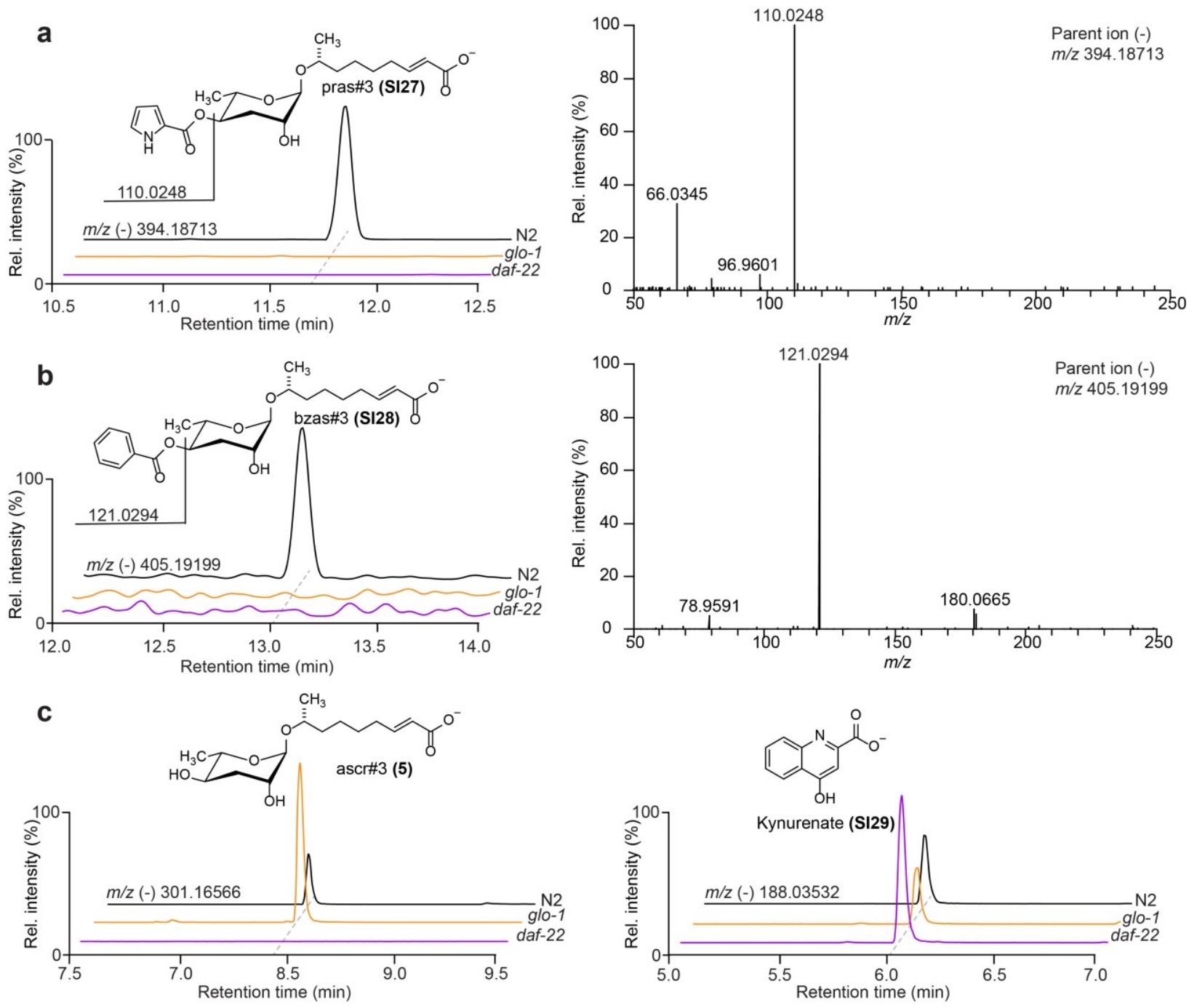

Figure S12. Ion chromatograms and $\mathrm{MS}^{2}$ fragmentation patterns of (a) pyrrole-3-carbonyl (SI27) and (b) benzoyl-bearing (SI28) ascarosides from untreated wildtype (N2) media metabolomes. (c) Control metabolites ascr\#3 (5) and tryptophan metabolite kynurenate (SI29). As expected, ascr\#3 (5) production was abolished in daf-22, but not glo-1 mutants, whereas kynurenate (SI29) production was not lost in either mutant. 


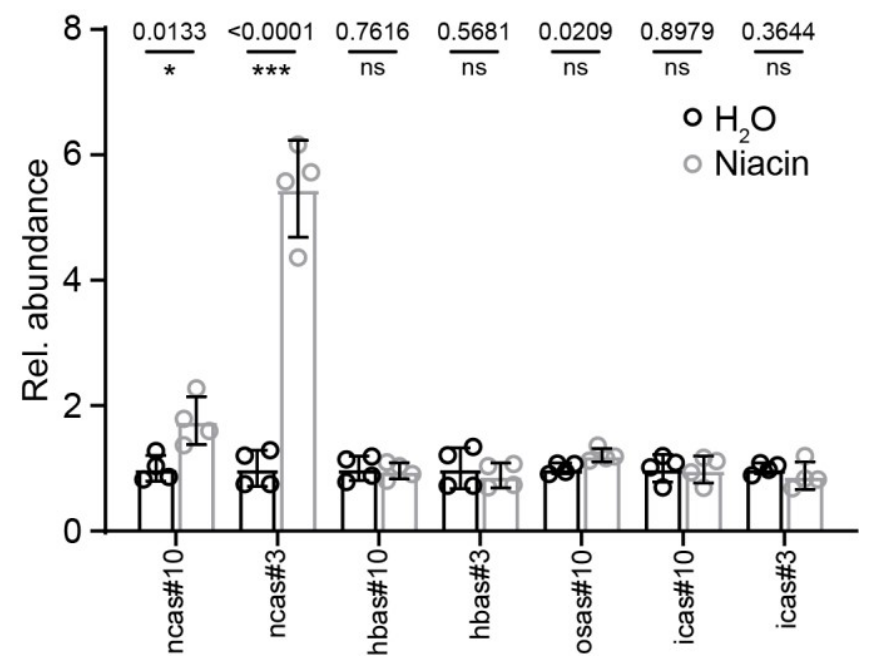

Figure S13. Feeding of aqueous $250 \mu \mathrm{M}$ niacin to wildtype (N2) worms for 4 days increases niacin-derived ascarosides compared to vehicle control treatment. Shown are means from four replicate experiments, and error bars represent standard deviation. 
a

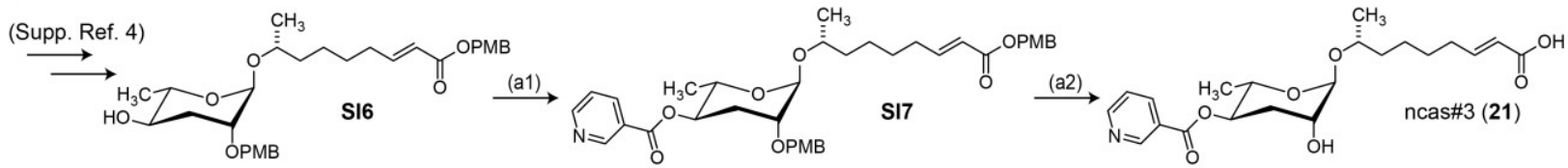

b
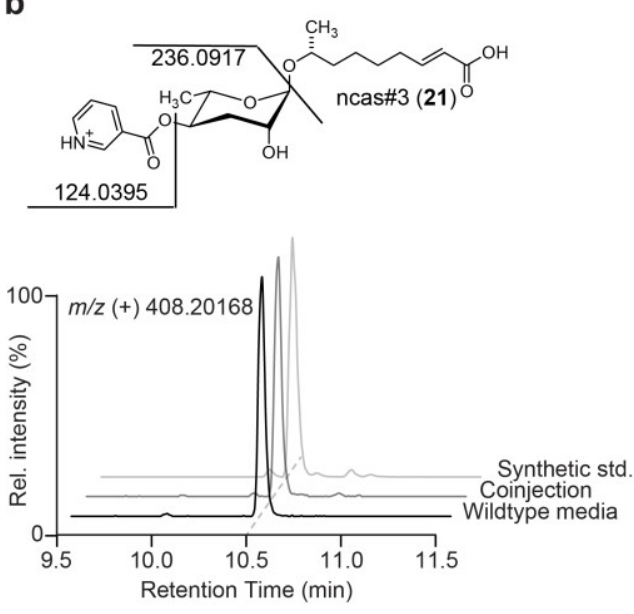

C

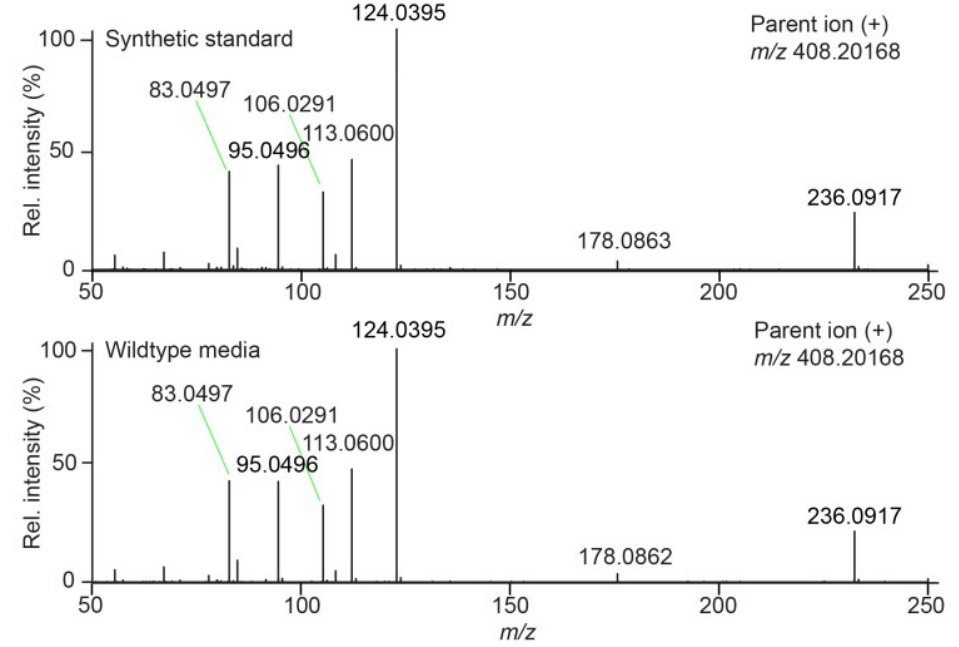

Figure S14. Identification of ncas\#3. (a) Following Zhang et al. ${ }^{4}$ and performing (a1) niacin (5.4 eq), EDC $\cdot \mathrm{HCl}(5.4 \mathrm{eq}), \operatorname{DMAP}(5.4 \mathrm{eq}), \mathrm{DCM}, 12 \mathrm{~h}$ (a2) TFA (100 eq), DCM, $20 \mathrm{~min}$. See Table S3 for NMR data of ncas\#3 (21). (b) lon chromatograms, acquired in negative ionization mode, showing peaks for ncas\#3 in natural (wildtype media) and synthetic samples. (c) $\mathrm{MS}^{2}$ spectra of parent $\mathrm{m} / \mathrm{z} 408.20168$ in positive mode from natural and synthetic ncas\#3 (21). 


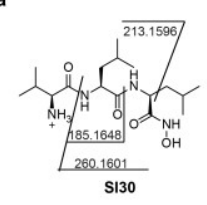

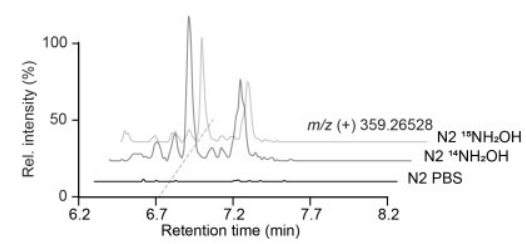
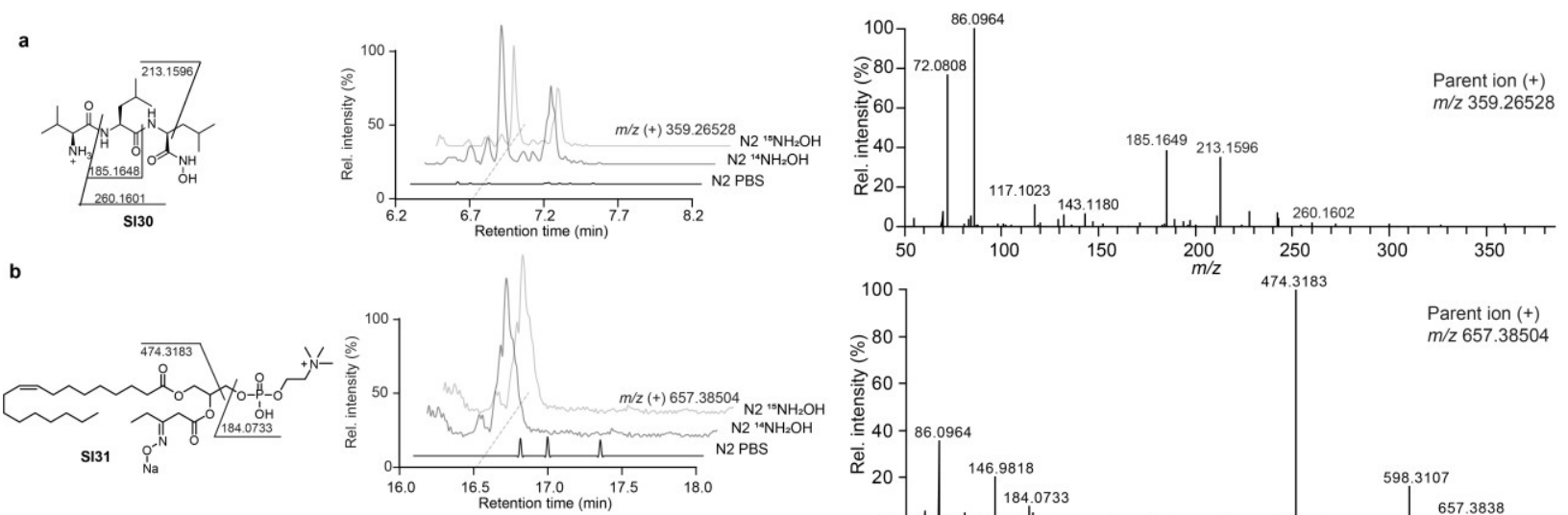

c
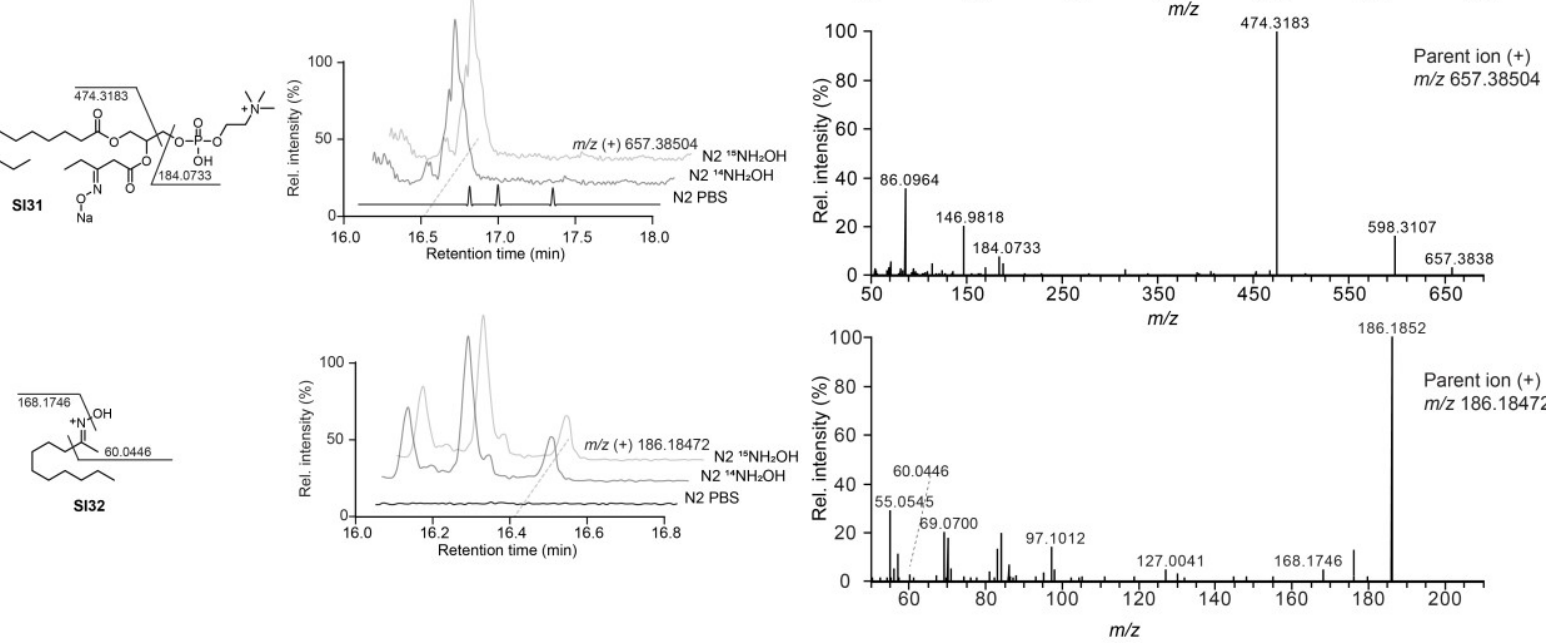

Figure S15. Examples for $\mathrm{NH}_{2} \mathrm{OH}$-labeled metabolites from non-ascaroside $\mathrm{MS}^{2}$ clusters, showing proposed structures, ion chromatograms, and fragmentation patterns; (a) peptide example, (b) phosphocholine lipid example, and (c) fatty ketone oxime example. 


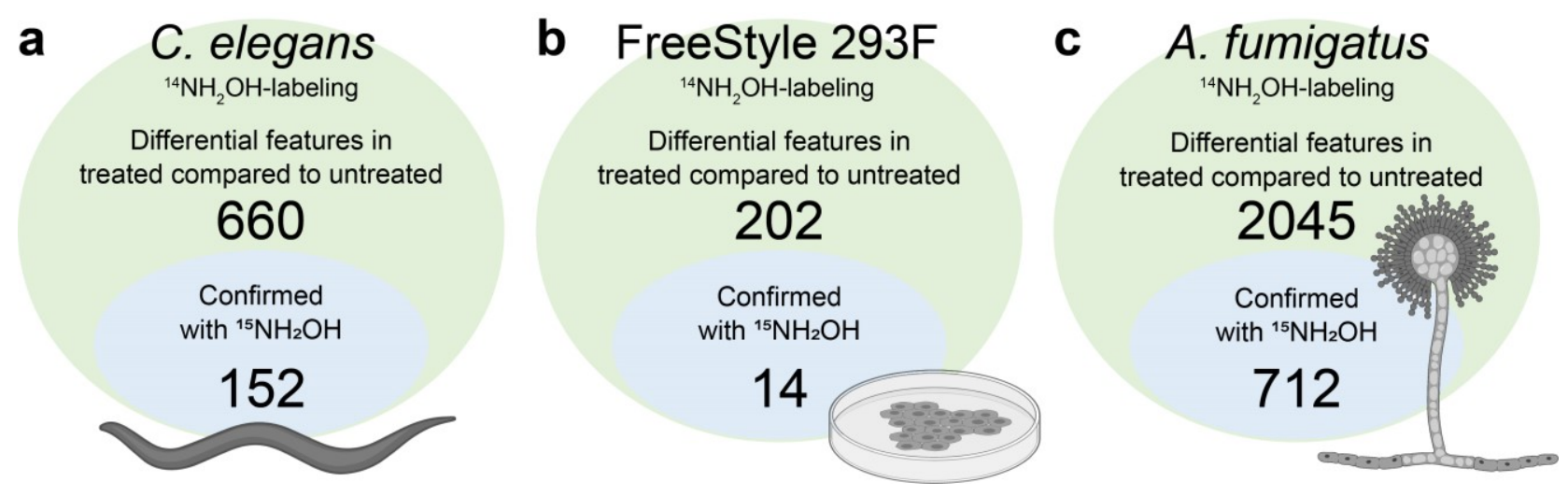

Figure S16. Inclusion of ${ }^{15} \mathrm{NH}_{2} \mathrm{OH}$ treatment improves filtering efficiency for untargeted analysis (negative ionization mode). ${ }^{14} \mathrm{NH}_{2} \mathrm{OH}$ treatment-derived datasets were filtered by removing features found in both PBS and ${ }^{15} \mathrm{NH}_{2} \mathrm{OH}$-treated samples. ${ }^{15} \mathrm{NH}_{2} \mathrm{OH}$-filtering was performed on (a) C. elegans N2 worms, (b) and FreeStyle 293F human cells, and (c) Aspergillus fumigatus. 


\section{Supporting tables}

Table S1. C. elegans strains used in this study.

\begin{tabular}{|l|l|l|l|}
\hline Strain Name & Genotype & Identifier & Source \\
\hline VC1785 & acox1.1(ok2257) I. & acox-1.1 null mutant & CGC \\
\hline RB859 & Y57A10C.6(ok693) II. & daf-22 null mutant & CGC \\
\hline JJ1271 & glo-1(zu391) X. & glo-1 null mutant & CGC \\
\hline PHX1951 & acot-1(syb1951) & acot-1 null mutant & Sunybiotech \\
\hline FCS43 & $\begin{array}{l}\text { acot-1(syb1951); acox- } \\
1.1(\text { ok2257) }\end{array}$ & $\begin{array}{l}\text { acot-1; acox-1.1 } \\
\text { double null mutant }\end{array}$ & This study \\
\hline
\end{tabular}


Table S2. Primers used in this study.

\begin{tabular}{|c|c|}
\hline Sequence & Use \\
\hline $\begin{array}{l}\text { ACCACCACATGCAAAGATCA } \\
\text { CСTATTCAACTCCACGGATG }\end{array}$ & PCR confirmation of acox-1.1 null mutant \\
\hline $\begin{array}{l}\text { TTGTTCCCTTCCTGGCTTGT } \\
\text { GAGGATCTAGCAAATGACCAC }\end{array}$ & PCR confirmation of acot-1 null mutant \\
\hline $\begin{array}{l}\text { GGTGTACTCCGCCAGTTCCG } \\
\text { AGGACCACTGGGAAGGGACC }\end{array}$ & qPCR primers for $W 03 D 8.8$ \\
\hline $\begin{array}{l}\text { TTTTTCTCGGCGGCACCACA } \\
\text { AGACTCAAGGAGACCGGGCA }\end{array}$ & qPCR primers for $W 03 D 8.8$ \\
\hline $\begin{array}{l}\text { TGGAACCGTGCTTGGCGAAA } \\
\text { GGGGCCATTTCCAGGTGGTT }\end{array}$ & qPCR primers for acot-1 \\
\hline $\begin{array}{l}\text { ATTGCACACCCCCGGTTGAC } \\
\text { TGCGGCGCCTTTCTGTTCAT }\end{array}$ & qPCR primers for acot-1 \\
\hline $\begin{array}{l}\text { TCCCATGCTGCGTACTGTGT } \\
\text { CGAGCTTTGTTCCACTGTCATCG }\end{array}$ & qPCR primers for $\mathrm{C} 31 \mathrm{H} 5.6 \mathrm{a}$ \\
\hline $\begin{array}{l}\text { ATTCCATGGGCAAGAGCACCC } \\
\text { ATGATTCCGTGGTGGGGGAA }\end{array}$ & qPCR primers for T05E7.1 \\
\hline $\begin{array}{l}\text { ACGACGAGTCCGGCCCATCC } \\
\text { GAAAGCTGGTGGTGACGATGGTT }\end{array}$ & qPCR primers for actin \\
\hline sg1: CCGGTTATATTAGTAACACCCGA & $\begin{array}{l}\text { Used by SunyBiotech to create allele acot- } \\
\text { 1(syb1951) (acot-1 null mutant) }\end{array}$ \\
\hline sg2: CCTCCAGTAGGAAGgtgcatttt & $\begin{array}{l}\text { Used by SunyBiotech to create allele acot- } \\
\text { 1(syb1951) (acot-1 null mutant) }\end{array}$ \\
\hline $\begin{array}{l}\text { GGTACATGTGAGAAGTTATA } \\
\text { TCGGATTTACAAAATTCTAC } \\
\text { TTCTGGTTTAAAATCAGTTG (poison primer) }\end{array}$ & $\begin{array}{l}\text { Primers for screening homozygous acox- } \\
1.1 \text { null alleles in acot-1/acox- } 1.1 \text { cross }\end{array}$ \\
\hline $\begin{array}{l}\text { AATGTACCCACCTGTCTTGA } \\
\text { TGCTCAAATCATCTACGGCG } \\
\text { ATACGAATGACAGGATTGGC (poison primer) }\end{array}$ & $\begin{array}{l}\text { Primers for screening homozygous acot- } 1 \\
\text { null alleles in acot-1/acox-1.1 cross }\end{array}$ \\
\hline
\end{tabular}


Table S3. NMR spectroscopic data for ncas\#3 (21). ${ }^{1} \mathrm{H}(600 \mathrm{MHz}),{ }^{13} \mathrm{C}(151 \mathrm{MHz}), \mathrm{HSQC}$, and HMBC NMR spectroscopic data for ncas\#3 in methanol- $d_{4}$.

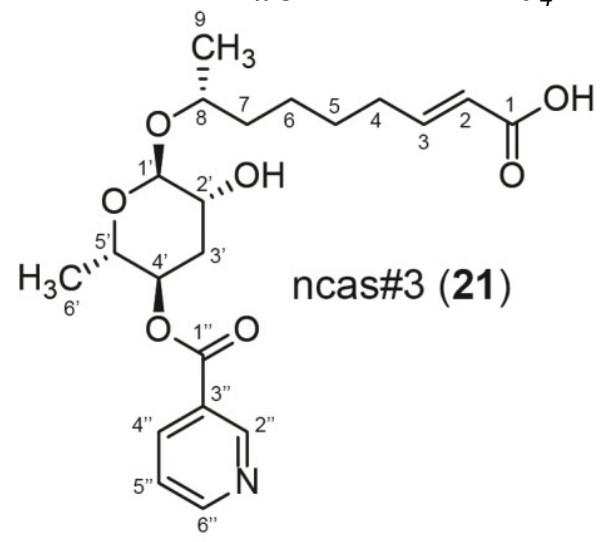

\begin{tabular}{|c|c|c|c|c|}
\hline Position & $\begin{array}{l}{ }^{13} \mathrm{C} \\
(\mathrm{ppm})\end{array}$ & ${ }^{1} \mathrm{H}$ (ppm) & ${ }^{1} \mathrm{H}-{ }^{1} \mathrm{H}$ Coupling constants $(\mathrm{Hz})$ & $\begin{array}{l}\text { Relevant HMBC } \\
\text { correlations }\end{array}$ \\
\hline $1^{\prime}$ & 97.5 & 4.74 & $J_{1^{\prime}, 2^{\prime}}=1.7$ & $2^{\prime}, 3^{\prime}, 5^{\prime}, 8$ \\
\hline $2^{\prime}$ & 69.2 & 3.79 & $J_{2^{\prime}, 3^{\prime} \mathrm{ax}}=3.6, J_{2^{\prime}, 3^{\prime} \mathrm{eq}}=3.3$ & $4^{\prime}$ \\
\hline \multirow[t]{2}{*}{$3^{\prime}$} & 32.7 & $2.01(\mathrm{ax})$ & $J_{3^{\prime} \mathrm{ax}, 3^{\prime} \mathrm{eq}}=13.0, J_{3^{\prime} \mathrm{ax}, 4^{\prime}}=11.5$ & $4^{\prime}, 5^{\prime}$ \\
\hline & & $2.21(\mathrm{eq})$ & $J_{3^{\prime} \mathrm{eq}, 4^{\prime}}=3.3$ & $1^{\prime}, 2^{\prime}, 4^{\prime}, 5^{\prime}$ \\
\hline $4^{\prime}$ & 72.3 & 5.15 & $J_{4^{\prime}, 5^{\prime}}=9.5$ & $3^{\prime}, 5^{\prime}, 6^{\prime}, 1^{\prime \prime}$ \\
\hline $5^{\prime}$ & 68 & 4.04 & $J_{5^{\prime}, 6^{\prime}}=6.4$ & $1^{\prime}, 3^{\prime}, 4^{\prime}, 6^{\prime}$ \\
\hline $6^{\prime}$ & 17.9 & 1.22 & & $4^{\prime}, 5^{\prime}$ \\
\hline 1 & 169.8 & & & \\
\hline 2 & 122.3 & 5.82 & $J_{2,3}=15.7, J_{2,4}=1.5$ & 1,4 \\
\hline 3 & 150.7 & 6.98 & $J_{3,4}=6.9$ & $1,4,5$ \\
\hline 4 & 32.8 & 2.28 & $J_{4,5}=6.9$ & $2,3,5,6$ \\
\hline 5 & 28.8 & 1.54 & & 3 \\
\hline 6 & 26.3 & 1.45 & & 8 \\
\hline 7 & 37.8 & $1.54,1.62$ & & \\
\hline 8 & 72.8 & 3.84 & $J_{8,9}=6.1$ & 1', 6,7 \\
\hline 9 & 19.1 & 1.16 & & 7,8 \\
\hline 1" & 165 & & & \\
\hline 5" & 125.4 & 7.65 & $J_{5^{\prime \prime}, 6^{\prime \prime}}=5.1, J_{5^{\prime \prime}, 4^{\prime \prime}}=8.0$ & 3", 4", 6" \\
\hline 3" & 128 & & & \\
\hline 4" & 139.6 & 8.48 & $J_{4^{\prime \prime}, 2^{\prime \prime}}=1.9, J_{4^{\prime \prime}, 6^{\prime \prime}}=1.7$ & 1", 2", 6" \\
\hline 6" & 153.1 & 8.79 & & 5", 3", 4", 2" \\
\hline $2 "$ & 150.2 & 9.15 & & 1", 3", 4", 6" \\
\hline
\end{tabular}




\section{Supporting references}

1. Brenner, S., The genetics of Caenorhabditis elegans. Genetics 1974, 77 (1), 71-94.

2. Baccile, J. A.; Spraker, J. E.; Le, H. H.; Brandenburger, E.; Gomez, C.; Bok, J. W.;

Macheleidt, J.; Brakhage, A. A.; Hoffmeister, D.; Keller, N. P.; Schroeder, F. C., Plant-like

biosynthesis of isoquinoline alkaloids in Aspergillus fumigatus. Nat Chem Biol 2016, 12 (6), 41924.

3. Smith, C. A.; Want, E. J.; O'Maille, G.; Abagyan, R.; Siuzdak, G., XCMS: processing mass spectrometry data for metabolite profiling using nonlinear peak alignment, matching, and identification. Anal Chem 2006, 78 (3), 779-87.

4. Zhang, Y. K.; Sanchez-Ayala, M. A.; Sternberg, P. W.; Srinivasan, J.; Schroeder, F. C., Improved Synthesis for Modular Ascarosides Uncovers Biological Activity. Org Lett 2017, 19

(11), 2837-2840. 
NMR spectra

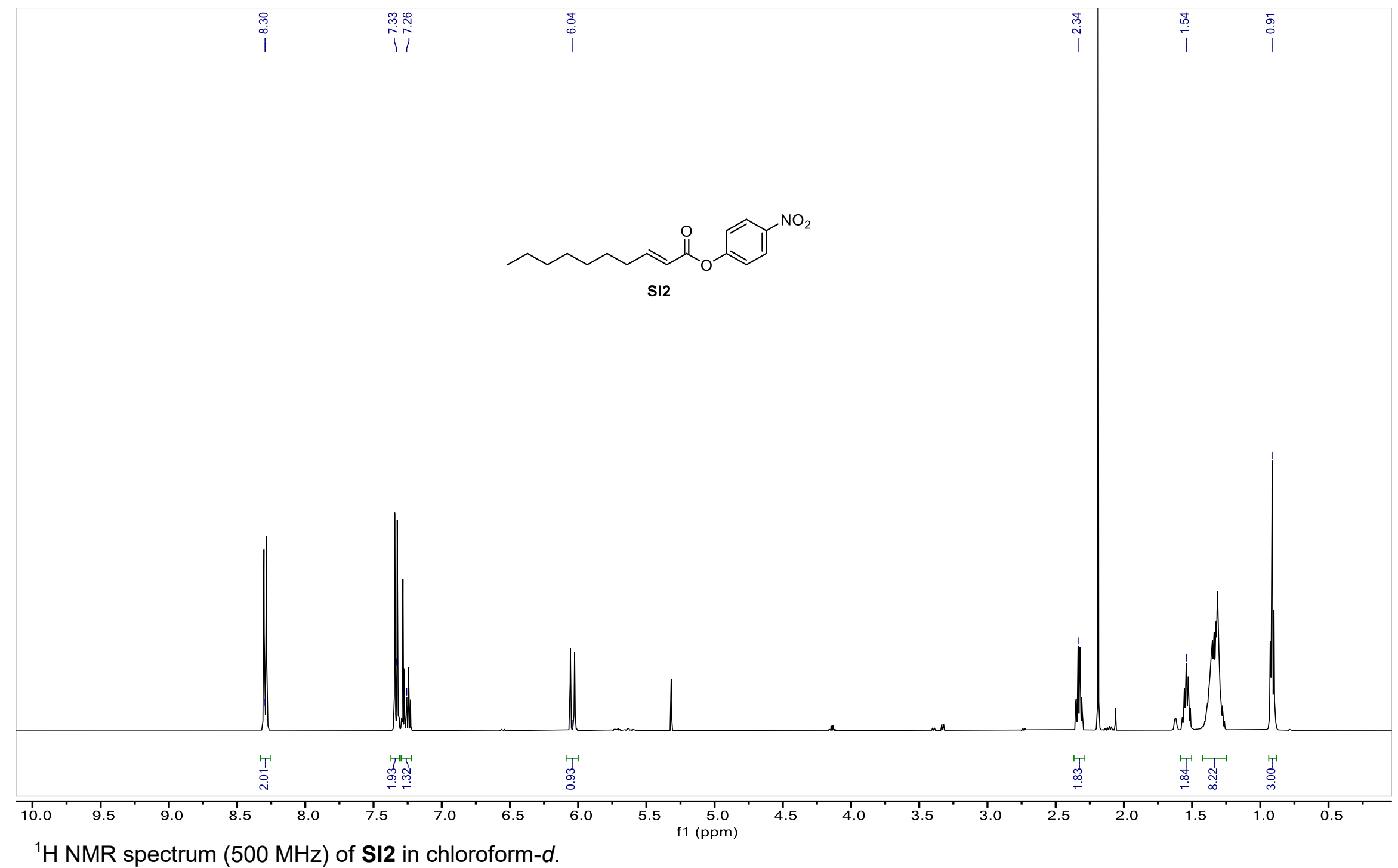



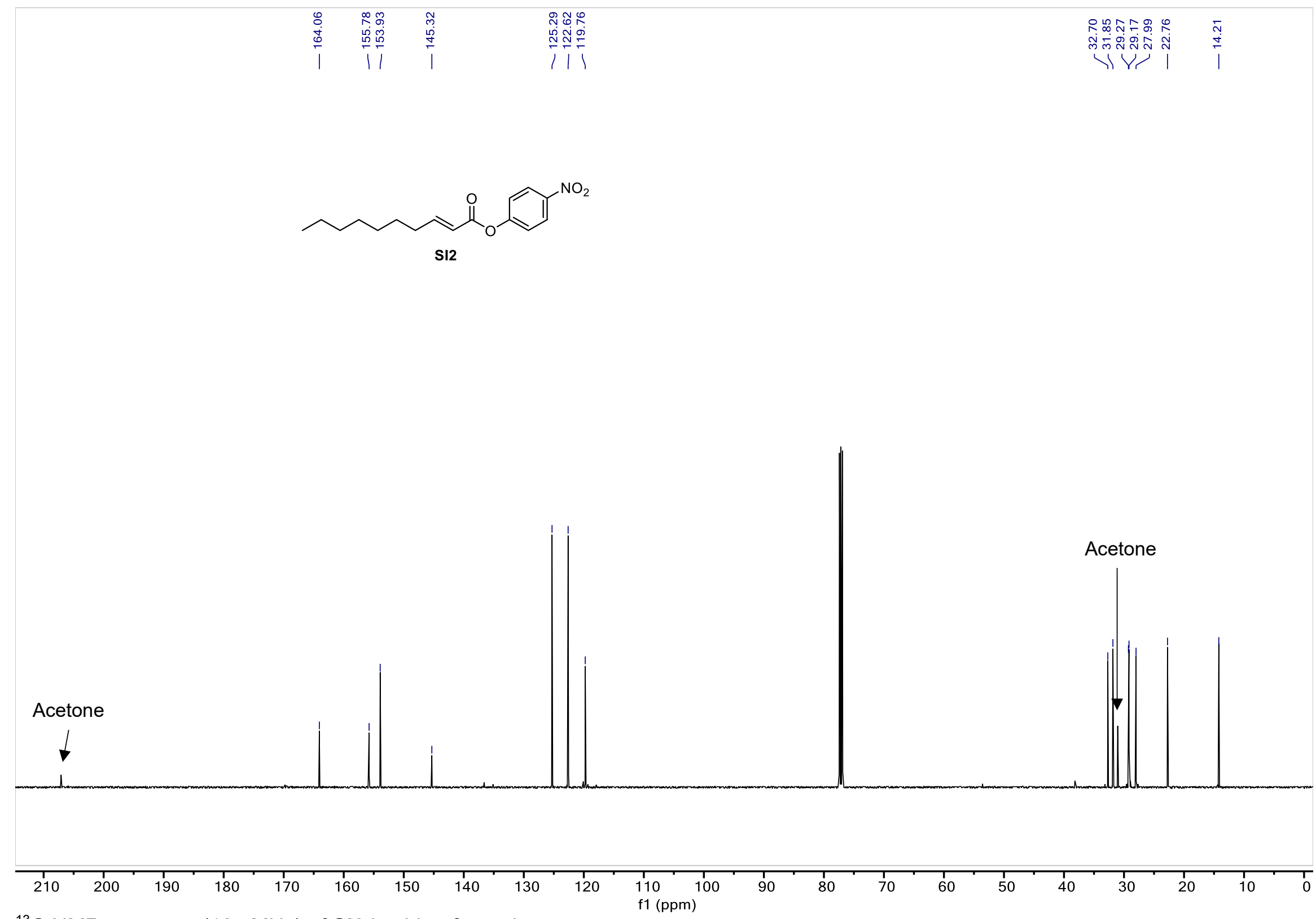

${ }^{13} \mathrm{C}$ NMR spectrum (125 MHz) of SI2 in chloroform-d. 


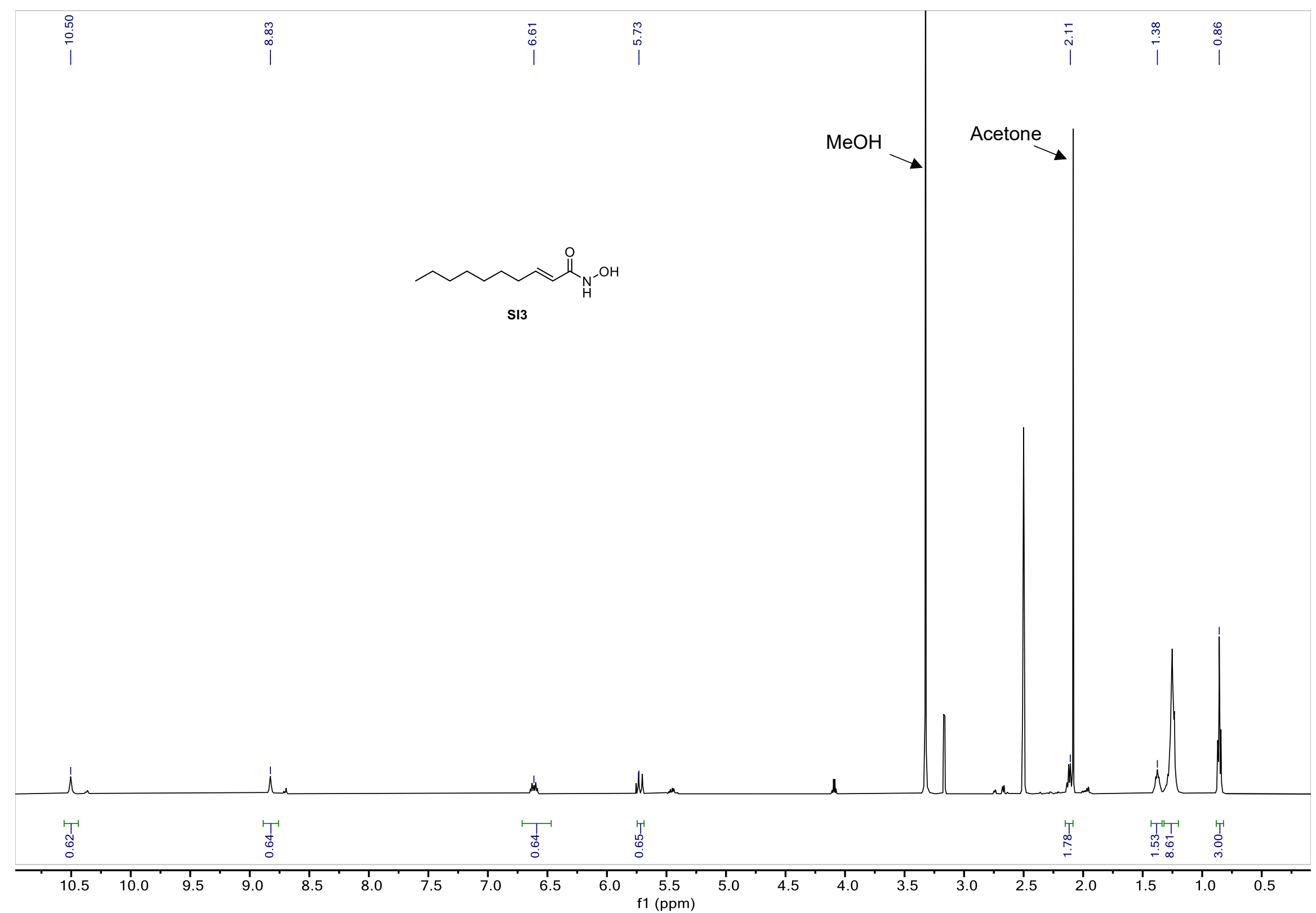

${ }^{1} \mathrm{H}$ NMR spectrum $(500 \mathrm{MHz})$ of SI3 in DMSO- $d_{6}$. 


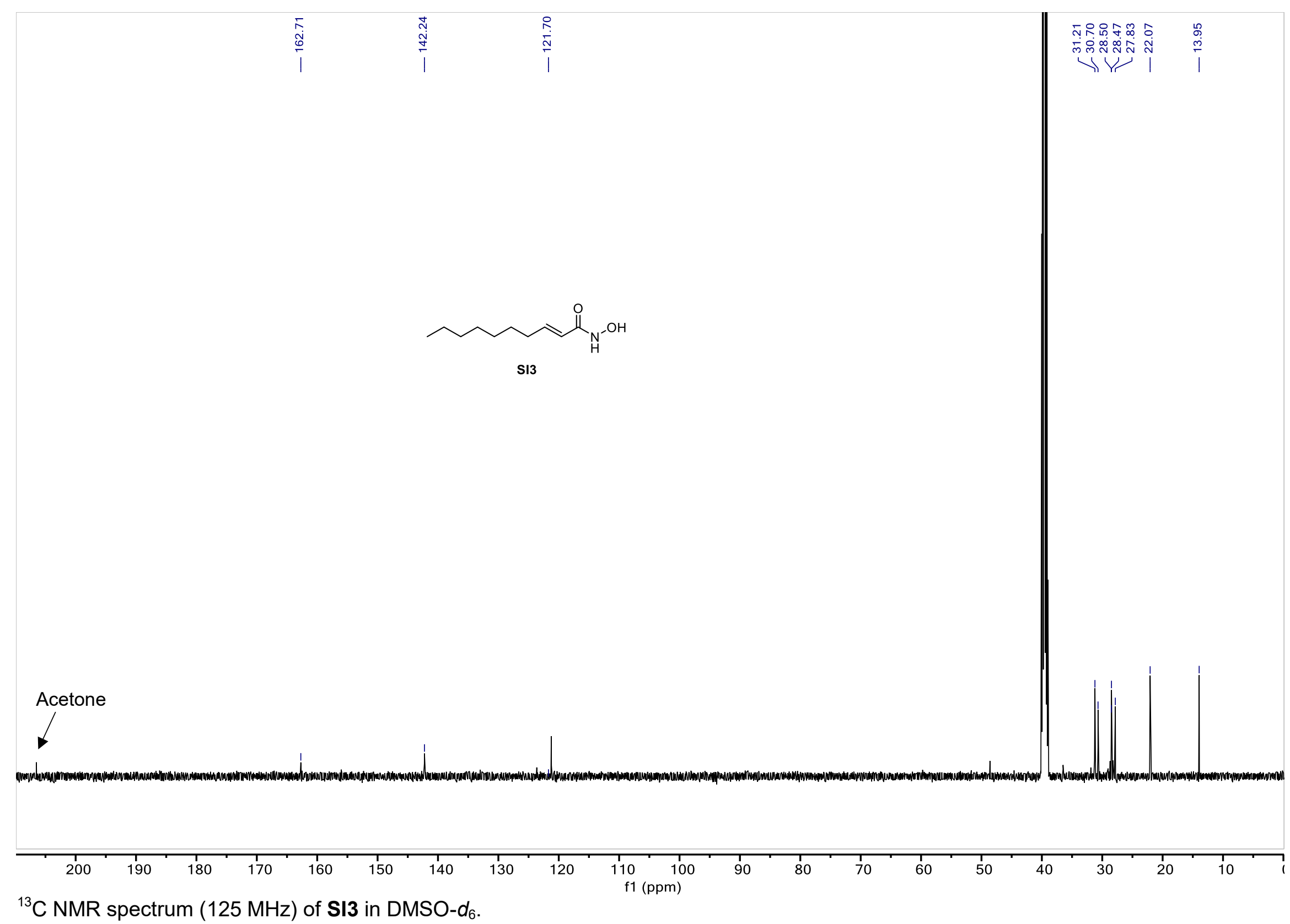




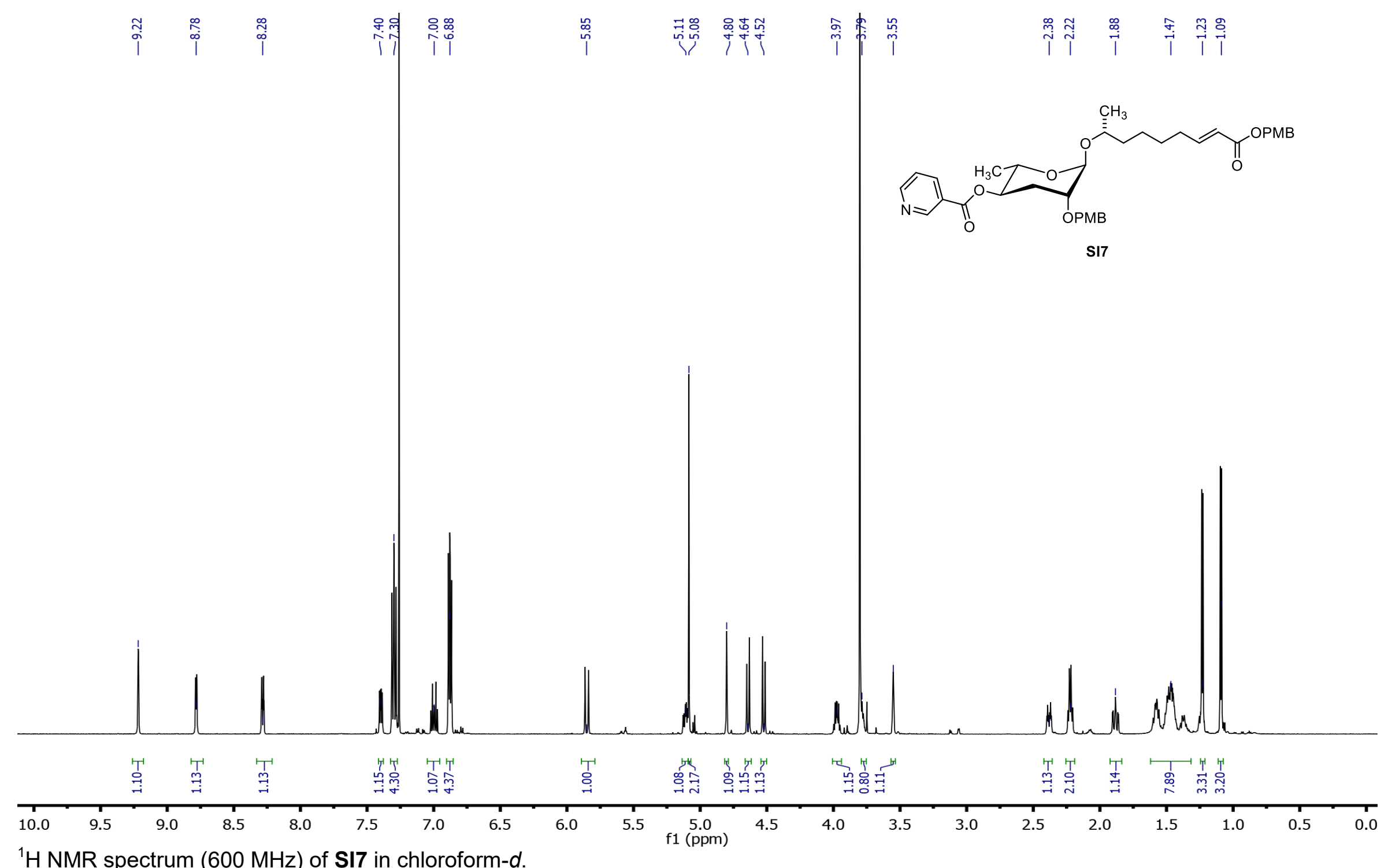

${ }^{1} \mathrm{H}$ NMR spectrum $(600 \mathrm{MHz})$ of $\mathbf{S} 17$ in chloroform- $d$. 


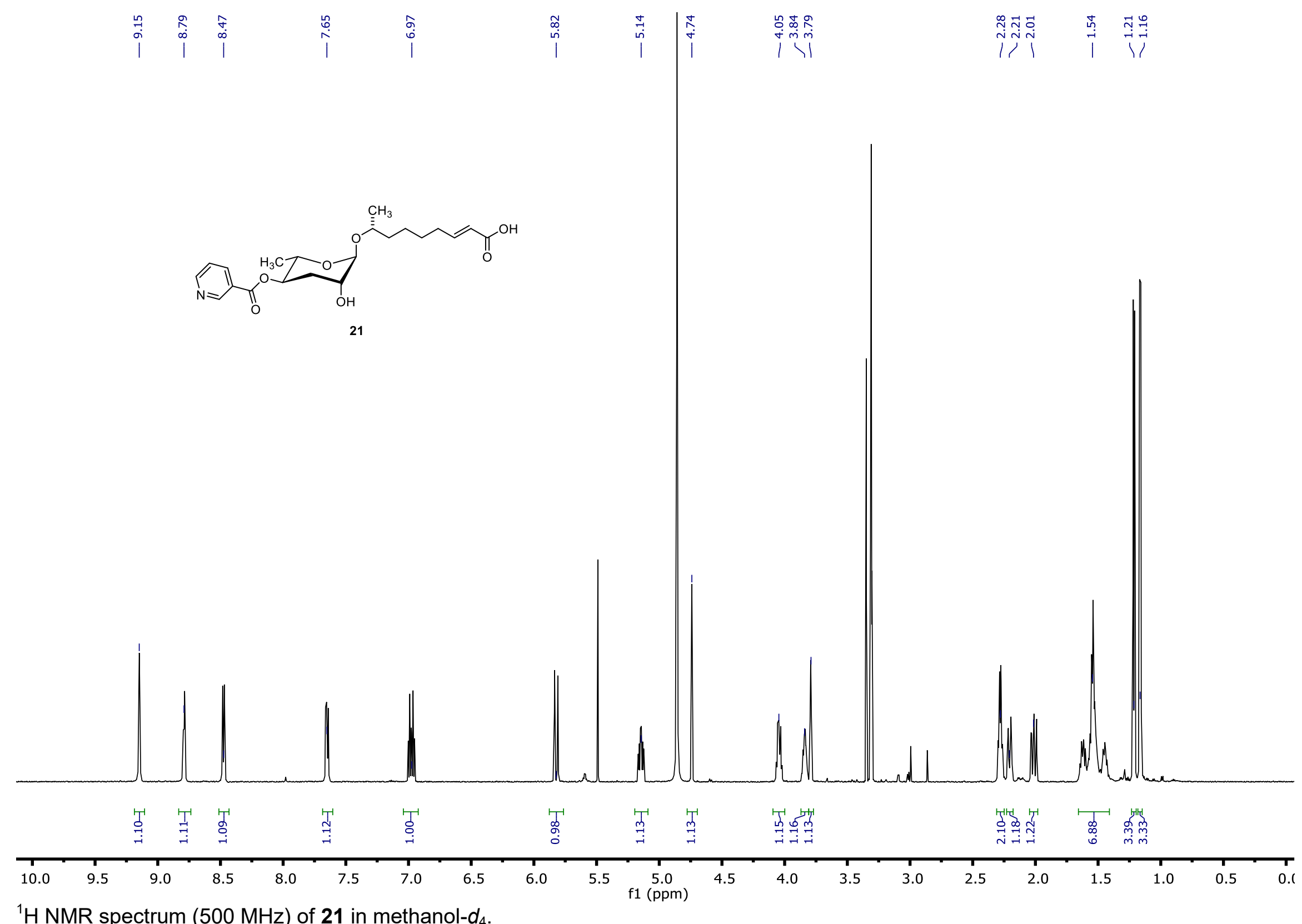

${ }^{1} \mathrm{H}$ NMR spectrum (500 MHz) of 21 in methanol- $d_{4}$. 


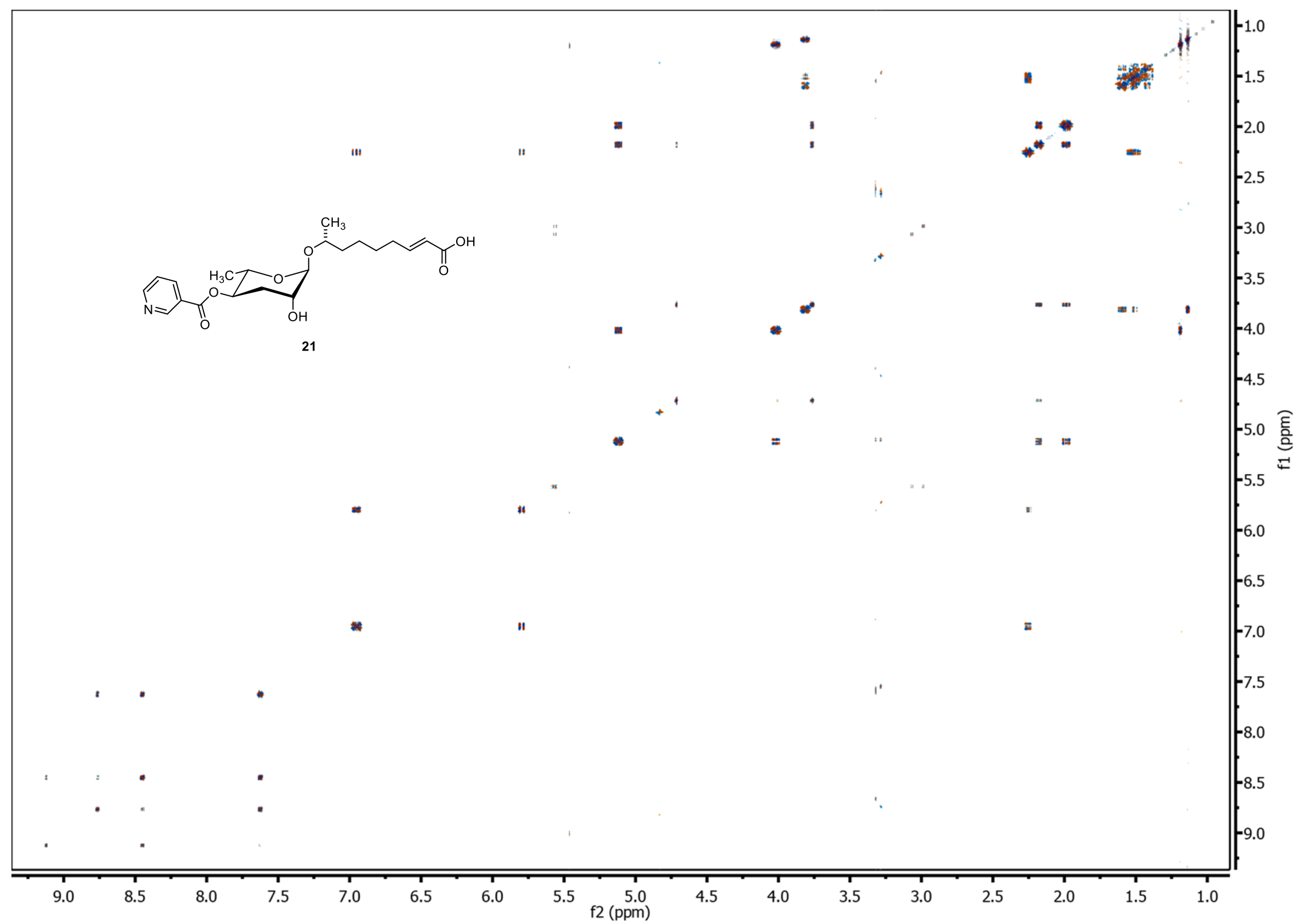

dqfCOSY spectrum $(600 \mathrm{MHz})$ of 21 in methanol- $d_{4}$. 


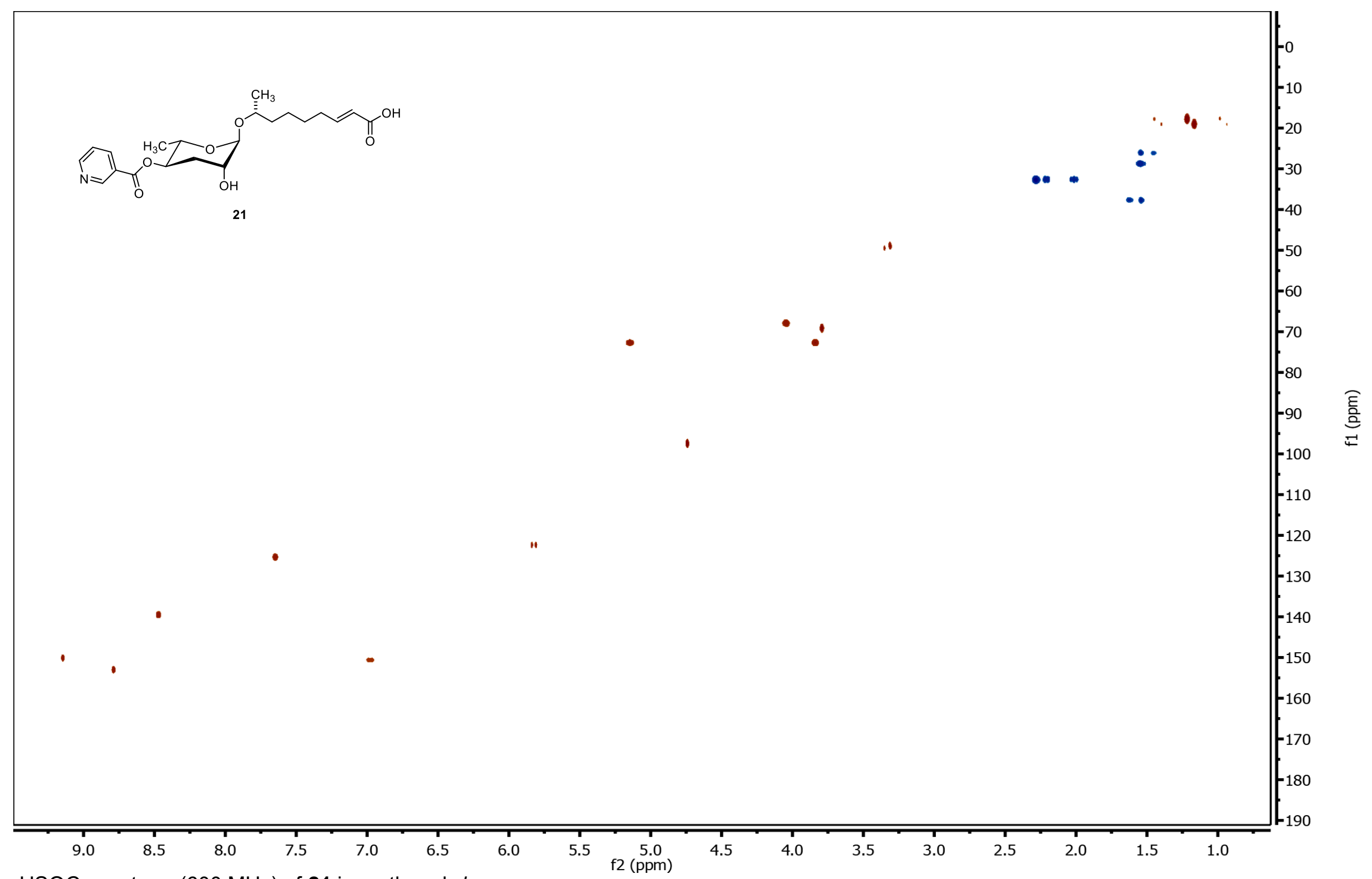

HSQC spectrum $(600 \mathrm{MHz})$ of 21 in methanol- $d_{4}$. 


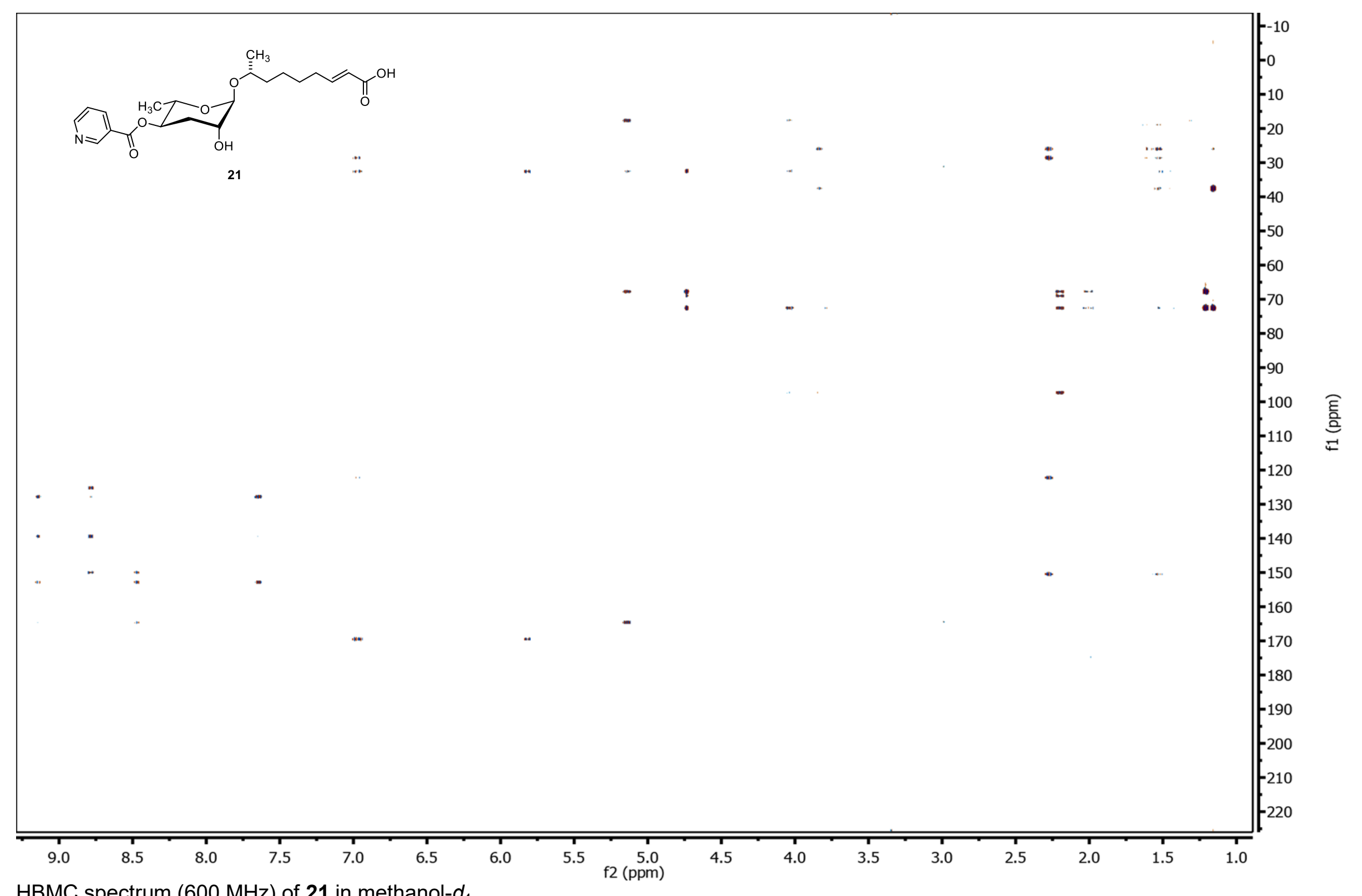

HBMC spectrum $(600 \mathrm{MHz})$ of $\mathbf{2 1}$ in methanol- $d_{4}$. 


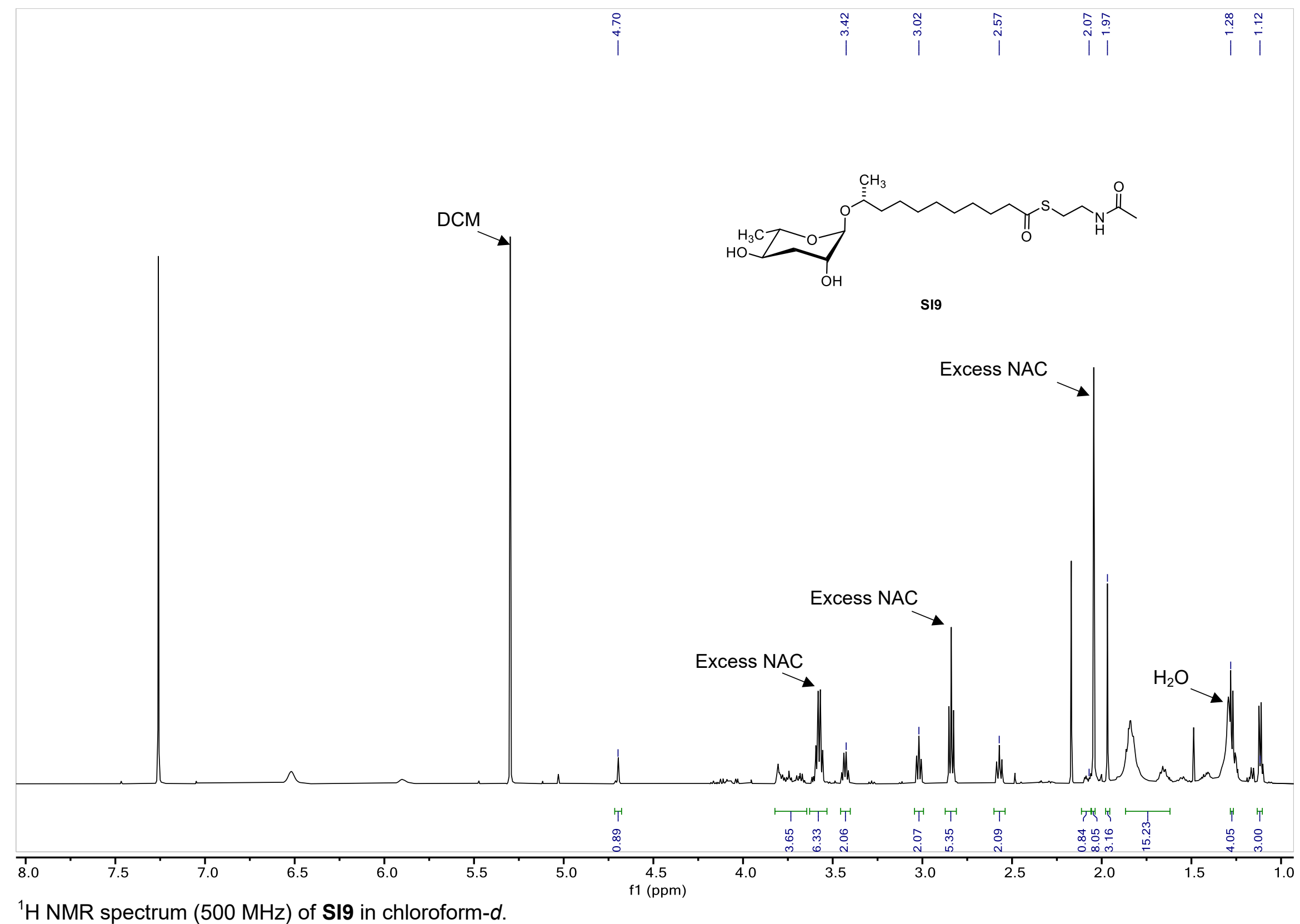




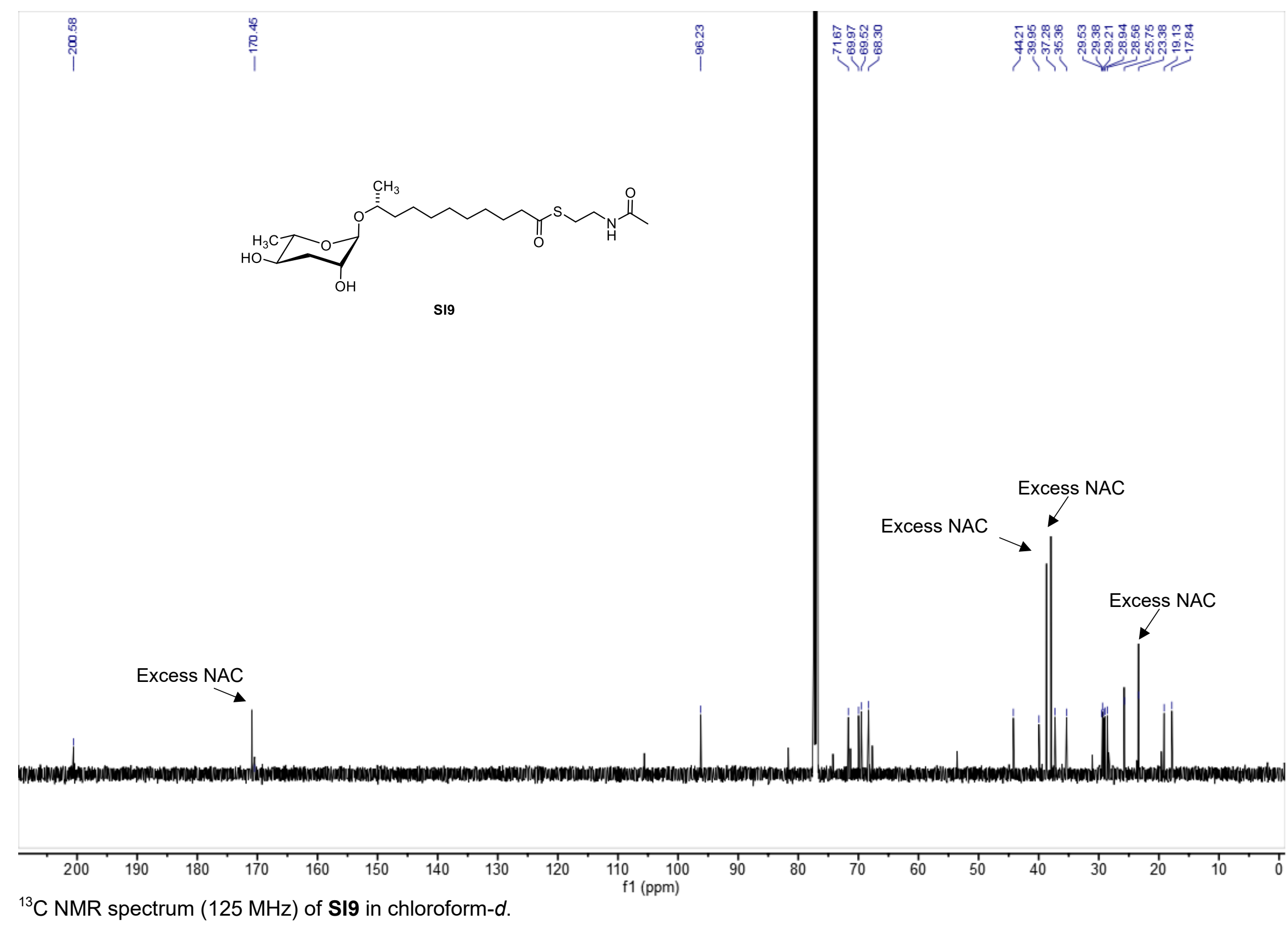




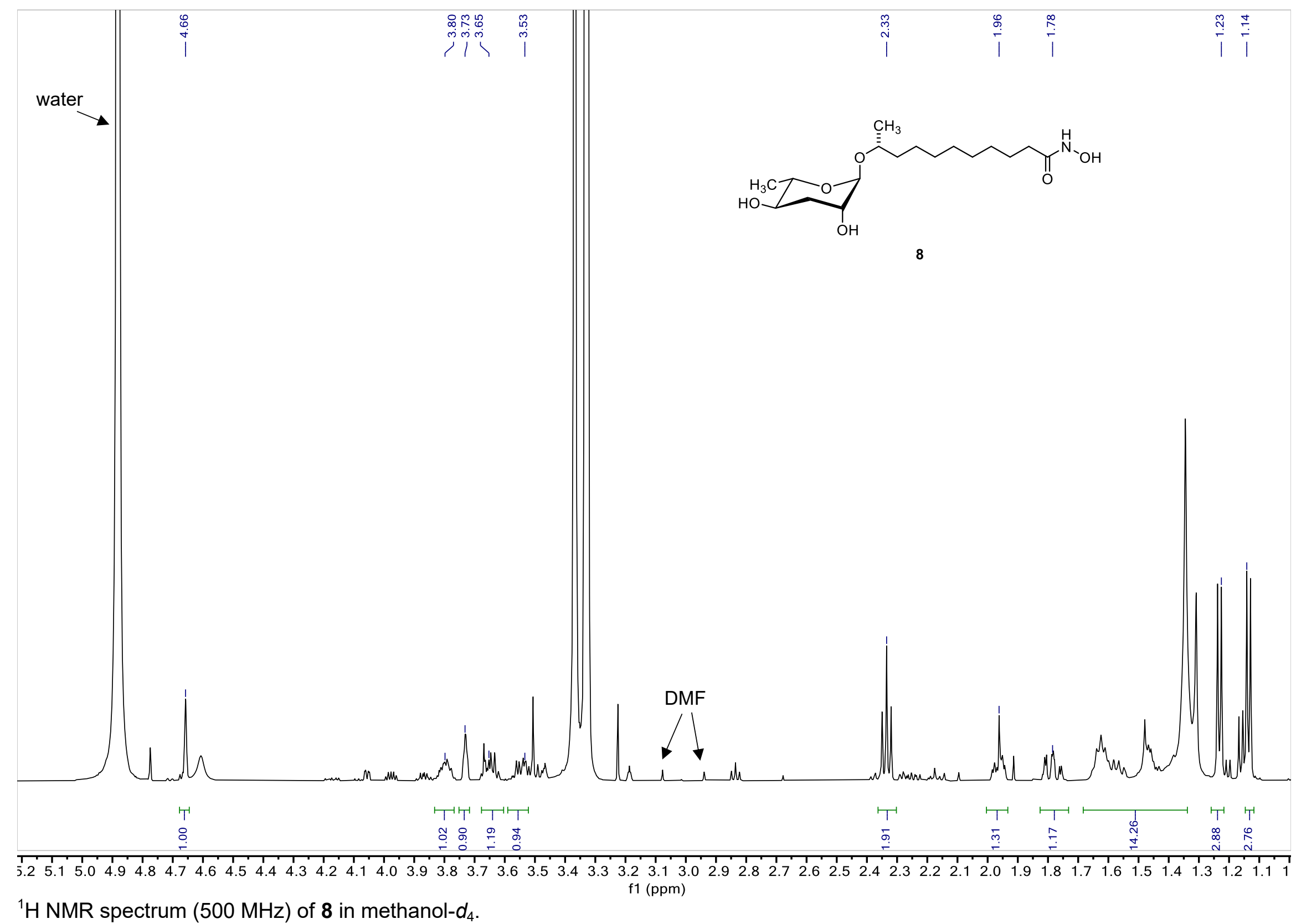




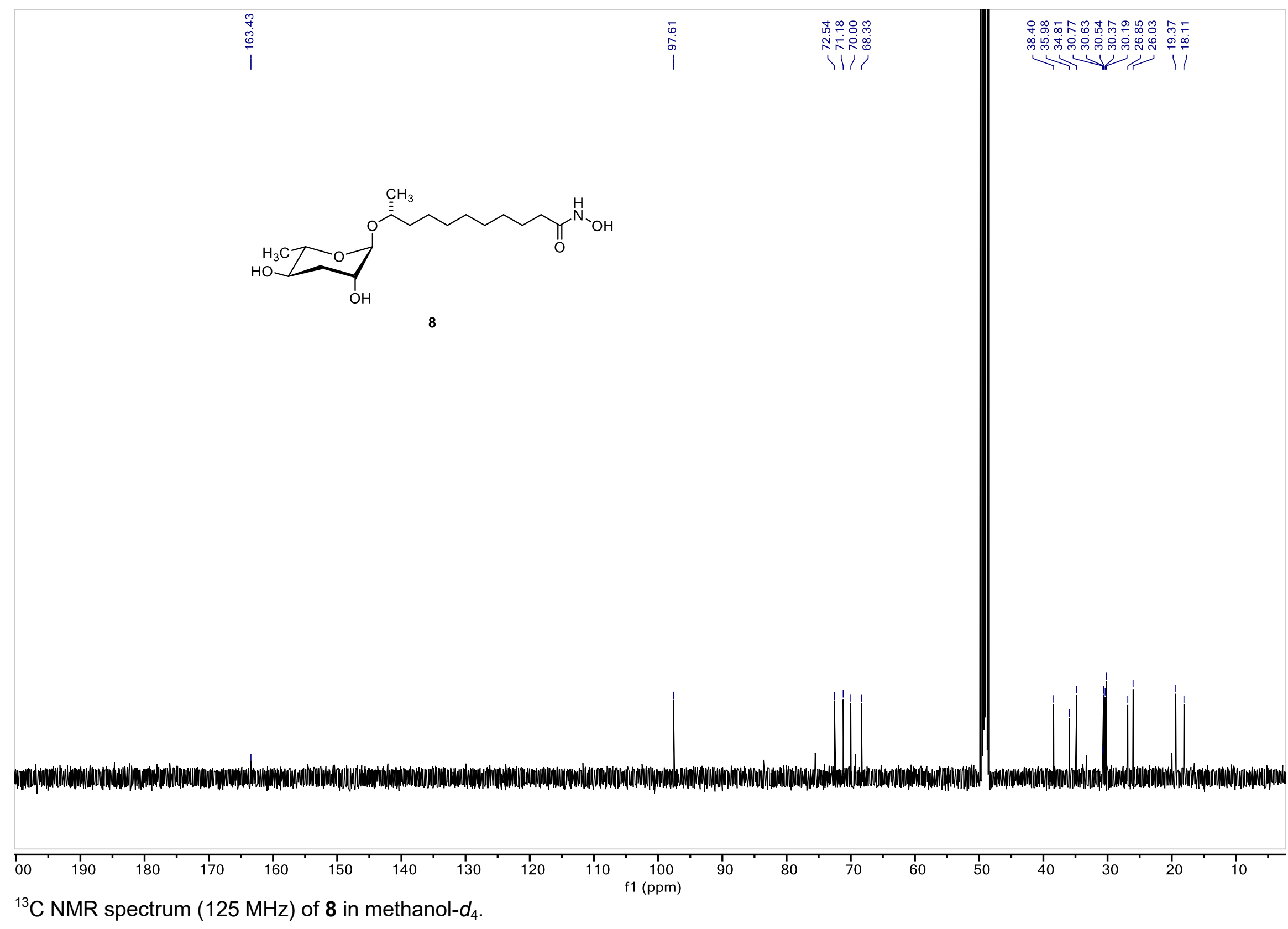




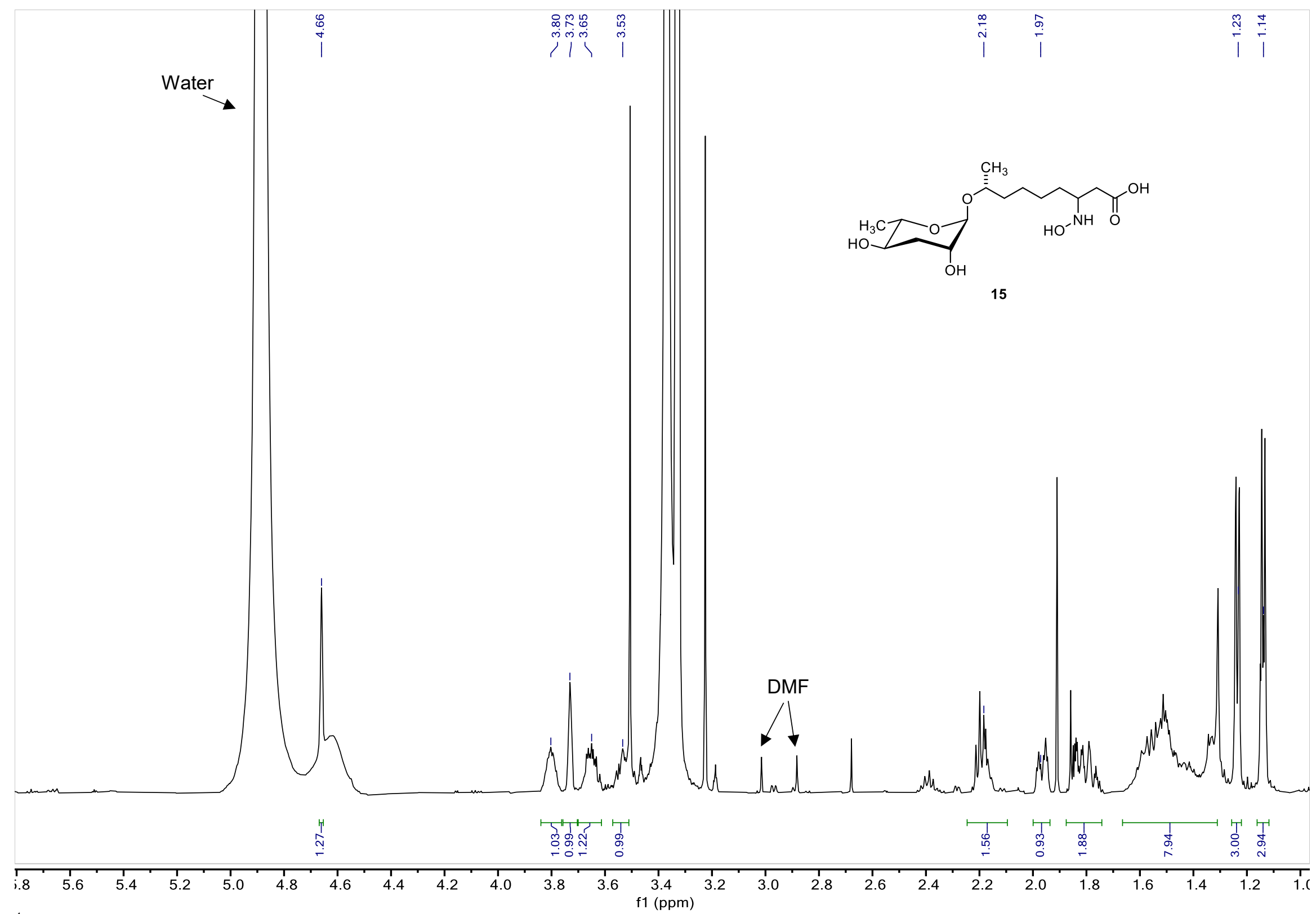

${ }^{1} \mathrm{H}$ NMR spectrum (500 MHz) of 15 in methanol- $d_{4}$. 


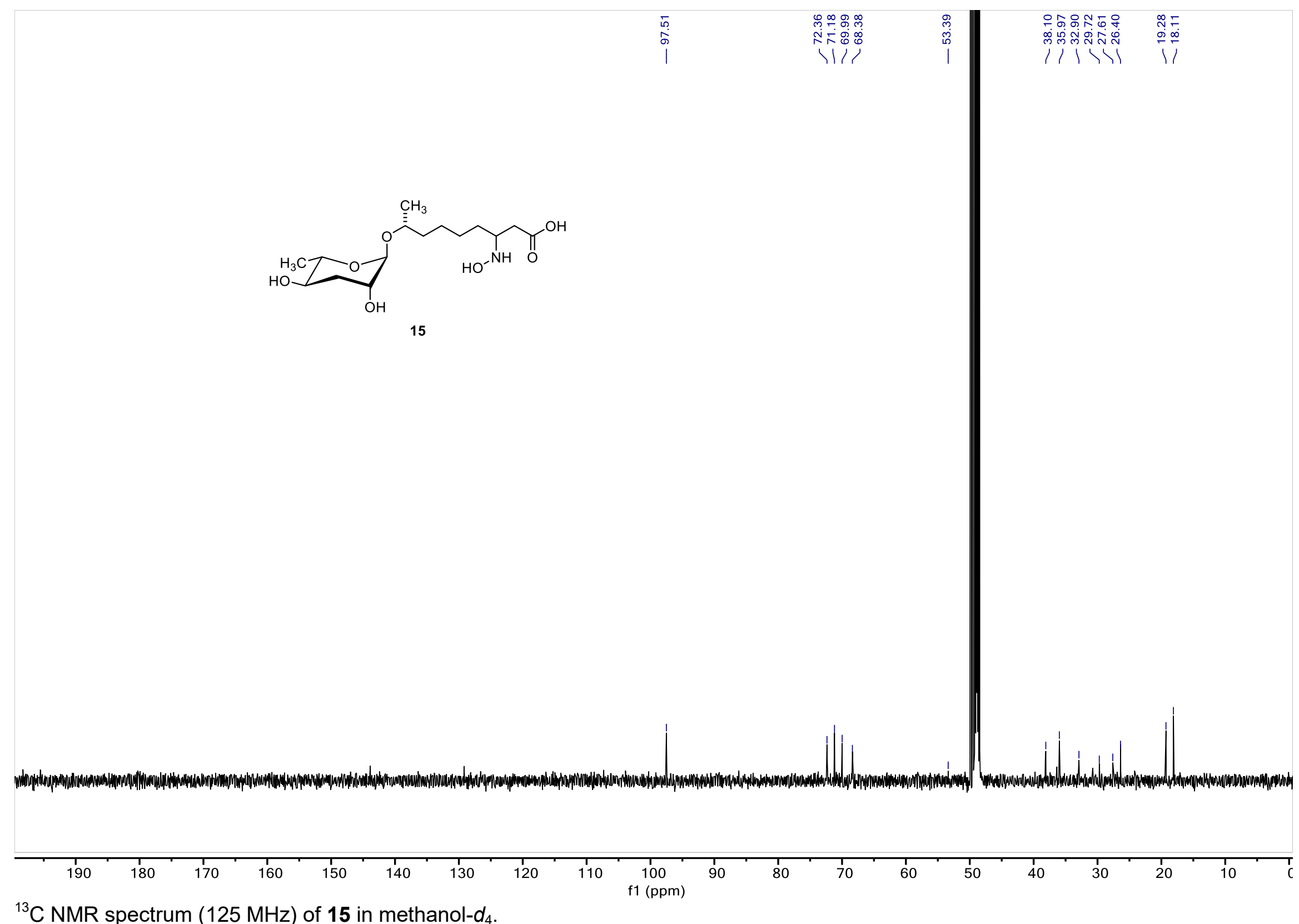

